\title{
Independent Panel Evaluation of Dry Sludge PISA Program
}

by

F. F. Fondeur

Westinghouse Savannah River Company

Savannah River Site

Aiken, South Carolina 29808

W. R. Wilmarth

This paper was prepared in connection with work done under the above contract number with the U.S.

Department of Energy. By acceptance of this paper, the publisher and/or recipient acknowledges the U. S. Government's right to retain a nonexclusive, royalty-free license in and to any copyright covering this paper, along with the right to reproduce and to authorize others to reproduce all or part of the copyrighted paper. 


\section{DISCLAIMER}

This report was prepared as an account of work sponsored by an agency of the United States Government. Neither the United States Government nor any agency thereof, nor any of their employees, makes any warranty, express or implied, or assumes any legal liability or responsibility for the accuracy, completeness, or usefulness of any information, apparatus, product, or process disclosed, or represents that its use would not infringe privately owned rights. Reference herein to any specific commercial product, process, or service by trade name, trademark, manufacturer, or otherwise does not necessarily constitute or imply its endorsement, recommendation, or favoring by the United States Government or any agency thereof. The views and opinions of authors expressed herein do not necessarily state or reflect those of the United States Government or any agency thereof.

This report has been reproduced directly from the best available copy.

Available to DOE and DOE contractors from the Office of Scientific and Technical Information, P. O. Box 62, Oak Ridge, TN 37831; prices available from (423) 576-8401.

Available to the public from the National Technical Information Service, U. S. Department of Commerce, 5285 Port Royal Road, Springfield, VA 22161. 


\section{DISCLAIMER}

Portions of this document may be illegible in electronic image products. Images are produced from the best available original document. 


\section{F. F.Fondeur}

\section{DISTRIBUTION}

T. E. Britt, 703-H

B. L. Lewis, 703-H

W. L. Tamosaitis, 773-A

S. D. Fink, 773-A

W. B. Van-Pelt, 773-43A

M. J. Barnes, 773-A

R. F. Swingle, 773-A

W. R. Wilmarth, 773-42A

M. S. Hay, 773-42A

P. E. Lowe, 773-41A

F. F. Fondeur, 773-A

D. T. Hobbs, 773-A

L. O. Dworjanyn, 735-11A

R. H. Ross, 703-H

G. J. Hutchens, 703-H

T. A. Nance, $723-\mathrm{A}^{-}$

E. J. Freed, 742-5G

S. R. Wilson, 704-28S

TIM

LWP Files c/o C. Canada, 773-A 
keywords: explosive, sludge, thermal analysis

retention: Permanent

\section{INDEPENDENT PANEL EVALUATION OF DRY SLUDGE PISA PROGRAM}

F. F. Fondeur

W. R. Wilmarth

August 30, 1999

Westinghouse Savannah River Company Savannah River Site

Aiken. SC 29808

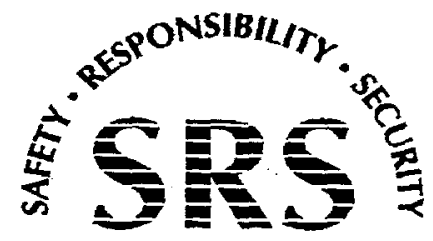




\section{INDEPENDENT PANEL EVALUATION OF DRY SLUDGE PISA PROGRAM}

\section{SUMMARY}

Dr. Kirk Yeager and Mr. Marvin Banks from Energetic Material Research and Technology Center (EMRTC) evaluated Savannah River Site (SRS) efforts in the Dry Sludge program. They evaluated four program areas: energetic material formation, stability, initiation, and propagation. The panel evaluation included a site visit (July 13 and 14) as well as a review of various reports ${ }^{1-10}$ and presentations by researchers involved in the program. A summary of their findings follows. Attachment 1 contains the full report. Attachment 2 includes the agenda for the meetings and copies of the presented materials.

- The panel endorses SRS efforts in the Dry Sludge Program

- The panel agrees with selecting mercury fulminate as a surrogate energetic compound and mercury oxalate as a possible energetic compound in the tank farm. They recommend a similar study of stability of Millon's base if synthesis proves feasible. The panel recommends no additional work - except perhaps radiation studies -- on silver nitride.

- The panel concurred with SRTC conclusions that caustic environment and radiation destroyed energetic compounds. However, the panel recognized that the addition of a caustic solution to the dry-sludge tanks might not effectively re-wet all the sludge and, therefore, reliance should be placed in degradation due to the radiation environment.

- The panel strongly recommends additional stability tests of energetic compounds - mercury fulminate, mercury oxalate, and Millon's base -- in a high radiation field ( $1 \mathrm{Mrad} / \mathrm{h})$ as a first priority. If an energetic material survives this test, then propagation studies may prove necessary to fully resolve safety concerns.

- The panel recommended additional impact test to determine the minimum impact energy and the highest fraction of energetic material in sludge if the radiation studies do not show marked (e.g. $>90 \%$ ) reduction in decomposition energy for the material over a relatively short period of time.

- The panel recommended contacts with Peter Hefferan and Gerald Laib as additional energetic material experts. They suggested review of additional literature work for completeness.

- The panel as well as SRS personnel found vendor test results inconclusive and confusing. The panel members, after further consultation with an additional expert in this technology, believes the vendor synthesis failed to 
yield as pure a mercury fulminate as used by SRTC personnel (the X-ray diffraction and thermal analysis data support this interpretation). As such, the panel members found the SRTC findings more credible. The panel recommends radiation stability testing of the vendor synthesized material only if readily available.

\section{REFERENCES:}

[1] M. J. Barnes, L. O. Dworjanyn, S. D. Fink, F. F. Fondeur, M. W. Geeting, M. S. Hay, R. F. Swingle, and W. R. Wilmarth,, "Examination of the Potential for Formation of Energetic Compounds in Dry Sludge," WSRCTR-98-00407, November 1998.

[2] D. T. Hobbs, "Possible Explosive Compounds in the Savannah River Site Waste Tank Farm Facilities," WSRC-TR-91-444, Rev. 1, April 30, 1995.

[3] . R. M. Wallace, "Explosion Hazard of Mercury and Silver Oxalates During Cleaning of Tank 16H," DPST-78-258, February 24, 1978.

[4] D. T. Hobbs, "Recommended Standard Materials for Evaluation of Dry Solid Energetic Reactions," WSRC-TR-98-00262, August 19, 1998.

[5] W. R. Wilmarth, "Mercury Fulminate and Mercury Oxalate Synthesis and Associated Sludge Testing," I-WPT-001, January 21, 1999.

[6] W. R. Wilmarth, "Contigency Plan for Shock-Sensitive Compound Handling," SRT-LWP-98-0123, rev. 1, July 31, 1998.

[7] Mercury Oxalate," SRS Material Safety Data Sheet Equivalent \#26988.00.

[8] "Mercury Fulminate," SRS Material Safety Data Sheet Equivalent \# 26970.00 .

[9] "Silver Nitride," SRS Material Safety Data Sheet Equivalent \# 26970.00.

[10] L. O. Dworjanyn, "Vendor Testing Of Sensitive Compounds In Simulated Dry Sludge," WSRC-RP-99-00428, June 1999. 
ATTACHMENT 1 
Dr. Kirk Yeager

New Mexico Tech/EMRTC

Socorro, NM 87801

July 22, 1999

Bill,

Here is our final report on your efforts. I have enclosed a bound copy for archive purposes and a loose copy for replication. The general report emphasizes the suggestions that Marv and myself made when we were on site. If you have any questions, please feel free to contact either me or Marv. Thanks for the hospitality while we were out there. We both enjoyed our visit.

Sincerely,

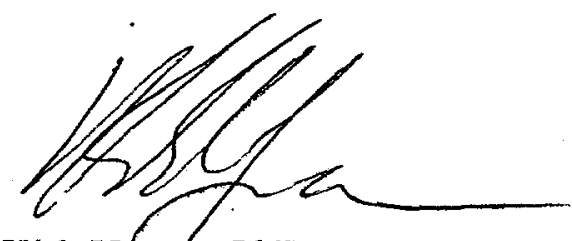

Kirk Yeager, $\mathrm{PhD}$

(Acting Associate Director or Research and Development) 


\title{
EMintc
}

Energetic Materials Research and Testing Center

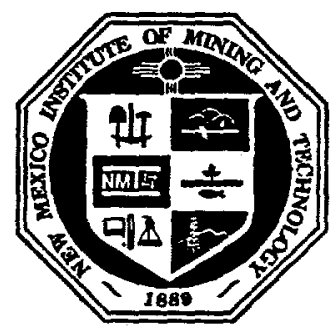

New Mexico Institute of Mining and Technology

801 Leroy Place

Socorro, New Mexico 87801

ANALYSIS OF RESEARCH EFFORTS EXAMINING ENERGETIC COMPOUND FORMATION IN DRY HIGH-LEVEL WASTE SLUDGE

EMRTC Report No. FR 99-14

Final Report Submitted to:

\author{
Bill Wilmarth \\ Savannah River Technology Center \\ 773-43A \\ Aiken, SC 29808 \\ by \\ Dr. Kirk Yeager and Mr. Marvin Banks \\ Principal Investigators
}

July 1999 
Introduction: From $6 / 13 / 99$ to $\not / 14 / 99$ both Dr. Kirk Yeager and Mr. Marvin Banks visited the Savannah River Site (SRS) to receive briefings on their efforts to study the potential of energetic material formation in dry high level waste sludge. This report will provide impressions of the research covered, analysis of results presented, and suggestions for future experimentation to complete the study described.

Background: The overall impression of EMRTC researchers was that the major concerns being addressed by SRS could be broken into two categories. Of initial importance is whether or not energetic materials could exist at all in the dry sludges. This concern encompasses two main issues; a.) whether or not conditions in the tanks would allow for formation of explosives, and b.) what would be the survivability of suspected explosives under the hostile tank environments. Presupposing that explosive compounds could both be formed and maintain integrity in the tanks, the second concern would be what hazards thesẽ materials could introduce. Under this area of study come the issues of a.) what amount of energy it would take to initiate entrapped explosives, and b.) what potential exists for propagation of an explosion through the sludge body if some of the material is initiated.

The overall problem can be viewed as a decision hierarchy with four stages. Each stage poses a question, with the answer dictating whether work has to be conducted on the stage below it. Figure 1 gives an overview of this hierarchy.

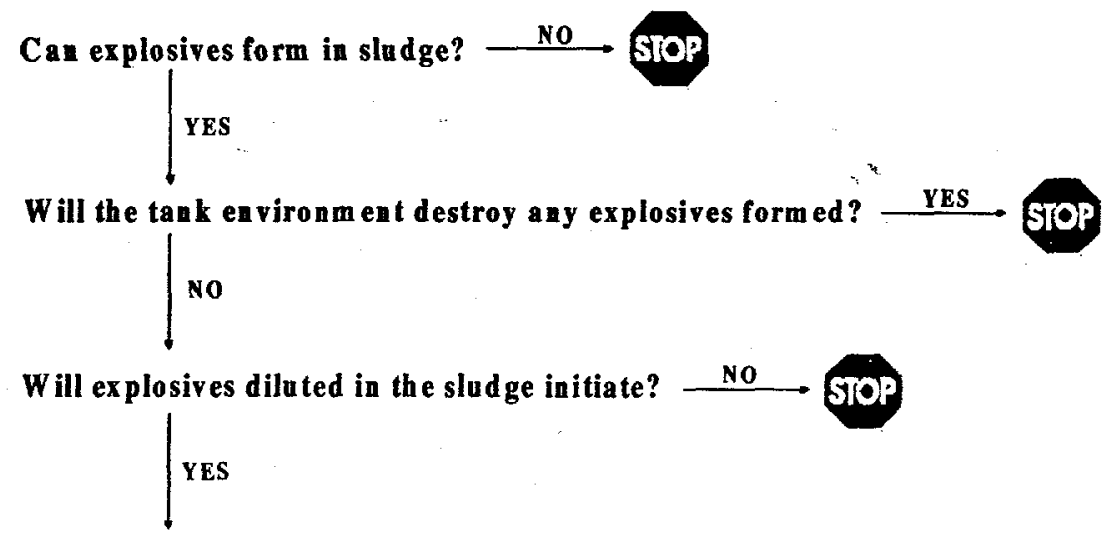

If initiated, can the resulting explosion propagate through the sludge?

Figure 1 - Decision making hierarchy 
Each stage in the hierarchy will be addressed in terms of analysis of the experiments conducted to date and suggestions for work needed to provide closure to the issues. An overview of concerns was provided to EMRTC researchers by SRS personnel. Specific areas were highlighted for comment. Before their departure from SRS, EMRTC personnel provided an "out-brief" addressing the concerns given to them. The outline of Questions posed by SRS, followed by the EMRTC briefing is provided in Appendix A. All concerns called out in the original SRS listing of questions will be addressed in this report.

Discussion: Each stage in the hierarchy will be covered as a separate unit.

Stage 1 - Can explosives form in sludge?

A tremendous body of work was done addressing this issue. In general it looked as if the chemical environment needed to produce a significant amount of explosives was not present. However, it was not possible to discount this possibility. Due to the high degree of certainty required in this situation, it was not possible to dismiss the presence of some level of explosive contamination. The past history of silver nitride alone makes it hard to argue against the freak production of energetics.

The relatively low levels of silver present in the dry tanks would argue against the formation of any significant amounts of silver compounds. For this reason, the detailed study of silver nitride may very well be overkill. A concentrated effort on the other potential explosives seems more prudent.

Study of mercury compounds does seem reasonable. The scenario of mercury combining with waste constituents to form primary explosives remains a remote possibility. SRS provided a well thought out overview of potential explosives which might exist in the tanks. Selection of mercury oxalate and fulminate for further study seemed logical. As pointed out by SRS scientists, the use of fulminate as a surrogate for the more likely (albeit unstable) mercury compounds formed brings certain problems with it. Care must be taken in both stressing that 
fulminate is only intended as a surrogate, and in generalizing fulminate data to reach conclusions about the other compounds suspected present.

Concern was raised over potential literature references which might have gone unnoticed. As most of the research covered was dedicated to the mercury-based explosives, a review of two well respected literature sources was conducted for these materials [1,2]. The results are provided in Appendix B, and will be used later in the report to support various conclusions drawn. Both oxalate and fulminates were stressed. No references could be found to Millon's base or related compounds. Vendor information for procurement of the literature sources utilized is given in Appendix C.

Stage 2 - Will the tank environment destroy any explosives formed?

Detailed studies of both mercury fulminate and oxalate were conducted to see if these compounds could withstand the hostile tank environments of high radioactivity and strong alkalinity. As both compounds were able to survive neutral dry sludge, extreme simulations had to be tested to determine their reaction to more realistic conditions.

Tests of the effects of caustic conditions on both materials showed promise. It seemed that neither mercury compound held up well to this environment. Unfortunately, the debate as to whether the compounds in the dry tanks saw sufficient caustic environments, or could be rewetted effectively to introduce additional caustic, made the logistics of this scenario too tentative.

In all cases it was agreed upon that high levels of radioactivity were present in the tanks. It is the opinion of EMRTC researchers that tests examining this effect showed the most promise of all of the research conducted. As both compounds showed significant decay (as displayed by DSC exotherms) with a dosage equivalent to only 1.5 hours in a tank, logic dictates that the time span of months or years should essentially eradicate them.

One important experiment that remains to be done is a greater dosing of the explosives being studied. Oxalate displayed the greatest extent of decomposition under the dosing tested, with a 
decrease to $1 / 3$ of its initial energy output. To feel fully confident in the ability of radiation to remove these explosives, it would be desirable to see a decrease in their presence on the scale of an order of magnitude or greater. This would serve as a much more definitive result.

At this point, the research results of the vendor should be mentioned. Whereas SRS scientists conducted a sound series of experiments in the opinion of EMRTC reviewers, vendor results tended to obscure some issues. Most importantly was the difference in the vendor fulminate. Again, it must be borne in mind that fulminate is not anticipated to exist in the tanks, but its use as a surrogate does require consistent results between SRS and its vendor.

After consulting other experts in the field, the behavior of SRS fulminate was confirmed to match that ideally expected [3]. The high temperature decomposition and complicated peak shape exhibited by the vendor fulminate shows that they did not obtain a pure form of the explosive. Of the literature presented in Appendix B, the experiments that best corroborate the results of SRS are given by Davis [4]. In the test described, mercury fulminate heated in a glass tube at $20^{\circ} \mathrm{C}$ per minute gave explosive decomposition at $175^{\circ} \mathrm{C}$. Both the conditions of the test and the results obtained closely match SRS data. No explanation can be given for the cause of the discrepancies displayed by the vendor fulminate.

External vendor data was sought to validate in-house testing at SRS. Unfortunately, the fulminate issues cloud this goal. It is the opinion of EMRTC reviewers that SRS fulminate was the better of the two compounds tested, and the results obtained with this material the more believable. The complexity of the vendor product makes interpretation of their results problematic. Two approaches seem to be available to resolve the issues raised. First, vendor data on fulminate can be ignored, as majority opinion favors the SRS product. Second, if any minor doubts remain, vendor "fulminate" can be irradiated to see if it also rapidly decomposes under doses expected in the tanks. Unavailability of vendor product would limit the options.

It should be stressed that of all the stages being examined, the explosive survivability issue exists as the most "black and white". If the suspected materials are found to be unable to survive under the harsh tank conditions, all other issues become moot. Studies of initiation and propagation 
become much more complex and difficult to relate to "real-world" conditions. The potential for explosives to segregate out in strata (or pockets) creates complexity in any analyses conducted in these next two stages.

\section{Stage 3 - Will explosives diluted in the sludge initiate?}

The main thrust of the research in this stage was to determine if sampling techniques designed to get cores of the sludge would initiate entrained explosives. As mentioned above, this area becomes much more difficult to interpret as problems arise in simulating the sludge body with small scale tests. Most tests used to measure sensitivity of explosives to insult operate with relatively small samples (20-40 mg). Reproducing conditions present in the tank body may not be possible with such a small sample. Therefore, the results of these tests must be taken in the context of the broader problem.

Use of the drophammer to probe sensitivity to impact seemed valid. This is the industry standard test, and provides good data. SRS chose to gently mix sludge with fulminate crystals. There is little else that can be done in terms of mixing. SRS researchers also chose to run the impact tests at full energy input. The use of lower insults might be advisable, as will be discussed below.

EMRTC reviewers were told of the problems that occurred in judging whether or not the explosively spiked sludges initiated. The production of smoke and color change was utilized to determine if the pure fulminate initiated. Color change was not a good indicator for the sludge samples, as they started out a similar color to the reacted fulminate. This left the presence of smoke as the only indicator. No smoke was seen for the sludge samples, which was taken as a sign that they did not initiate. Unfortunately, some SRS data seemed to point towards the presence of elemental mercury in the impact tested samples. This would be a sign of initiation. The net result of these tests introduces some unwanted ambiguity.

It is suggested that a few additional experiments be conducted to resolve some of the issues that arose during these impact tests. Of prime importance is gaining a better consensus of whether a sample has initiated or not. To do this, several approaches can be taken. First the percentage of fulminate in the sludge can be increased until an obvious sign of initiation is observed (such as 
visible smoke). The $3 \mathrm{mg}$ of pure fulminate may not produce enough smoke when surrounded by all the particulate matter of the sludge. Another way to judge a reaction would be to make a surrogate sludge out of white solids such as sodium nitrate and alumina. This would make it easier to see any dark spots in the impacted sample. Once a level of comfort is reached with the ability to judge, whether or not a sample was initiated, quantification of the energy needed to create reaction should be done. Some idea of how much energy input is needed to create an initiation of the fulminate in sludge would be valuable. This number would provided a base-line value for types of sampling that could be undertaken with a margin of safety. It should be noted that there is almost no way that pockets or strata of explosive in the sludge can be accounted for with the small-scale tests. At best a bracketing region of energy could be derived with pure fulminate on one end, and the fulminate diluted in the sludge at the other extreme. The uncertainty surrounding the exact nature of the sludge introduces an unavoidable uncertainty.

Stage 4 - If initiated, can the resulting explosion propagate through the sludge?

A shock, caused by a hand tool being dropped into the sludge (or by a natural disaster) could initiate an explosion. There is a concern that if concentrated areas of mercury or silver formed into primary explosive that these concentrated pockets could be initialed by a shock and the resulting explosion propagate though the sludge layer. At present, no tests have been conducted to examine the potential of this scenario. If the further testing recommended above shows that explosives are not destroyed by tank conditions, testing for propagation feasibility would be recommended.

Although the concentration of the mercury or silver compounds would be low (7\% or less), detonation tests could be run on a "worst-case" surrogate sludge to determine if propagation would occur. Tests of this type are performed in a steel pipe (high confinement) to reproduce a "worst-case" scenario. The sludge could be loaded to $150 \%$ or greater concentration with mercury fulminate, thus allowing a rather large safety factor. The device would be initiated with a booster and detonator or hot wire. Velocity pins would be mounted on the tube wall to track the progress of the shock wave inside the tube. Velocity pins increase the confidence level of results because, in many instances, fragments are hard to recover if the shock propagates to a full detonation. 
The steel confinement tube (pipe) should be as large as possible, but because the surrogate sludge has to be manufactured in the laboratory, it would be necessary to limit the inside diameter and the length. Two tests on each mixture, using a tube with an inside diameter of 2inches and a length of 10 times the diameter, is suggested. Figure 2 shows the general test hardware after a non-propagation.

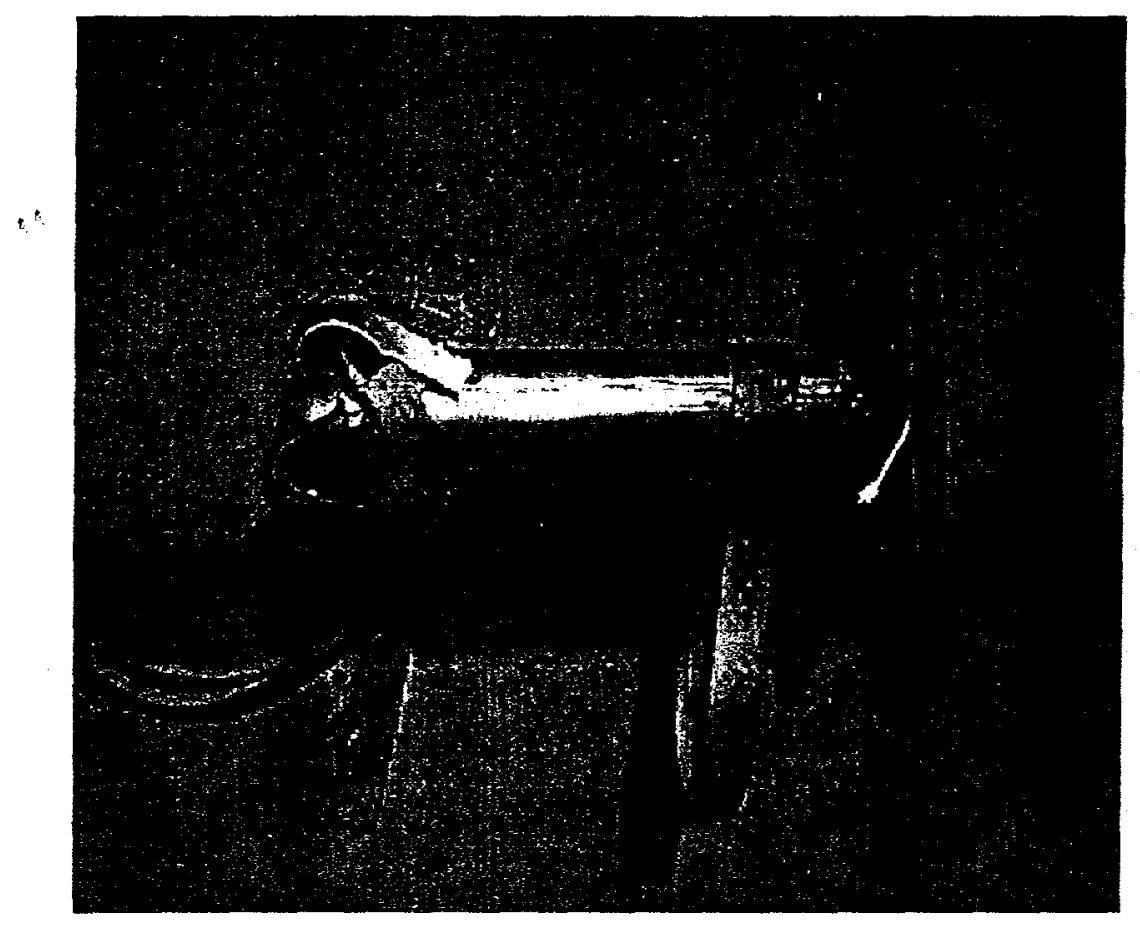

Figure 2. Results of "High Temperature Gap Test" that did not propagate a detonation. The booster caused the banana peeling effect at the left hand side of the tube. Broken heating belts (red) can be seen.

One method of initiating the experiment is with a detonator and a booster. The booster would have the same diameter as the shock tube and have a length $1 \frac{1}{2}$ times the diameter. The booster would be packed with Composition C-4 high explosive. An alternative method is to load the end of the device with mercury fulminate and initiate the primary explosive with a hot wire. The hot wire would be made from a short piece of resistance wire connected to a power source. 
Ancillary Issues: To ensure complete understanding, the questions posed by SRS (and provided in Appendix A) will be addressed sequentially.

\section{Do you recommend any additional tests?}

Several additional tests were outlined in the report above. The most important of all tests recommended would be the increased dosage of the test explosives. As the destruction of these materials through irradiation would mitigate all other concerns, this should be top priority. In addition, if possible, it would be a good follow through to irradiate both the vendor fulminate and a sample of Millon's base (if it could be successfully made). This would aid in closing all potential concerns. Additional drophammer tests were discussed, as well as tests for propagation. Whether these should be pursued simultaneously with radiation tests remains a decision that SRS needs to make. The testing scheme to date at SRS has addressed multiple issues at the same time. This approach seems wise if resources allow its continuation, as time will be saved if one avenue proves fruitless.

\section{Do the proposed tests with silver nitride add significant value to the current data?}

The problems described by SRS personnel in isolation of this compound seem to indicate that its existence would imply that no handling procedures could be implemented at all in its presence. Fortunately the low concentration of silver seems to dictate that little of the material should be able to form. At present, tests with the nitride might only serve to complicate the main issues. If any tests should be conducted with it, they should be limited to radiation experiments. Great care is recommended if work is continued in this area.

\section{Should we consult with other individuals or organizations?}

Two individuals with unique talents in the area of primary explosives were mentioned. Peter Hefferan has already been contacted by EMRTC researchers, and was given contact information for Bill Wilmarth. Perhaps one of the nation's experts on primary explosives is Gerald Laib. He can be reached for consulting work on energetic materials at (301)-774-5049. 


\section{Do you know literature data that we overlooked or sources we should investigate?}

Relevant literature has been included in Appendix B, with vendor sources to procure it given in Appendix C.

\section{Have we investigated at sufficient scale to conclude safety of operations?}

The DSC scale experiments are ideal to determine the survivability of materials in different configurations. In general, these experiments will provide good reliable data for Stage 2 concerns. Drophammer results are more problematic. The issue of replicating tank conditions with milligram scale samples was addressed. Short of moving on to larger scale propagation techniques, little can be done to compensate for this shortcoming of small-scale testing methodologies. If it is determined that explosives can survive in tank conditions, larger experiments will be deemed of significant value.

\section{Would you recommend alternate sample preparation of handling methods?}

Overall methods described by SRS seemed safe and adequate for the operations. The use of glass for explosives synthesis poses inherent risks. Most importantly, glass does not show up on an X-ray. This may make for unpleasant exploration of wounds if glassware becomes shrapnel. Leaded glass, plastic, or metal are used in most EMRTC operations when feasible. Keep sample size in the region discussed in the briefings. Scaling up to even the gram level can create a tremendous increase in hazards.

\section{Do any specific test results cause concern?}

The presence of significant amounts of explosives after short-term irradiation shows the need for larger dosage experimentation. The data produced by SRS seemed sound and well analyzed. Discrepancies in vendor data did not produce much confidence overall. Ideas were provided to overcome this shortfall.

The overall use and interpretation of the Carius tests conducted by the vendor did create some concern. The vender reported the results of five tests and submitted a profile for a sixth. The Association of the British Pharmaceutical Industry furnished the guidelines for the Carius tube tests ". The appropriateness of this test for explosive materials is not known. 
In order to evaluate the vender data, Table 1 was constructed. The final pressure at $250^{\circ} \mathrm{C}$ (from the venders Carius tube profiles) was added to the table in order to try and form a trend caused by the addition of MF to the sludge. The pressure readings were taken from the graphs found in Appendix 5 of the venders report. References will be made to pages 26 and 27 of 32 found in "Report No.: WE1905RP". Any data added to the table by EMRTC will be in bold script.

\begin{tabular}{|c|c|c|c|c|}
\hline $\begin{array}{c}\text { Sample } \\
\text { Name }\end{array}$ & $\begin{array}{c}\mathrm{W}_{\mathrm{MF}} \\
(\mathrm{grams})\end{array}$ & $\begin{array}{c}\mathrm{T}_{\text {onset }} \\
\left({ }^{\circ} \mathrm{C}\right)\end{array}$ & $\begin{array}{c}\mathbf{T}_{\text {gas (onset) }} \\
\left.\text { (vendors } \mathrm{P}_{\mathrm{o}}\right) \\
\left({ }^{\circ} \mathrm{C}\right)\end{array}$ & $\begin{array}{c}\text { Pressure } \\
\text { at 250 } \\
\text { (psig) }\end{array}$ \\
\hline $\begin{array}{c}\text { Mercury } \\
\text { Fulminate (MF) }\end{array}$ & 2.37 & 186.34 & 185.57 & 319 \\
\hline $\begin{array}{c}10 \% \text { MF in CS } \\
\text { Run 1 }\end{array}$ & 0.3026 & $\begin{array}{c}\text { N/D } \\
\text { No exotherm }\end{array}$ & $\begin{array}{c}140.1 \\
\text { Onset ??? }\end{array}$ & 23 \\
\hline $\begin{array}{c}10 \% \text { MF in NS } \\
\text { Run 2 }\end{array}$ & 0.3067 & $\begin{array}{c}\text { N/D } \\
\text { No exotherm } \\
\text { No onset }\end{array}$ & 37 \\
\hline $\begin{array}{c}10 \% \text { MF in CS } \\
\text { Run 3 }\end{array}$ & 1.020 & 114.63 & 141.96 & 209 \\
\hline $\begin{array}{c}\text { 10\% MF in NS } \\
\text { Run 4 }\end{array}$ & 0.991 & $\begin{array}{c}117.5 \\
\text { No exotherm }\end{array}$ & $\begin{array}{c}148.79 \\
\text { No onset }\end{array}$ & 603 \\
\hline $\begin{array}{c}\text { Run 5 Repeat } \\
\text { of Run 4) }\end{array}$ & No exotherm & No onset & 517 \\
\hline
\end{tabular}

Table 1. Data from the vender report with additions made by EMRTC

The following comments can be made about the specific results:

a.) The cook-off profile of the mercury fulminate (MF) test provided by the vender is very good. This would be normal for this kind of material.

b.) Run 1 has no onset temperature, but an onset temperature of $140.1^{\circ} \mathrm{C}$ is given for the pressure. This pressure rise may or may not have a relationship to the reaction of MF.

c.) Run 2 profiles do not appear to have an onset temperature, but an onset temperature of $140.1^{\circ} \mathrm{C}$ is given for the pressure. There is no obvious pressure acceleration shown on graph CWE1965e/f.txt. Moisture and many non-energetic materials will result in profiles similar to this. It would seem difficult to identify a temperature/pressure threshold without a temperature response caused by a reaction.

d.) For Run 3, the vendor identified an onset temperature of $114.63^{\circ} \mathrm{C}$ and a temperature at which gas generation began to accelerate $\left(141.96^{\circ} \mathrm{C}\right)$. From the profile, it appears that the onset temperature starts at 127 to $130^{\circ} \mathrm{C}$ rather than the temperatures reported. 
e.) The profile for Run 4 shows neither an onset temperature nor a point of accelerating gas production. No conclusions can be drawn from this test. The profile of the repeat of Run 4 (Run 5) shows no reaction occurred.

The conclusions drawn by the vender seem hard to justify after carefully reviewing the data. Since no baseline tests were performed on the caustic sludge or the neutral sludge, it is hard to judge the effects of the addition of small amounts mercury fulminate. If consideration is given to the pressure at $250^{\circ} \mathrm{C}$, the results become even more confusing.

If the thermal data is needed to support the (SRTC) DSC data, the above series - should be repeated. The small sample sizes limits the amount of gas that can be produced. It is suggested that larger sample sizes be used for the next round of tests. One-liter tests would introduce sample sizes which would allow any reactions taking place to be easily identified. It is imperative that at least one baseline test be run on both the caustic sludge and the neutral sludge. There is no way to interpret profiles from the "loaded" cook-off tests without knowing how the sludge behaves without mercury fulminate added.

The tests should have been run in triplicate. Experience has shown that making a judgment on the results of only one test is risky. One baseline test on each of the "unloaded" surrogate sludge samples should be sufficient.

The SRTC research group has obtained very good data from their DSC tests. It would be.. valuable to have data from a larger scale tests to support their findings. EMRTC does not feel that the vender data contributes much support.

\section{Would you recommend testing with any alternate energetic compound?}

Testing with surrogates of suspected mercury compounds may lead to "philosophical" debates about their applicability to real-world problems. If possible, some additional tests with the most likely candidates would be prudent. These tests should be limited to radiation survivability, as this is the most definitive experiment. Fulminate will provide a worse case scenario in other test areas. 
9. Do you know of other instances of energetic materials formed in highly alkaline solutions? Normally a basic environment is used to dispose of most energetic materials. Their formation in this type of situation is not common.

10. Do you know of any industry analogies we should consider?

Your industry has too many unique variables (such as high levels of radioactivity) to readily compare to any others.

11. Do you believe any energetic compounds likely survive these environments (i.e. caustic and radiation)?"

EMRTC reviewers would find the likelihood of any of these materials forming in the first place remote. Data for both caustic and radiation destruction of explosives makes it unlikely that these materials would survive. The logical tests to provide more definitive proof of this have been suggested. 
References:

1. Penney L. Davis, The Chemistry of Powder and Explosives, John Wiley \& Sons, NY, 1956.

2. Encyclopedia of Explosives and Related Items, Picatinny Arsenal, Dover, NJ.

3. Private conversations with Peter Hefferan of Cartridge Activated Devices.

4. Penney L. Davis, The Chemistry of Powder and Explosives, John Wiley \& Sons, NY, 1956, p 435. 


\section{APPENDIX A}

SRS questions about research efforts

$\&$

EMRTC “out-brief” outline 


\section{¿(üu!̣e!̣pes pue ग!̣sneo}

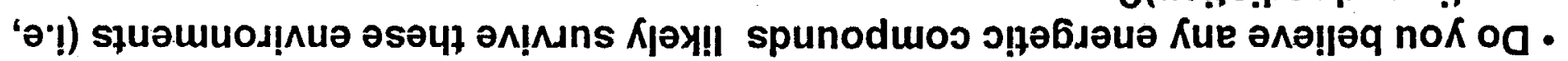

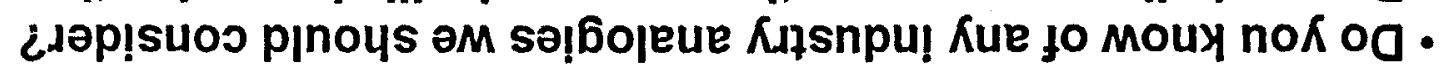
¿əisem dno se yons suo!znjos

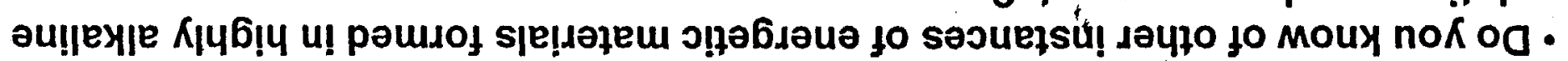

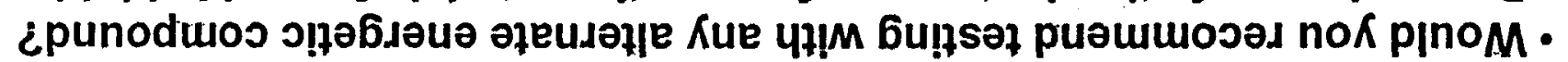

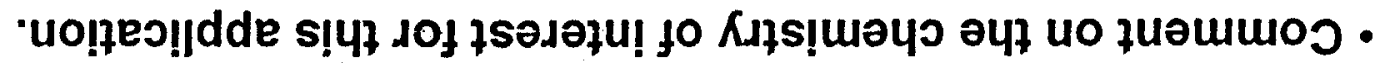

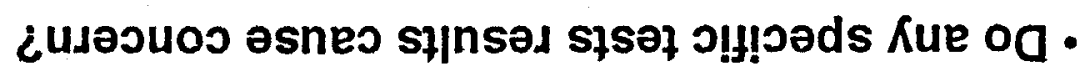

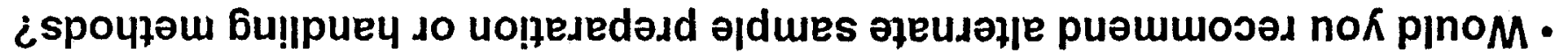

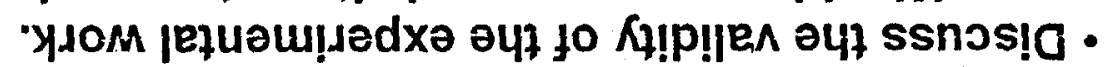

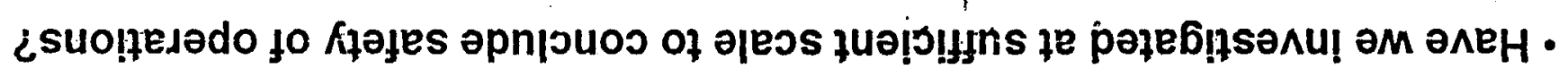

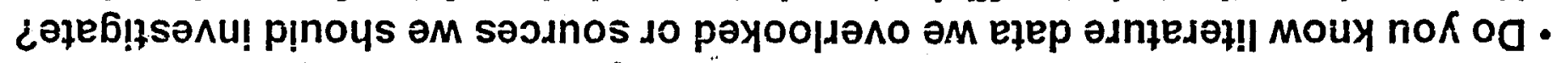

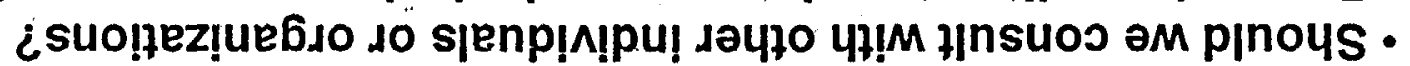

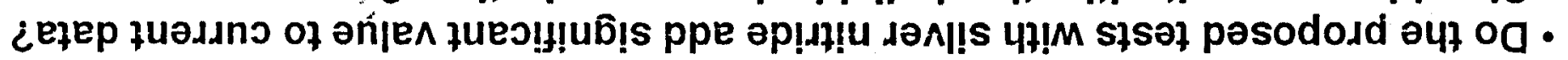

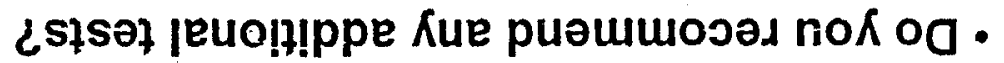

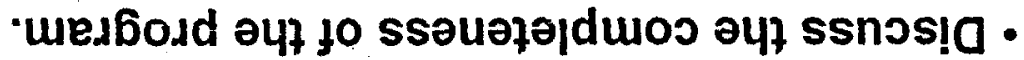

Hodəy 6u!do|ә^әg u! jәp!suos of suo!fsəno 


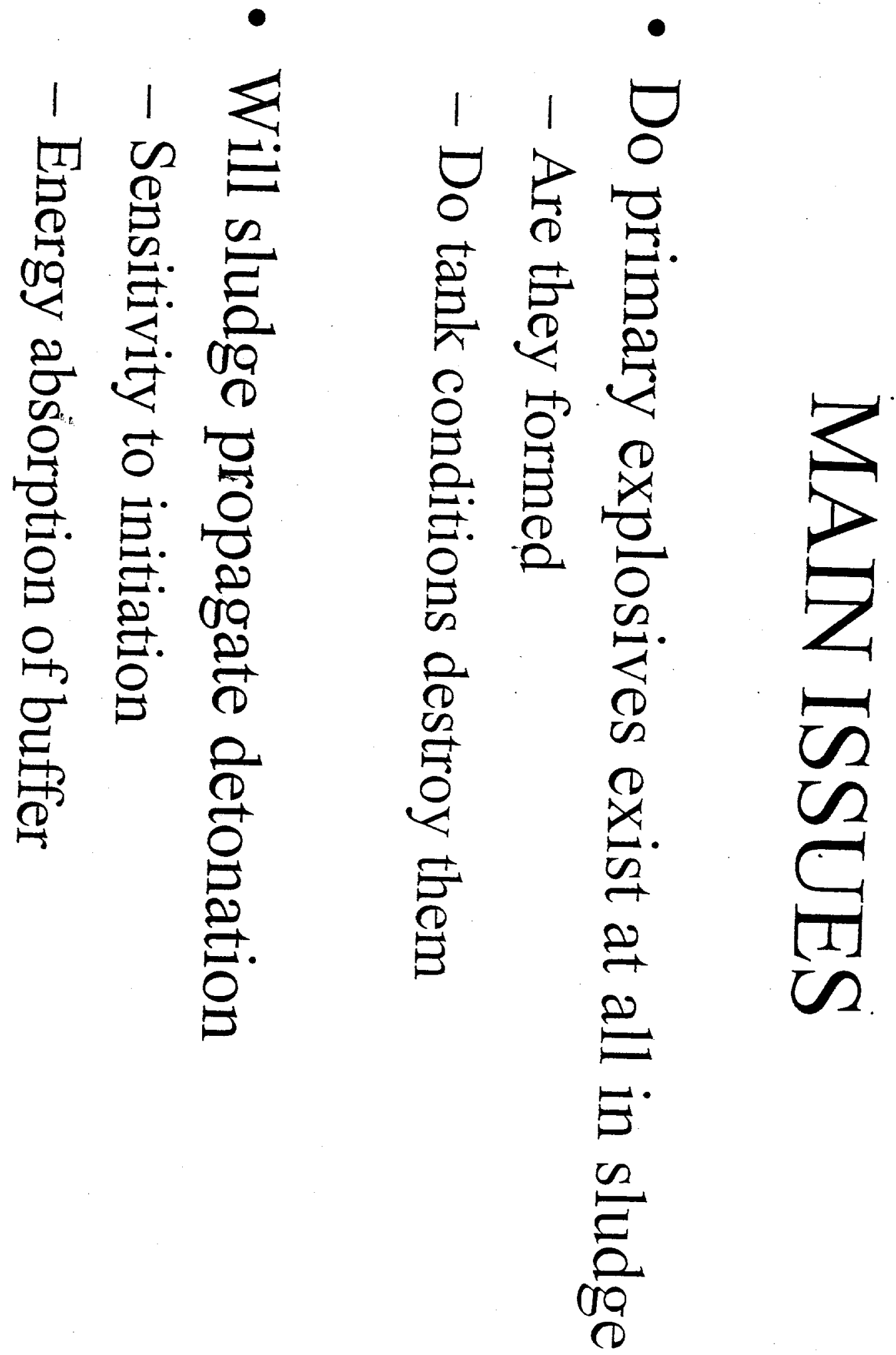




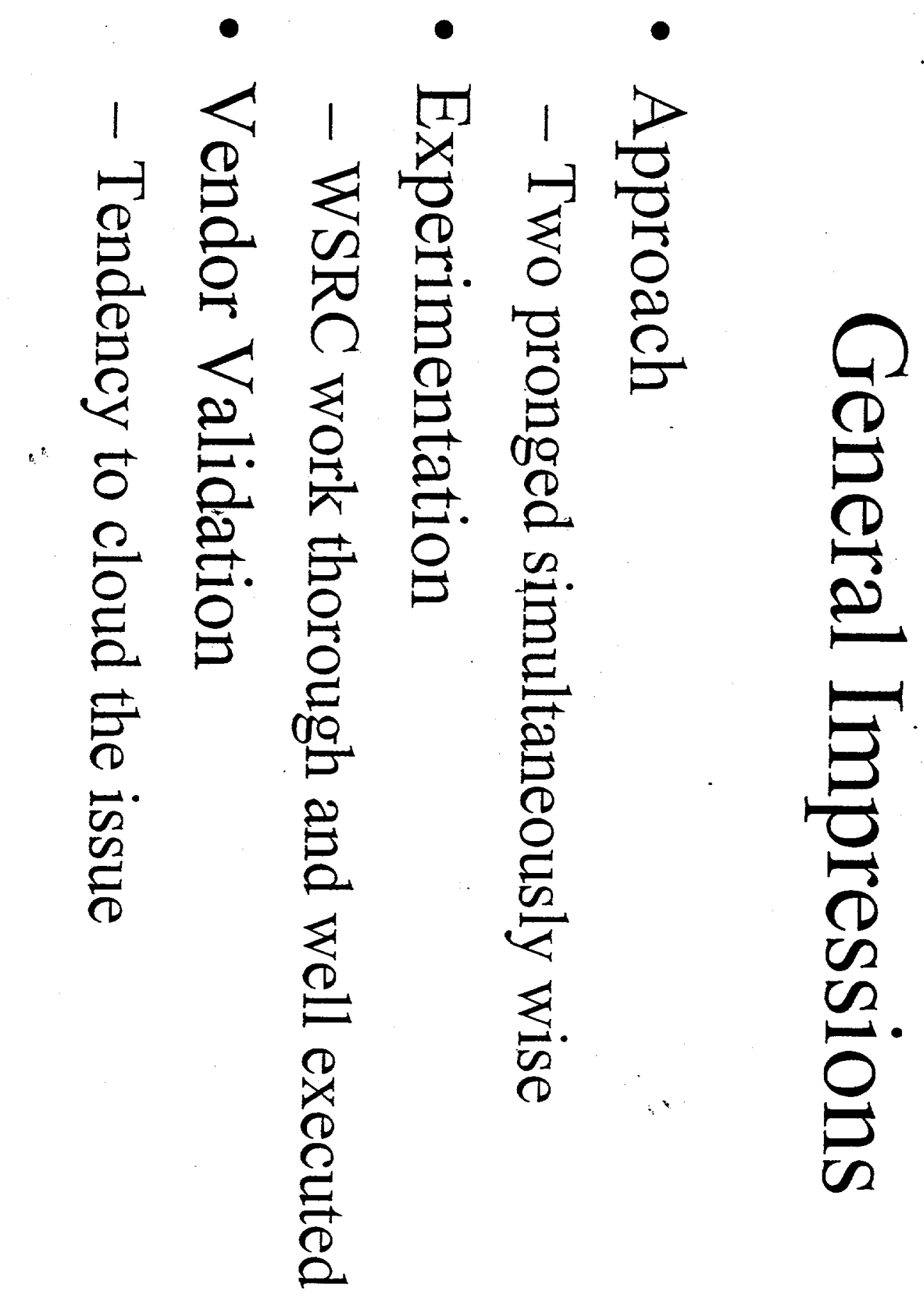




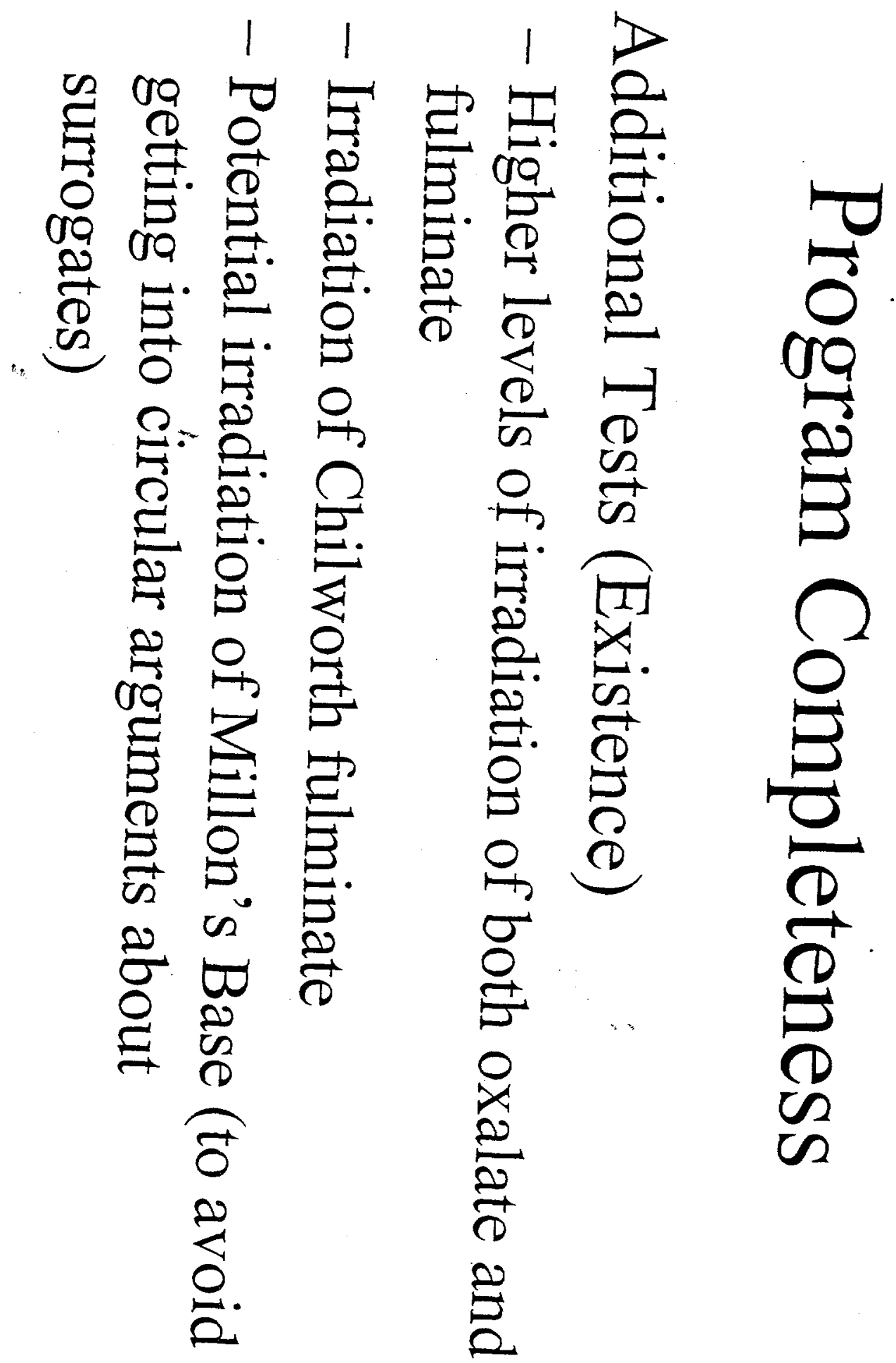




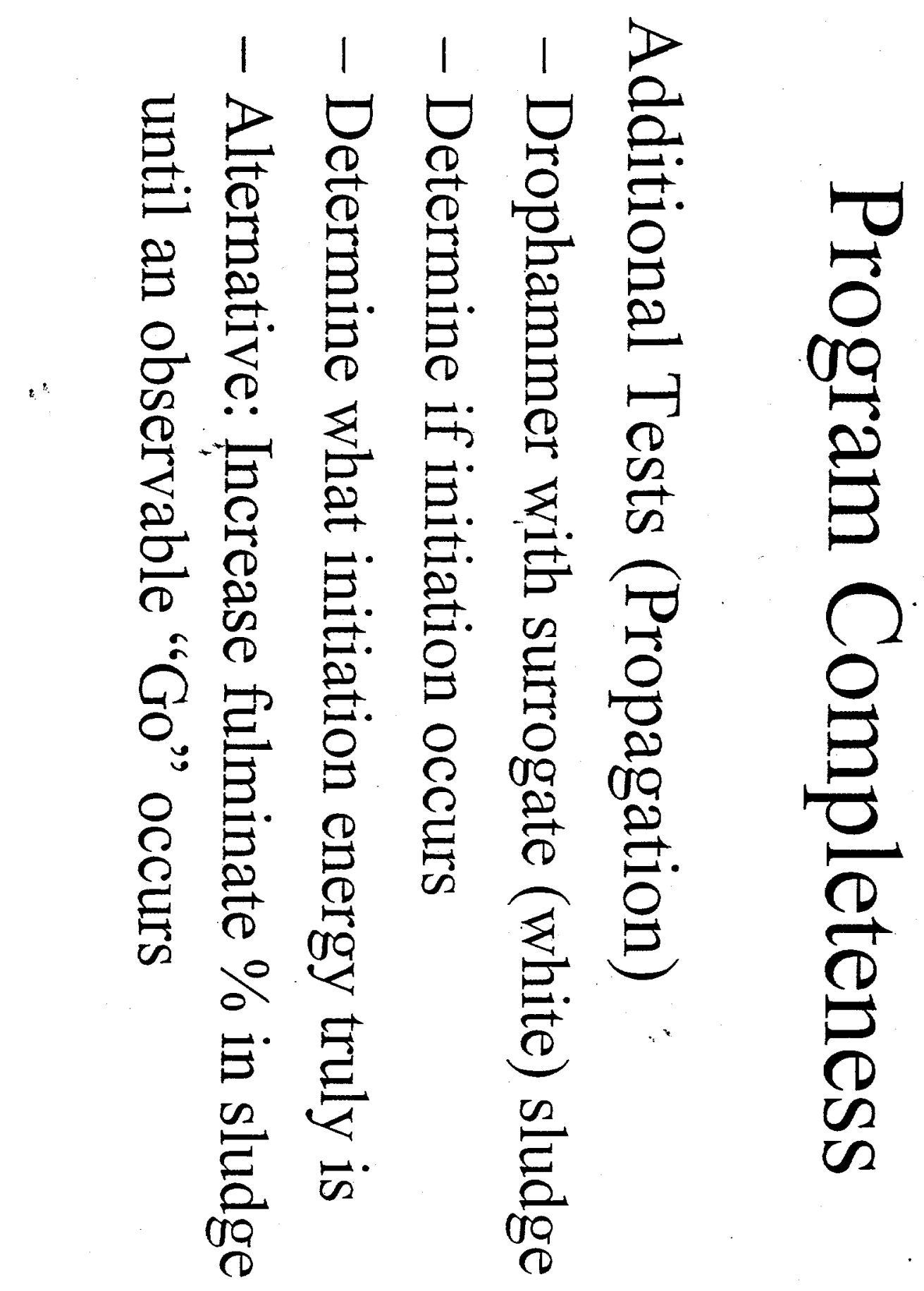




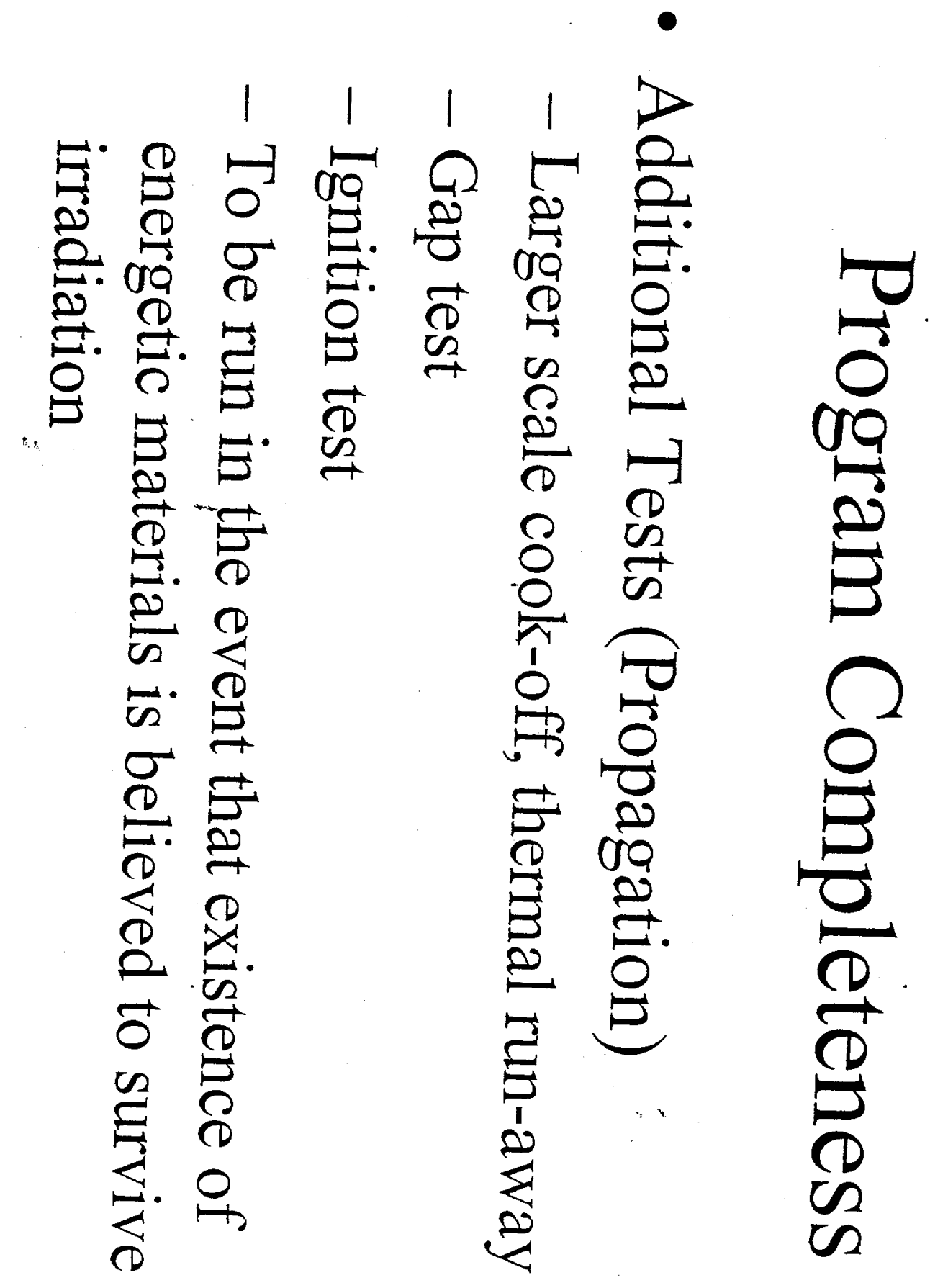




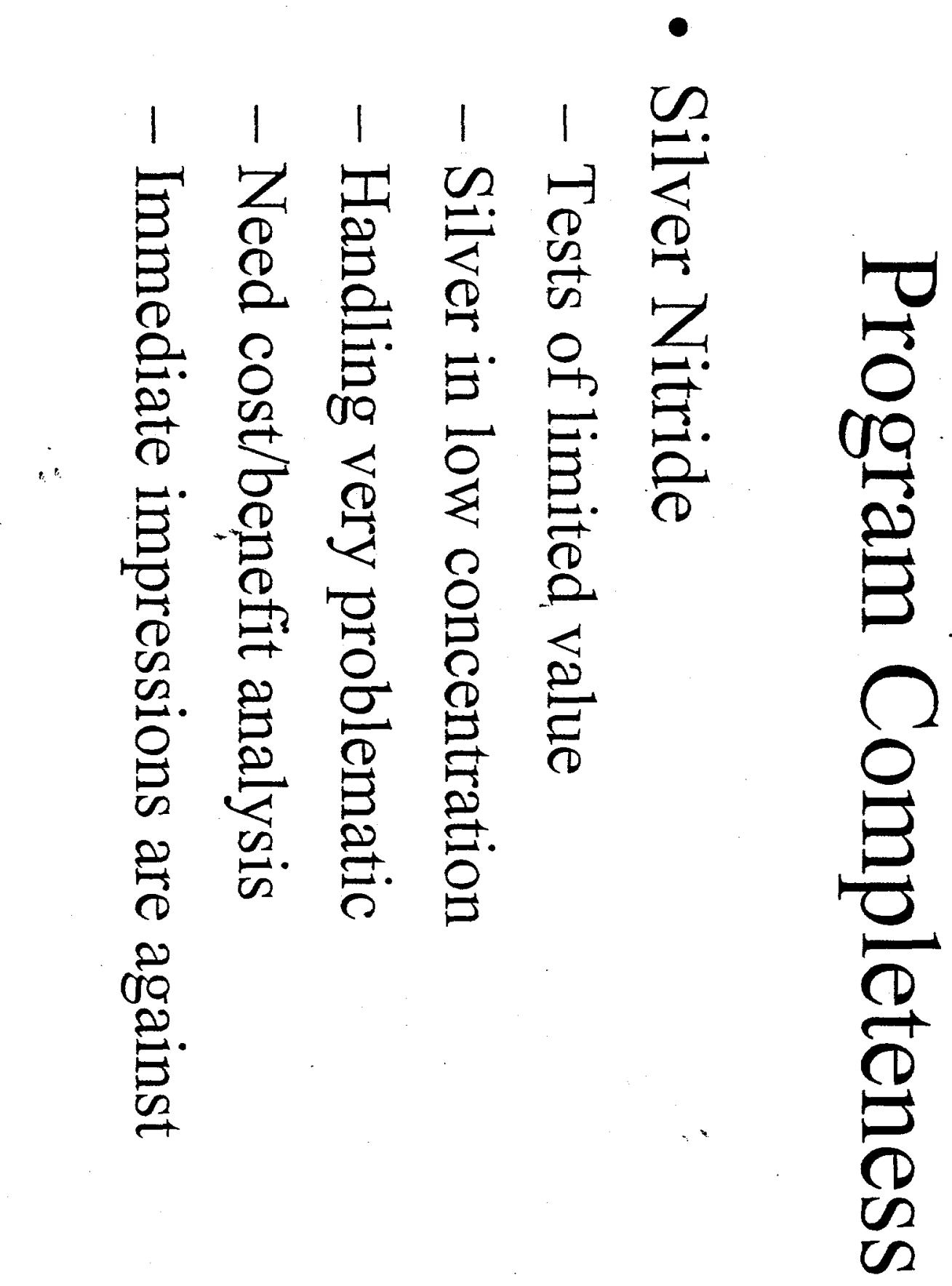




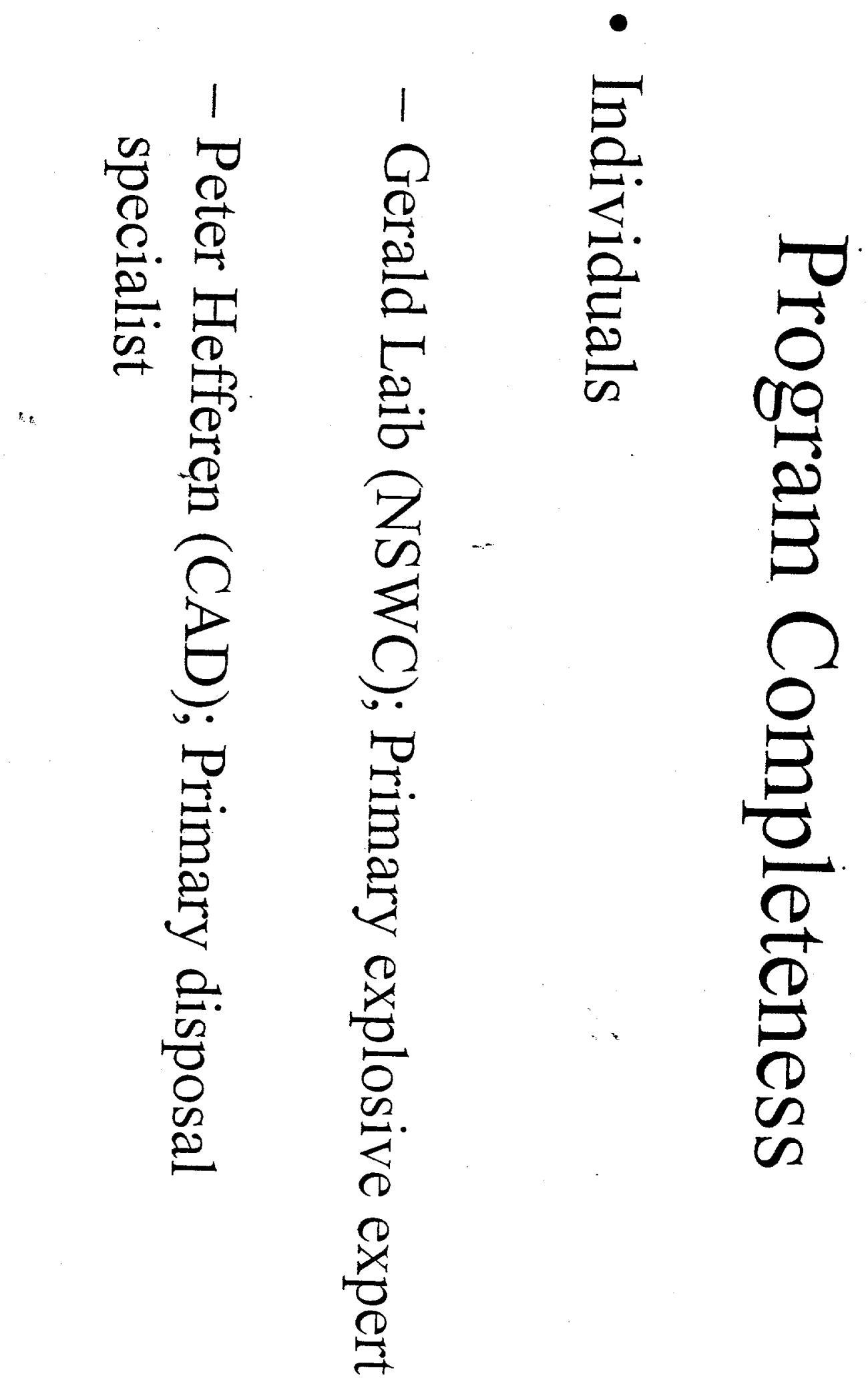




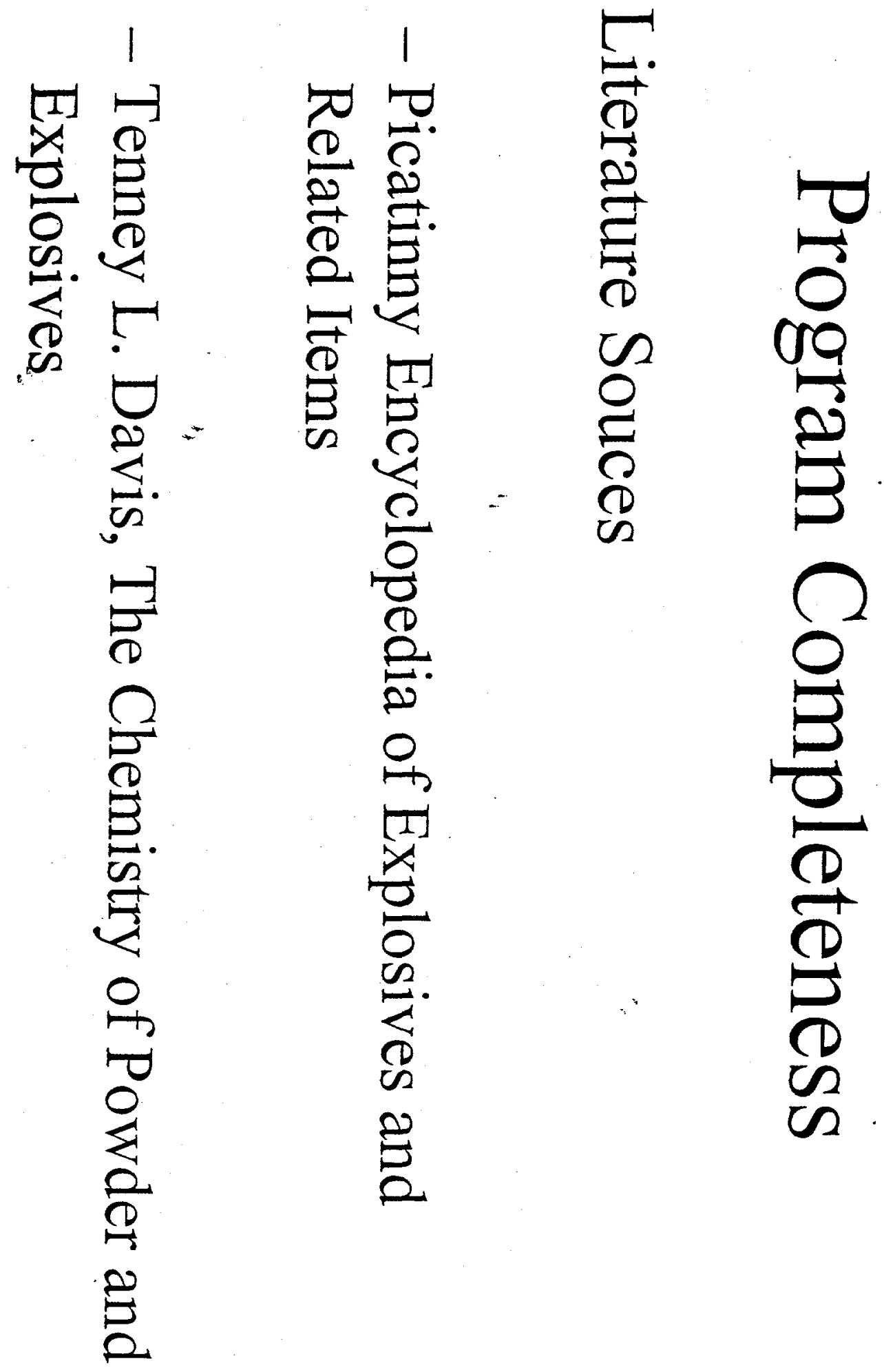



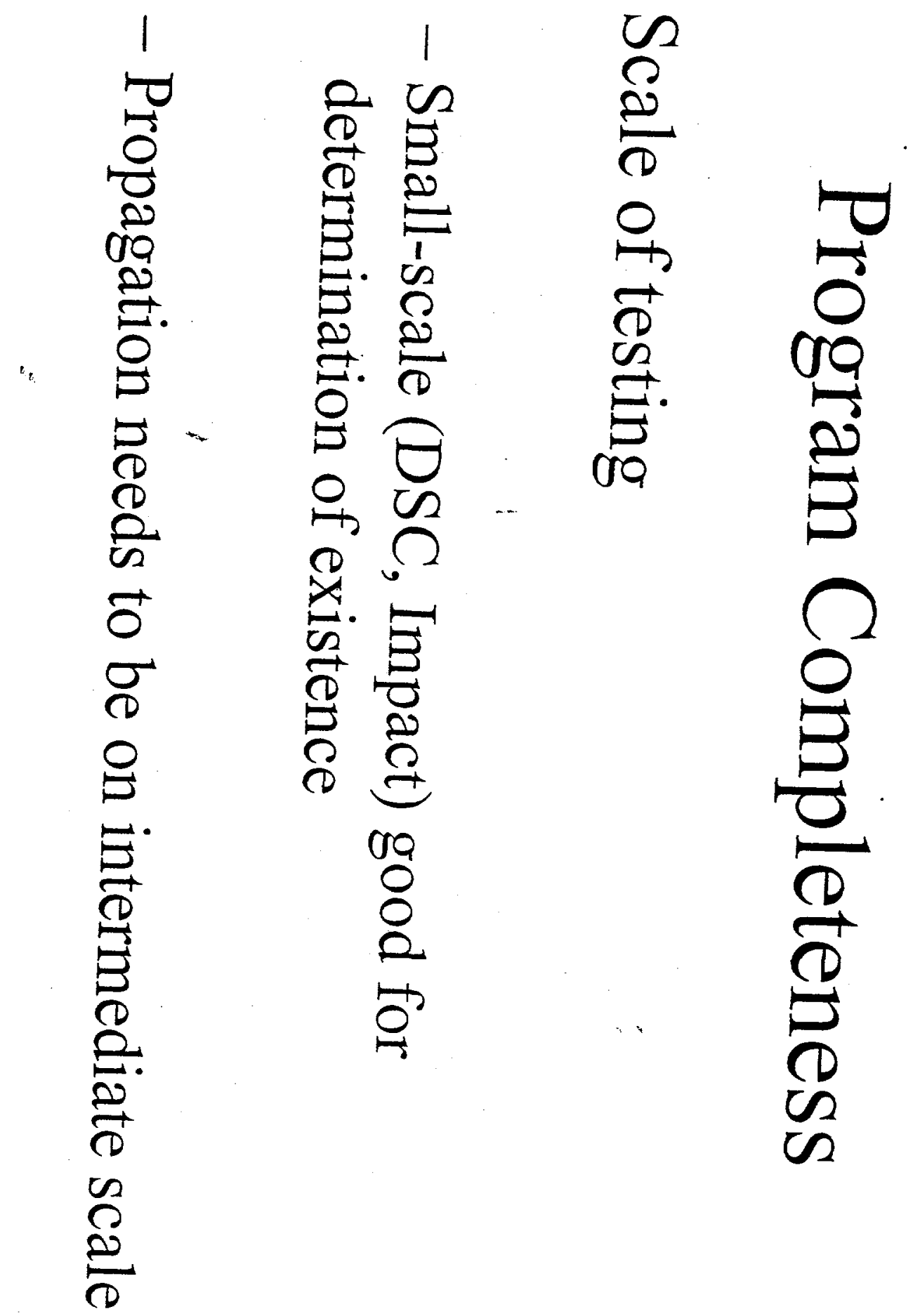


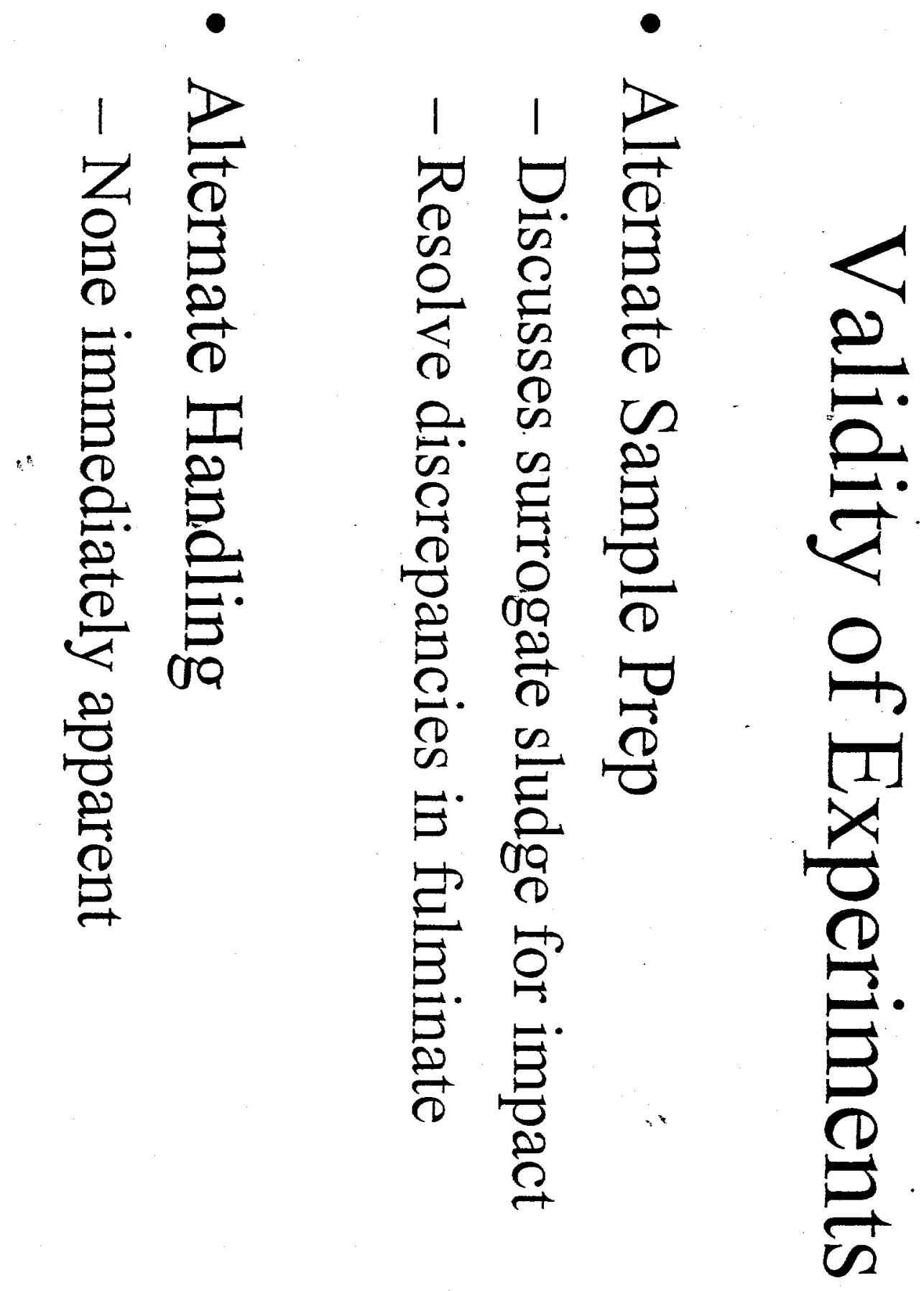




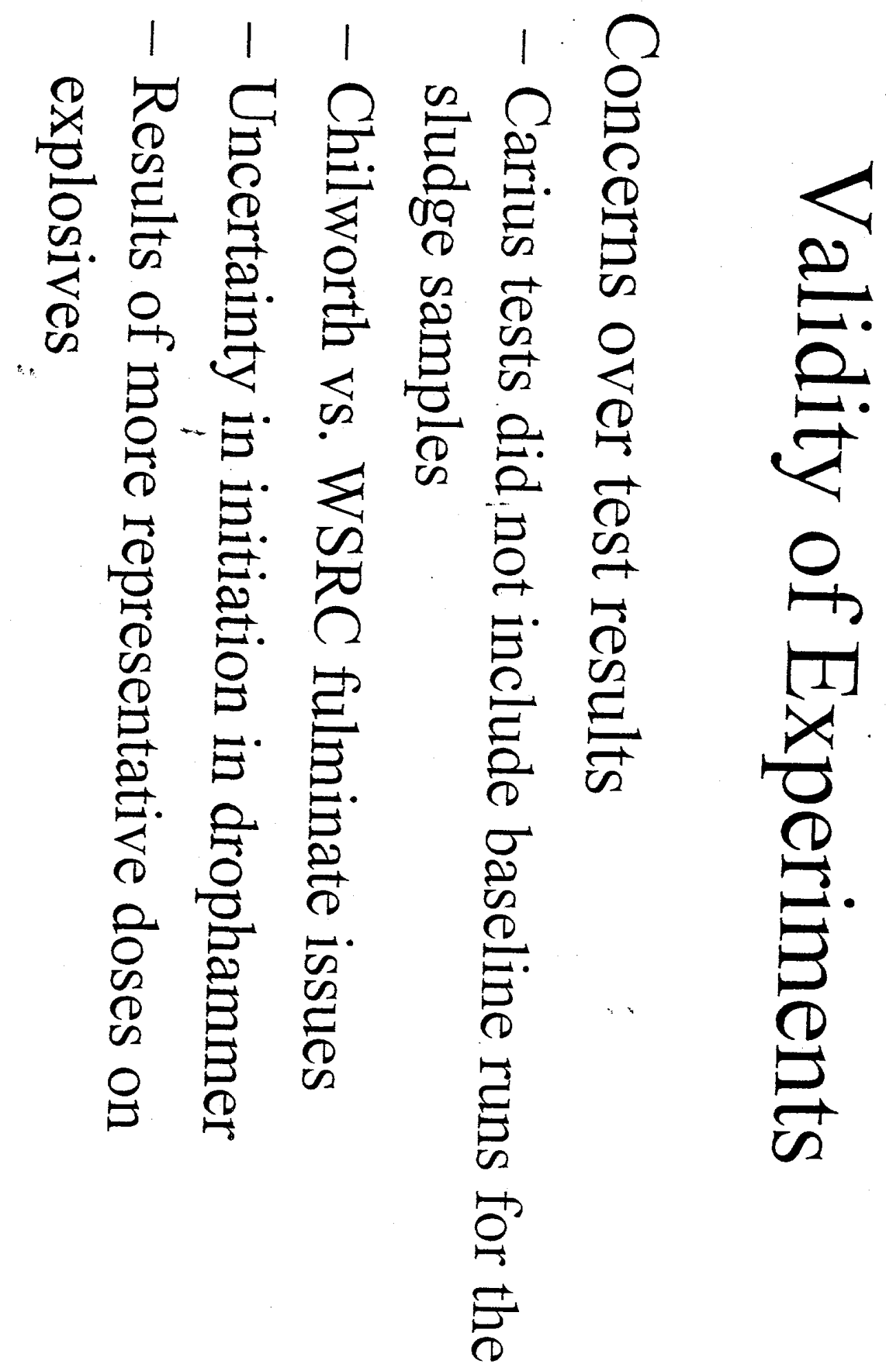




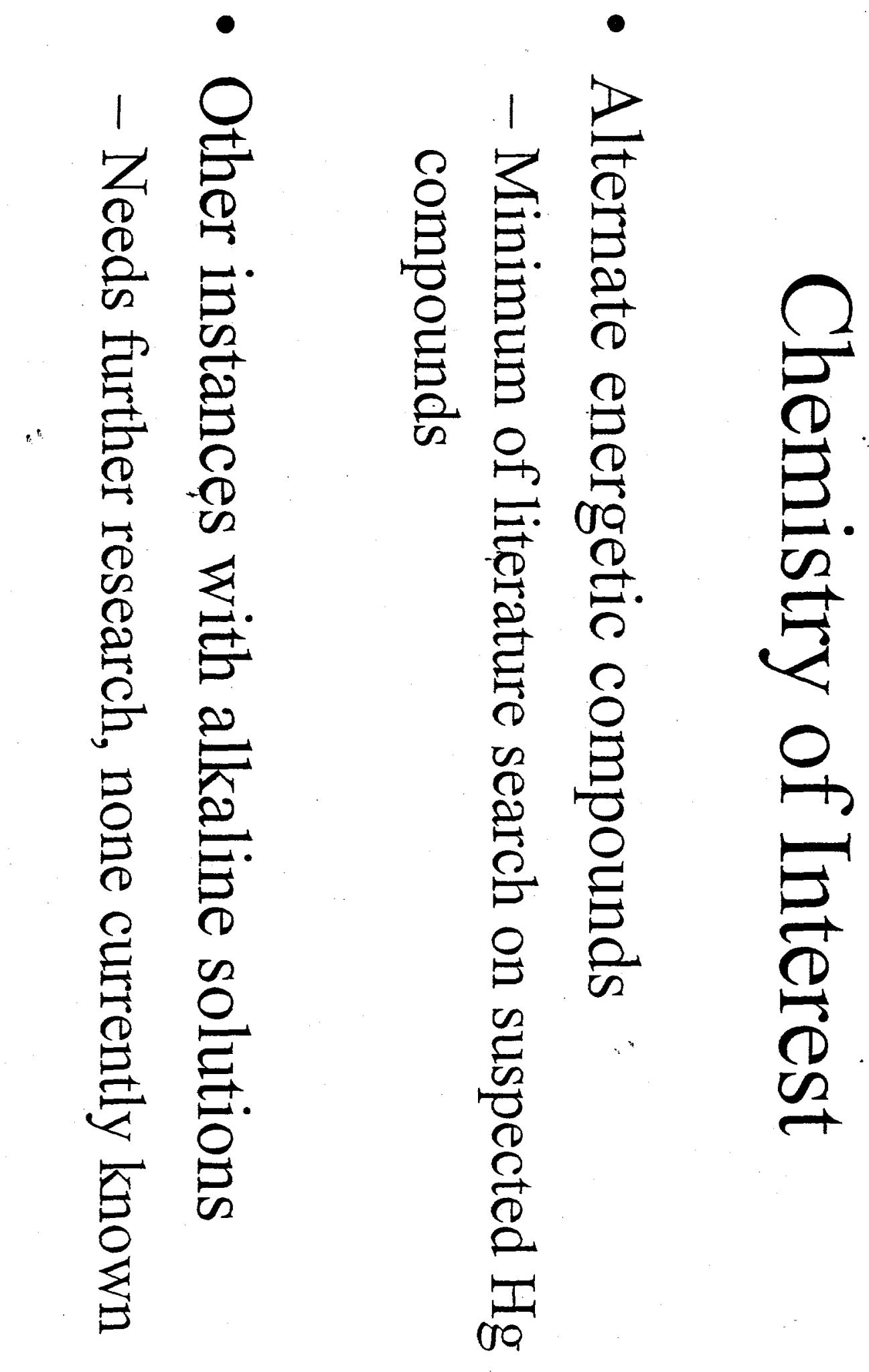




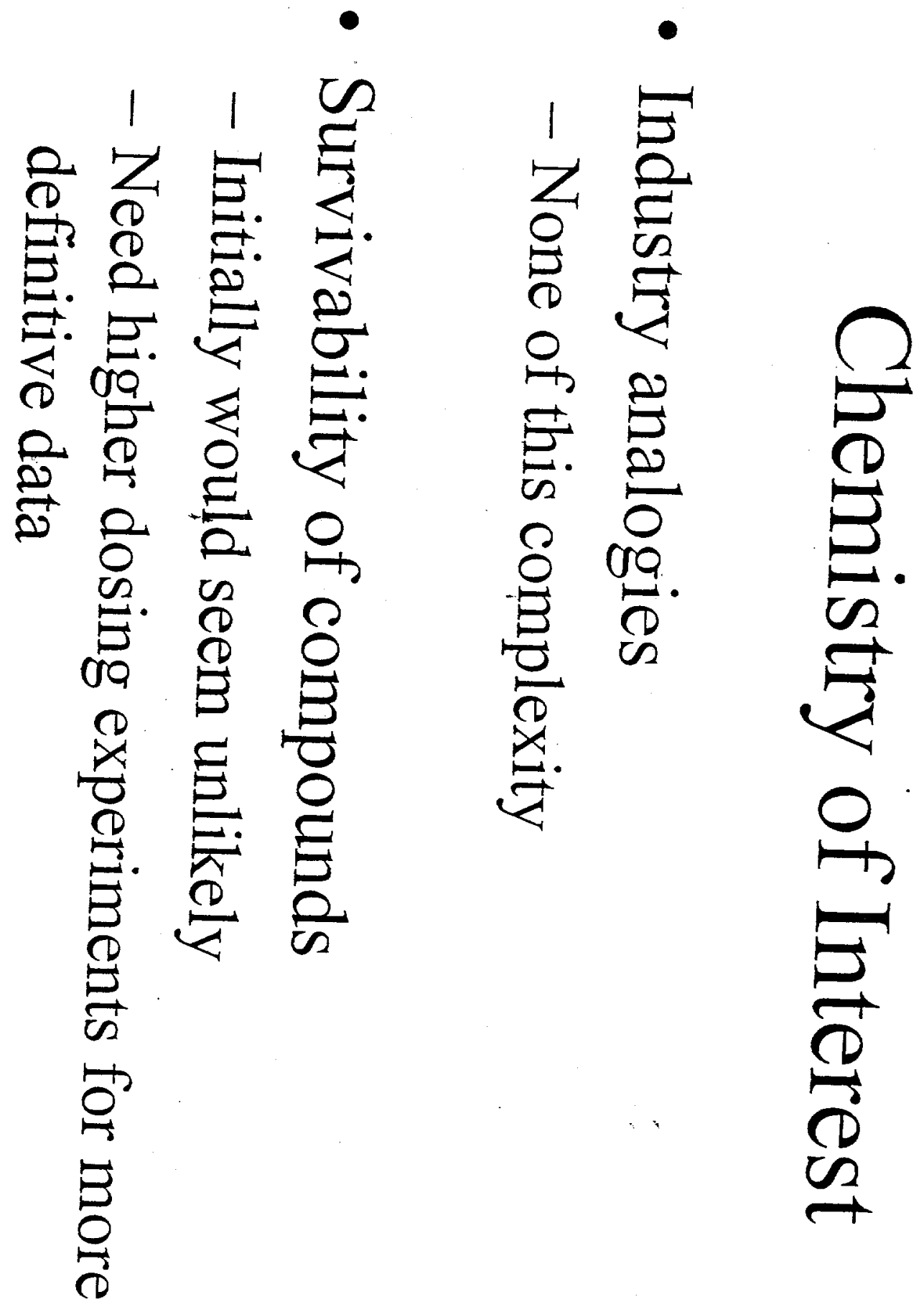




\section{APPENDIX B}

Literatüre Review of Explosives

Based on Mercury

Studied by SRS 


\title{
ENCYCLOPEDIA OF EXPLOSIVES
}

\author{
AND \\ RELATED ITEMS \\ PATR 2700 \\ VOLUME 8
}

BY

SEYMOUR M. KAYE

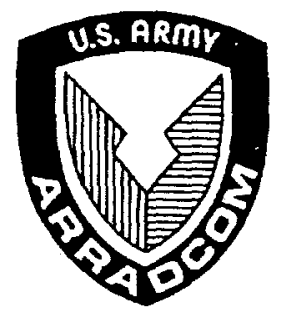

US ARMY ARMAMENT RESEARCH AND DEVELOPMENT COMMAND

LARGE CALIBER

WEAPON SYSTEMS LABORATORY

DOVER, NEW JERSEY 
(Oct 1963), 45-6 7) Merck (1968), 194-L 8) CondChemDict (1971), 158-L 9) Sax (1975), 512-L \& 988-L

Lead Oxalate. $\mathrm{PbC}_{2} \mathrm{O}_{4}, \mathrm{mw} 295.23$; wh, heavy powd; mp, decomps $300^{\circ}$; d $5.28 \mathrm{~g} / \mathrm{cc}$. Insol in $w$, sl sol in acet ac, sol in dil nitric ac \& fixed alkali hydroxides. Poisonous!

Warren (Ref 1 ) evaluated $\mathrm{Pb}$ oxalate as a possible replacement for MF in primer compns, and concluded that it lacked the sensitivity necessary for an initiating agent. Sensitivity data obtained are given below:

Drop Test. (BurMines app; $2 \mathrm{~kg} \mathrm{wt}$ ) $100+$ inches Expln Temp Test, $5 \mathrm{sec}$. > $500^{\circ}$ Sand Test (200g bomb)

Initiation by fuse, $g$ sand crushed 0

Initiation by $0.3 \mathrm{~g} \mathrm{MF}, \mathrm{g}$ sand crushed 0

There is no US Mil Spec for $\mathrm{Pb}$ oxalate Refs: 1) K.S. Warren, 'Properties of Possible Constituents of Primer Compositions. Metallic Salts of Chlorous and Oxalic Acids", PATR 1389 (1944) 2) Merck (1968), 613-R

Mercurous Oxalate. $\mathrm{Hg}_{2} \mathrm{C}_{2} \mathrm{O}_{4}$, mw 489.22, wh cryst powd. Prepd by Souchay \& Lenfsen (Ref 2) by treating sol mercurous salts, such as the nitrate, with oxalic acid. Insol in cold $w$, alc \& eth; decompd by hot w; insol in dil sulfuric acid; sol in dil hydrochloric and nitric acids

Explds on impact $(\operatorname{Ref} 2)$; does not expld or deflagrate on heating or rubbing in a procelain mortar (Ref 3)

There is no US Mil Spec for Mercurous oxalate Refs: 1) Beil 2, $516 \&$ [489] 2) A. Souchay \& E. Lenfsen, Ann 103, 308 (1857) 3) A. Langhans, SS 15, 89-90 (1920)

Mercuric Oxalate. $\mathrm{HgC}_{2} \mathrm{O}_{4}$, mw 288.61, wh cryst powd; mp, decomps. Prepd by Souchay \& Lenfsen (Ref 2) by adding an aq soln of mercuric nitrate to an aq soln of oxalic acid. Insol in cold $w$, difficulty sol in hot $w$ and dil sulfuric acid; sol in dil hydrochloric and nitric acids

Explds on heating or impact (Ref 2); deflagrates on rubbing in a porcelain mortar (Ref 3)
Warren (Ref 4) evaluated mercuric oxalate as a possible replacement for MF in primer compns, and concluded that it lacked the sensitivity necessary for an initiating agent. Sensitivity data obtained are given below:

Drop Test (BurMines app; 2kg wt)

Expin Temp Test, 5 sec

95 inches $170^{\circ}$

Sand Test (200g bomb)

- Initiation by fuse, $\mathrm{g}$ sand crushed 0 Initiation by $0.3 \mathrm{~g} \mathrm{MF}, \mathrm{g}$ sand crushed 6.5

There is no US Mil Spec for Mercuric oxalate Refs: 1) Beil 2, 516 \& [489] 2) A. Souchay \& E. Lenfsen, Ann 102, 42-44 (1857) 3) A. Langhans, SS 15, 89-90 (1920) 4) K.S. Warren, "Properties of Possible Constituents of Primer Compositions. Metallic Salts of Chlorous and Oxalic Acids", PATR 1389 (1944) Note: $\mathrm{R}$. Philip reported that $\mathrm{Hg}$ oxalates are always present as impurities in commercial MF, and that the determination of $\mathrm{Hg}$ is not sufficient to give the true fulminate content $[R$. Philip, SS 7, 110, 156, 180, 198 \& 221 (1912)]

Potassium Oxalate. $\mathrm{K}_{2} \mathrm{C}_{2} \mathrm{O}_{4} \cdot \mathrm{H}_{2} \mathrm{O}$, mw 184.23; colorl, odorless crysts; mp, loses $\mathrm{H}_{2} \mathrm{O}$ at about $160^{\circ}$, when ignited is converted into carbonate without appreciable charring; $d 2.13 \mathrm{~g} / \mathrm{cc}$, sol in $3 p$ of $w$. Can be prepd by heating a mixt of $K$ formate or carbonate with oxalic acid and a small amt of $K$ hydroxide, with subsequent extraction of w. Highly toxic by inhalation and ingestion

$\mathrm{K}$ oxalate was used as a cooling agent in mining expls such as Oxalate Blasting Powder (see in this Vol) and Gelatine-Prosperit (see in Vol 6, G52)

There is no US Mil Spec for $\mathrm{K}$ oxalate Refs: 1) Beil 2, 513, (224) \& [485]

2) Daniel (1902), 592 3) Naoúm, NG (1928), 418 4) Merck (1968), 856-L 5) CondChemDict (1971), 723-R

Silver Oxalate. $\mathrm{Ag}_{2} \mathrm{C}_{2} \mathrm{O}_{4}, \mathrm{mw} 303.78$, wh cryst powd; $\mathrm{mp}$, decomps violently between $130^{\circ} \& 190^{\circ}$ (see below); d $5.03 \mathrm{~g} / \mathrm{cc}$. Sol in $24000 \mathrm{p}$ of $\mathrm{w}$, moderately concd nitric acid, and ammonia. Can be prepd by mixing cold solns of oxalic acid and $\mathrm{Ag}$ nitrate (Refs 1,2 \& 6) 


\section{ENCYCLOPEDIA OF EXPLOSIVES AND}

RELATED ITEMS

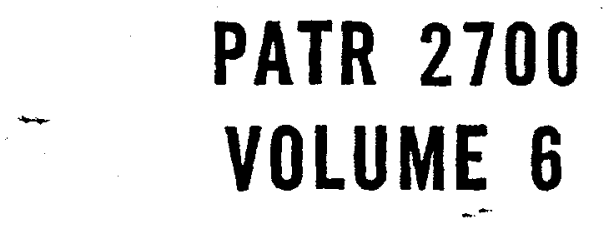

BY

BASIL T. FEDOROFF

8

OLIVER E. SHEFFIELD

\section{ASSISTED BY}

THE FRANKLIN INSTITUTE RESEARCH LABORATORIES

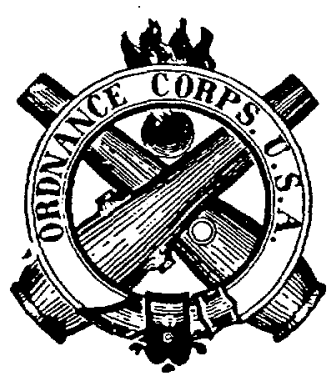

PICATINNY ARSENAL

DOVER, NEW JERSEY, USA 
of Amm iodide on SF. It is a less violent expl than SF \{ Ref $1, \mathrm{p}[777]\}$

Codmium Fulminate, $\mathrm{Cd}(\mathrm{ONC})_{2} ; \mathrm{mw} 196.45, \mathrm{~N}$ 14.26\%; wh crysts, wp - expl at $215^{\circ}$ in 5 sec; sol in w \& methanol; sl sol in ethanol. Can be prepd by shaking $\mathrm{Cd}$ amalgam with MF dissolved in methanol. Heat of deton $470 \mathrm{cal} / \mathrm{g}$. It is a powerful expl resembling MF in its props. It is stable when kept dry but decomp in the presence of moisture. Smallest amts which cause detonation of: Tetryl $0.008 \mathrm{~g}, \mathrm{PA}$ $0.05 \mathrm{~g}$, TNT $0.11 \mathrm{~g}$, TNAnisol $0.26 \mathrm{~g} \&$ TNXylene $0.35-\left[\operatorname{Ref} 1_{;}\right.$P (376) \& Ref 23, PP $\left.407 \& 411\right]$

Copper (l) Fulminate or Cuprous Fulminate. See Vol 3 of Encycl, p C $520-R$ and Davis (Ref 23, p 407) gives smallest amts of Copper Fulminate which cause detonation of: Tetryl $0.025 \mathrm{~g}$, PA $0.08 \mathrm{~g}$, TNT $0.15 \mathrm{~g}$, TNAnisole $0.32 \&$ TNXylene $0.43 \mathrm{~g}$

Copper (1) Fulminate Explosive Complexes, listed below a re described in Vol 3 on PP C520-R \& C521-L:

Copper(l)-barium Fulminate, $\mathrm{Ba}\left[\mathrm{Cu}(\mathrm{ONC})_{8}\right], 4 \mathrm{H}_{2} \mathrm{O}$ Copper(I)-calcium Fulminate, $\mathrm{Ca}\left[\mathrm{Cu}(\mathrm{ONC})_{3}\right], 4 \mathrm{H}_{2} \mathrm{O}$ Copper (II)-dicopper (I) Fulminate, $\mathrm{Cu}\left[\mathrm{Cu}_{2}(\mathrm{ONC})_{4}\right]$; $2 \mathrm{H}_{2} \mathrm{O}$

Copper (I)-disodium Fulminate, $\mathrm{Na}_{2}\left[\mathrm{Cu}(\mathrm{ONO})_{3}\right]$, $3 \mathrm{H}_{2} \mathrm{O}$

Copper(I)-sodium Fulminate, $\mathrm{Na}\left[\mathrm{Cu}(\mathrm{ONC})_{2}\right]$ Copper(I)-strontium Fulminate, $\mathrm{Sr}\left[\mathrm{Cu}(\mathrm{ONC})_{4}\right]$, $2 \mathrm{H}_{2} \mathrm{O}$

\footnotetext{
Mercuric Fulminate or Mercury Fulminate [Fulminate de mercure in $F_{r}$, Knallquecksilber in Ger; Fulminato di mercurio in Ital; Fulminato de mercurio in Span; Gremuchaya rtut' in Russ; and Raikö or Raisan suigin (Thunder Mercury) in Japan $\mathrm{H}_{2} \mathrm{Hg}(\mathrm{ONC})_{2}$. Structural formula not established. Pepin Lehalleur (Addnl Ref J, P 141) proposed $\mathrm{Hg}\left(\mathrm{ON}: \mathrm{C}_{2}\right.$ and that of Scholl $\mathrm{H}_{\mathrm{B}}=\mathrm{ON}: \mathrm{C}: \mathrm{C}_{\text {. }}$ $-17 \%$ \& to $\mathrm{CO}-5.5 \%$; hydrate $\mathrm{Hg}(\mathrm{ON}: \mathrm{C}) .1 / 2 \mathrm{H}_{2} \mathrm{O}$ (crystd from w) (Ref 23, p 410) has $m$ w 293.64, N 9.55\%. Anhydrous form (crystd from alc) is
}

white to grey orysts of density 4.42-4.43, exploding at $210^{\circ}$ in 5 sec; its appareat density is 1.55 to 1.75; when subjected oo pressures of 3,1020 \& 50 thousand psi, densities of 3.0, 3.6, 4.0 \& 4.3 are obtd. Pressures of 25 to 30 thousand psi (or more) cause the desensitization of $M F$ to the extent of becoming dead-pressed. Such material merely ignites and burns when subjected to contact with flame, but it can be detonated if it is covered with a layer of loose or sl compressed MF and ignited

MF is sol in 1 liter of $w$ to the extent of: $0.71 \mathrm{~g}$ at $12^{\circ}, 1.74$ at $49^{\circ}$ and 7.7 at $100^{\circ}$ (Ref 23, p 410); only sl sol in cold ethanol. It decomp in the presence of aq solns, chlorides, carbonates, hydroxides etc. Due to the presence of small amts of $\mathrm{Hg}$, formed by exposure of MF to light or elevated temps, it readily forms amalgams with Co, brass or bronze, thus componeats contg these metals must be protectively coated if used with MF. $\mathrm{MF}$ is also sol in pyridine and aq $\mathrm{NH}_{3}$ or $\mathrm{K}$ cyanide and can be recovered from pyridine by adding $w$ and from $\mathrm{NH}_{3}$ \& cyanide solns by adding acid

MF reacts with concd $\mathrm{HCl}$ to form hydruxylamine, $\mathrm{H}_{2} \mathrm{~N}$.OH, \& formic acid, $\mathrm{HCOOH}$, and it reacts with Na thiosulfate in aq soln to form $\mathrm{Hg}$ tetrathionate, accdg to the equation:

$$
\begin{aligned}
& \mathrm{Hg}_{\mathrm{g}} \mathrm{ON}: \mathrm{C}_{2}+2 \mathrm{Na}_{2} \mathrm{~S}_{2} \mathrm{O}_{3}+\mathrm{H}_{2} \mathrm{O} \rightarrow \\
& \mathrm{HgS}_{4} \mathrm{O}_{6}+2 \mathrm{NaOH}+\mathrm{NaCN}+\mathrm{NaNCO}
\end{aligned}
$$

This reaction can be used for detn of purity of MF Preparation of MF

MF was first prepd in the $17_{\text {th }}$ century by Swedish-German alchemist Baron Johann Kunkel von Löwenstern living from 1630 to 1703 (Hackh's Dict gives 1638 as date of birth). He obed this dangerous expl by treating mercury with nitric acid and alcohol. The method was described in the book of Kunkel published in 1716 after his death. This book is listed and the prepn is briefly described by Davis (Ref 23, p 404) and Pérez Ara (Ref 24, $P$ 541). A brief biography of Kunkel is given in Ref 24, p 541 and in Hackh's (1944), p 474 
As no use of Kunkel's expl was found by him and by other alchemists, the compd became forgotten until Edward Howard of England rediscovered it in 1799-1800. He described its prepn in PhilTransRoySoc 1800, 204, and his method of prepn is given in Davis (Ref 23, $p$ 404). Howard examined props of MF but it does seem that he proposed its use as a percussion initiator of $\mathrm{BkPdr}$. This honor belonged to the Scottish Clergyman Alexander Forsyth who patented in 1807 in England such a device. The history of this and of later development of MF initiators and of various types of cartridges is described in Vol 5 of Encycl, p D755-R \& D756-L. More important applicacion of MF was in A. Nobel's Blasting Cap invented in 1867. This cap was used for detonation of NG and Dynamite (See "Fulminate

Blasting Cap" in Vol 5 of Encycl, P D1588-R)

Besides describing Howard's method, Davis (Ref 23) described on p 406 a laboratory method using $5 \mathrm{~g}$ of $\mathrm{Hg}$. We found that it is safer to start with $2 \mathrm{~g} \mathrm{Hg}$. and to proceed as follows:

\section{Laboratory Preparation:}

1) $2 \mathrm{~g}$ of pure redistd $\mathrm{H}_{\mathrm{g}}$ is a dded to $10 \mathrm{ml}$ of pure nitric acid (sp gr 1.42) in a 100-ml Erlenmeyer placed under a hood and left there without agitation until complete dissolution 2) The resulting soln of $\mathrm{Hg}$ nitrate in excess of acid is poured into $20 \mathrm{ml}$ of $90 \%$ alcohol contd in the $2 \mathrm{nd} 100-\mathrm{ml}$ flask, which is placed in a trough of running water located under a hood and behind a safety glass or plastic. A vigorous reaction results, accompanied first by evoln of white fumes, then by brownish-red and finally again by white fumes. At the same time crysts of MF deposit on the bottom of the flask. After about 20 mins, the fuming ceases and the contents of flask are poured into a $250-\mathrm{ml}$ beaker contg cold $\mathrm{w}$. After the bulk of acid $w$ has beea removed by decantation, the crysts are transferred onto a Büchner connected with suction flask to be washed with w until it becomes neutral to litmus. This gives about $3.4 \mathrm{~g}$ of crude greyish (due to presence of small amt of metallic $\mathrm{Hg}$ ) product, which corresponds to good-grade commercial product. It can be stored under water until a sample is required for exptl purposes. Then part of product is dried in a desiccator

MF has been thoroughly investigated especially before and during WWI by Col Solonina of Russia (Addnl Ref A). Other investigators were Liebig, Chandelon, Bechmann, Tschelzof (Chel'tsoff), Wöhler, Martin, Langhans \& Stettbacher (Ref 17, p 141 )

Pepin Lehalleur (Ref 17, PP 143-44) described Liebig's and Chandelon's methods of maauf which have beea used in France

Pérez Ara (Ref 24, p 545) briefly describes an industrial method using $1 \mathrm{~kg}$ of $\mathrm{Hg}, 9 \mathrm{~kg}$ of nitric acid and $8-12 \mathrm{~kg}$ of alcohol. He also describes on $P 546$ industrial methods of Bechmaan, de Bruyn and of the Troisdorf Fabrik of DAG in Germany. All of these methods differ only slightly from the US method described below. The method of de Bruyn, instead of adding acidic $\mathrm{Hg}$ nitrate to alc, bubbles vapors of alc thru the soln of $\mathrm{Hg}$ in nitric acid. The reaction proceeds at $70^{\circ}$. In the method of the Troisdorf Fabrik, small quantities of $\mathrm{Zn} \&$ $\mathrm{Cu}$ are added during dissola of $\mathrm{Hg}$ in aitric acid $(2 \mathrm{~g}$ of $\mathrm{Zn} \& 3 \mathrm{~g}$ of $\mathrm{Cu}$ per $600 \mathrm{~g} \mathrm{Hg}$ and $5 \mathrm{~kg}$ nitric acid). This method is claimed to give white MF

In all methods, except that of Troisdorf, the resulting MF is of greyish color due to the presence of small quantity of free $\mathrm{Hg}$. Such MF is not suitable for loading in to caps made of $\mathrm{Cu}$ or $\mathrm{Cu}$-contg alloys such as brass or bronze. This is because free $\mathrm{Hg}$ atcacks Cu forming a $\mathrm{Cu}$ amalgam, and this will react with MF to form Cuprous Fulminate which is less stable and more sensitive than MF

In order to avoid the formation during manuf of greyish MF, Solonina proposed a dding $1.5 \mathrm{~g}$ of $\mathrm{CuCl}_{2}$ per each $5 \mathrm{O}_{\mathrm{g}}$ of $\mathrm{Hg}$ during its dissoln in nitric acid, whereas Adler proposed dissolving in nitric acid a small quantity of $\mathrm{Za}$ before adding $\mathrm{Hg}$ ( $4 \mathrm{~g} \mathrm{Zn}$ per $50 \mathrm{~g} \mathrm{Hg}$ )

Accdg to Davis (Ref 23, p 407), MF can also be prepd by replacing ethanol with acetaldehyde, paraldehyde, metaldehyde or dimethy and ethylacetal. Another method consists of 
treating the $\mathrm{Na}$ salt of nitromethane with an aq soln of $\mathrm{HgCl}_{2}$ at $0^{\circ}$ to form a wh ppt of mercuric nitromethanate. This gradually becomes yel and when digested with warm dil $\mathrm{HCl}$ yields MF

MF can also be manufd by Biazzi Process. Since it is not described in Vol 3 of this Encycl, PP C501ff, under "Continuous Methods for Manufacturing Explosives" it is suggested that info be obtained directly from Dr Mario Biazzi, Ing, Vevey, Swiczerland

\section{Manufacture of MF in the USA}

The following method used to be employed at Picatinny Arsenal and probably is still used in othe: US plants because similar method is described in Ref 32 and Ref 35 (1967)

In order to produce MF of quality complying with requirements of US Military Specifi-

cation JAN-M-219, all raw materials: mercury, nitric acid and ethanol should be of high puricy Procedure:

1) About I lb of pure, redistilled mercury was carefully added to an open earthenware vessel (or a 5 liter flask) contg 8 to $10 \mathrm{lbs}$ nicric acid (d 1.4), which was in excess of the amount required by the equation: $3 \mathrm{Hg}_{\mathrm{g}}+8 \mathrm{HNO}_{3} \rightarrow$ $3 \mathrm{Hg}\left(\mathrm{NO}_{3}\right)_{2}+2 \mathrm{NO}+4 \mathrm{H}_{2} \mathrm{O}$

A large number of such charges were usually prepared and allowed to stand overnight until the $\mathrm{Hg}_{\mathrm{g}}$ was completely dissolved 2) A 10 gallon Pyrex flask or balloon, contg 8-10 lbs of $95 \%$ alcohol and fitted with a reflux condenser, was placed on a rack in a trough with running cold water. This installation had to be either outside or in a building provided with an exhaust system

3) With the condenser removed, the acidic soln of mercuric nitrate was poured into the alcohol and then the condenser was replaced. After about 2-3 minutes, a violent reaction started and the liquid boiled $w$ ith evoln of white fumes. Most of these fumes were recovered by the condenser, however. As the reaction approached the end point, the color of the fumes usually changed to brownish-red due to the decomposition of nitric acid by heat. As this heat might also decompose the MF (which had just formed), a small quantity of dilute alcohol had to be added at this poinc to moderate the reaction. The reaction normally lasted about $1 \frac{1}{2}$ hours and MF crystallized

5) After cooling the charge in the flask, it was dumped onto a cloth screen and the crystals of MF washed with cold running water to remove excess nitric acid and impurities known as "fulminate mud"

6) The washed MF was then drained and packed into cloth bags which were stored in tanks of water until required for use

For shipment, the bags were packed in barrels of wet sawdust

7) When required for use, the MF was removed from the bag and spread on a cloth in a thin layer and dried in a special building where the temp was carefully regulated to $43^{\circ}\left(110^{\circ} \mathrm{F}\right)$

8) The acid mother liquor and the water washings were neutralized with alkali, evaporated to recover the alcohol and treated to recover any $\mathrm{Hg}$ or its salts

The usual yield was about 1.25 parts of slightly greyish MF per one part of $\mathrm{Hg}$. Its purity was $98-99 \%$, which corresponded to usual commercial product (Ref 32, p $588 \&$ Ref 35, PP 7-5 \& 7-6)

The intermediate products of oxidation an and nitration involved in the prepn of $M F$ are as follows:

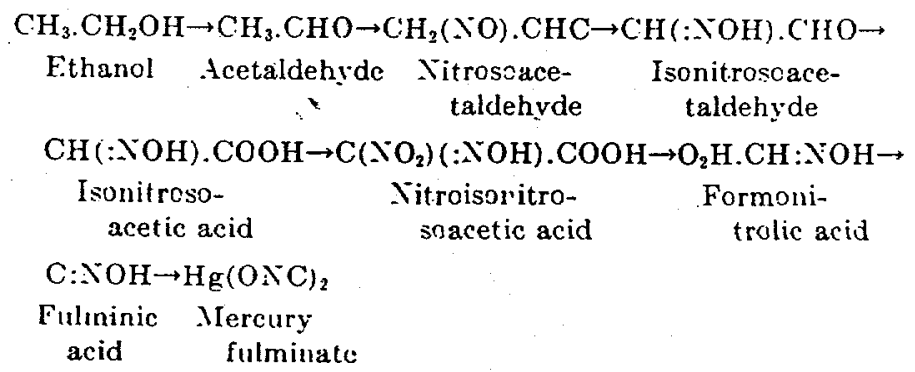

(Ref 35, P 7-6.\& Ref 23, p 407)

Accdg to Ref 35, p 7-6, the above commercial product can be purified to $99.75 \%$ by dissolving it in concd Amm hydroxide, filtering the soln, cooling the filtrate, and reprecipicating slowly, adding concd nitric acid with rapid agitation, while keeping the temp below 
35. The pped pure $M F$ is washed with :distd w until free of acid. The yield is $80-87 \%$

Accdg to Ref 17, p 146, a fairly pure MF can be obtd by rinsing the crude MF (packed on two layers of filter paper placed in a Büchaer) with several portions of $80-85 \%$ ethanol, thoroughly removing by suction each rinsing and testing it. by diluting with $w$. The completion of rinsing is indicated by absence of turbidity on addn of $w$

There are two other methods of purification listed in Ref 17, P 146. Steiner dissolved crude MF in concd aq soln of $\mathrm{KCN}$ followed by adding coned $\mathrm{HCl}$ and washing the resulting Ppt with w. Solonina dissolved 1 part of crude MF in 7 parts of pyridine, filtered the soln and poured it into 100 parts of cold $w$

The size of the crysts of MF is an important factor. While very finely di vided MF (consisting mostly of fragments of crysts) is undesirable because the crysts might contain large amt of impurities, thus diminishing the efficiency of MF, too large crysts are also not desirable because they are very sensitive to friction and shock. Therefore, the US Military Specifications such as JAN-M-219, provide a certain minimum and maximum size for crysts. Fig F24 reproduced from Ref 35, p 7-5, shows

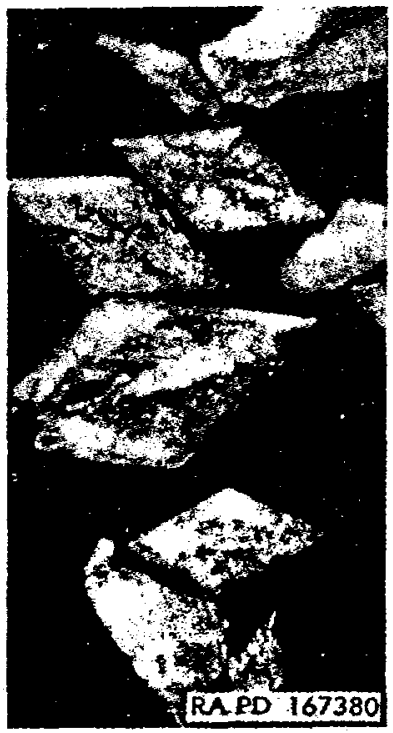

FIG F24 MF Crystals typical crysts magaified 125 times. The Fig 94 on $p 409$ of Ref 23 (not reproduced here) shows crysts for use in primer compos, magnified 35 times

If crysts of MF are so small that they look like colloidal particles, the material is very difficult to initiate evea if it is nearly $100 \%$ pure

Explosive and Other Properties of MF (Refs 5, 7, $9,11,12 \mathrm{a}, 15,16,17,21,22,23,24,25,26,27$, $28,29,30,32,33,34,35,37 \& 38$ ) (Also Addal Refs F, R, S, T \& X):

Activation Energy. 29.81kcal/mol; Induction Period $0.5-10 \mathrm{sec}$ (Ref 34)

Ballistic Mortar Test - not found

Bebavior Towards Flame. When a single cryst is igaited,-it burns rapidly with a flash, but does not detonate; when a layer of crysts is ignited, a high order of deton takes place

Brisance by Sand Test in $200 \mathrm{~g}$ Bomb. 0.4g MF crushes 17.9 to $23.4 \mathrm{~g}$ sand compared with $48 \mathrm{~g}$ for TNT, which means 27.3 to $59 \%$ of TNT. It is greater than LA and smaller than DADNPh

Compatibility with Metals. When dry - reacts rapidly with $\mathrm{Al} \& \mathrm{Mg}$ and slowly with $\mathrm{Cu}, \mathrm{Zn}$, brass \& broaze. When wet - reacts immediately with $\mathrm{Ai} \& \mathrm{Mg}$ and rapidly with $\mathrm{Cu}, \mathrm{Zn}$, brass \& bronze. Dry or wet does not attack iron or steel (Ref 34)

Destruction of $M F$ can be a chieved by adding it, with stirring, to at least 10 times its weight of $20 \%$ $\mathrm{Na}$ thiosulfate. Some poisonous cyanogen gas may be evolved (Ref 34 ).

Deterioration of MF in Storage at 10-20, 30-35. 50 and $80^{\circ}$. See under Stability of MF in Storage Detonation Rate for Presised $M F, \quad 3500 \mathrm{~m} / \mathrm{sec}$ at d 2.0, 4250 at $3.0 \& 5000$ at 4.0 (Ref 34)

Electric Spark; Sensitivity to. MF is capable of being ignited by a spark from a person charged to less than 5000 volts, a condition that is possible in plant operations. Brown et al (Ref 27) give for Sensitivity to Electrostatic Discharge 0.025 joules (Ref 34) Explosion (or Ignition) Temperature. $210^{\circ}$ (in $5 \mathrm{sec}$ ), $239^{\circ}$ in $1 \sec \& 263^{\circ}$ in $0.1 \mathrm{sec}$ (no cap used) (Ref 34)

Flammability Index - not found 
Friction Pendulum Test. Expl on fiber \& steel shoes (Ref. 34)

Gas Volume Evolved on Explosion - $243 \mathrm{cc} / \mathrm{g}$ (Ref 34)

Heat of Combustion. $938 \mathrm{cal} / \mathrm{g}$

Heat of Explosion. $427 \mathrm{cal} / \mathrm{g}$

Heat of Formation. $226 \mathrm{cal} / \mathrm{g}$

Heat Test at $100^{\circ}$. Explodes in 16 hrs (Ref 34)

Hygroscopicity. Gains $0.02 \%$ at $30^{\circ} \% 90 \% \mathrm{RH}$

(Ref 34)

Impact Sensitivity Tests. Bur Mines ApP - 5cm for $2 \mathrm{~kg}$ wr (20mg sample); Pic Arsn ApP - 4 inches for $1 \mathrm{lb}$ wt (30mg sample) (Ref 34). It is more seasitive than LA of LStyphoate (Ref 35)

Initiating E/ficiency of MF. Although MF is not as efficient an initiator as LA or DAzDNPh, it is satisfactory when used in conjunction with Tetryl, RDX or PETN boosters. During the 1 st half century MF was almost the only initial detonating agent u sed and its efficiency was considered satisfactory (Ref 35) Initiating Efficiency. Grams of MF Required to Give Complete Initiation: 0.25 for TNT,

0.20 for Tetryl, 0.19 for RDX and 0.17 for PETÑ (Ref 34). Also Expl D 0.85, TeNAniline 0.25 and PA 0.21 . Rather different values are given by Davis (Ref 23, p 407): Tetryl 0.29, PA 0.30, TNT 0.36, TNAnisole 0.37 \& TNXylene $0.40 \mathrm{~g}$ Initiating Sensitivity to E ectrostatic Discharge. See under Electric Spark; Sensitivity to International Heat Test $(75 \%$. Loss in $w t$ in 48 hrs $0.18 \%$ (Ref 34 )

Loading Into Blasting Caps pressed at 3000 psi (Ref 23, p 410)

Plate Dent Test - not found

Power (or Strengtb) by Trauzl Lead Block

Test. 37 to $50 \%$ TNT (AddnlRef T); $51 \%$ (Refs 12a \& 34). It is more powerful by Trauzl Test than LA (Ref 35) Rate of Detonation. See Detonation Rate Rifle Bullet Impact Test - not found Sand Tes:. See under Brisance Sensitivity to Electric Spark or to Electrostatic Discharge. See under Electric Spark

Sensitivity to Initiation - not found Sensitivity to Pressure. When pressed at pressures in excess of 25000 psi, MF will become dead-pressed, which means that it will aot detonate either by flame, percussion or stab action. When such MF is ignited by heat or flame (as happens in electric detonators), it will bum but not detonate. How- . ever, it is possible to detonate the deadpressed material by means of a strong Blasting Cap or by covering it with loose (or sl pressed MF) and then igniting the ensemble. In these cases the velocity of deton is even higher than for material that has not been dead-pressed (Ref 35 \& AddalRef $T$ )

Specific Heat. $1.1 \mathrm{cal} / \mathrm{g} /{ }^{\circ} \mathrm{C}$ (Ref 34) Stability. Accdg to Ref 35, p 7-7, the relatively poor stability of MF has been its most disadvantageous characteristic and the main reason for efforts to replace it with a superrior substitute. The usual stability tests are only applicable to temps up to about $85^{\circ}$ due to expln in a relatively short time at temps above $85^{\circ}$. When MF deteriorates, it is chiefly with the production of a non-explosive solid rather than gaseous products of decompa. It has been found that when its purity has been reduced to approx $92 \%$, the initiating efficiency is practically destroyed, although the material will explode when ignited. Then purity has been reduced to $95 \%$, the stability is considerably impaired. (Note: Because of the poor stability of MF, it is no longer permitted by the US Military for service use)

Stability of MF in Storage. MF of purity $99.75 \%$ has been found to require storage at $50^{\circ}$ for 24 months to become deteriorated to $92 \%$ (Ref 35, p 7-7). Different results are given in Ref 34, $p$ 203, where MF of $99.75 \%$ purity deteriorated in 18 mos to $94.81 \%$, while $98.86 \%$ deteriorated at the same period to $79.99 \%$. Still other results are given in Table 7-3 on p 7-7 of Ref 35. Here, after storage at $50^{\circ}$ for 8 months, the purity decreased to $95 \%$ and after 11 mos to $92 \%$. When stored at $80^{\circ}$, purity dropped to $95 \%$ in half a day and to $92 \%$ in one day. When stored at $30-35^{\circ}$ purity dropped to $95 \%$ in 1.7 years and to $92 \%$ in 5.8 years. When stored at $10-20^{\circ}$, a purity of $95 \%$ was 
obed in $7-8$ years, while $92 \%$ was obed after 9-10 years

Stab Sensitivities at Various Densities are given in Table listed on p 202 of Ref 34 Storage. MF is stored under water and transported in a wet condition, because in the dry state it is extremely sensitive to any mechanical action. In winter it is stored in 50/50-water/methanol or water/ethanol. MF should aever be stored together with any other expl(s) because the expln of even a relatively small ant of MF present in a dried state might cause the detonation of wet $M F$ and other expls. If any of the material coatg MF is's spilled on the floor or table, it must be destroyed by washing with a satd soln of Na thiosulfate (Ref 35 ) Thermal Conductivity. $1 \times 10^{-4} \mathrm{cal} / \mathrm{sec} / \mathrm{cm} /{ }^{\circ} \mathrm{C}$

(Ref 34)

Tbermal Stability. See Heat Test at 100', International Test $\left(75^{\circ}\right)$ and Vacuum Stability Test at $100^{\circ}$

Toxicity of MF. Mercury and its compds are of recognized toxicity. The handling of MF is not unduly hazardous from a toxicity viewpoint, but should be done with the minimum contact with the skin. Its dust should not be inhaled and it has been recommended that, in order to avoid undue toxicity, the air in loading plant buildings should contain not more than $0.1 \mathrm{mg}$ of MF per cubic meter (Ref 35)

Trauzl Lead Block Test. See under Power (or Strength)

Vacuum Stability Test at $100^{\circ}$. Explodes (Ref 34)

Velocity of Detonation. See Detonation Rate Volatility - not found

Uses of MF. Until the invention of LA (Lead Azide), MF was practically the only expl used both in primers, blasting caps and detonators, either by itself or in compns. Then loaded alone in b]asting caps [also known as "commercial (or nonmilitary) detonators"] it is subdivided into eight numbers accdg to the amt of MF contd in them: No 1 contains $0.30 \mathrm{~g}$, No 20.40 , No 30.54 , No 40.65 , No 50.80 , No 61.00 , No 71.50 and No 8
$2.00 \mathrm{~g}$. The Table on p 414 of Davis (Ref 23) gives also external dimensions in $\mathrm{mm}$. This classification is intemational. Nos 6,7 and 8 caps are the only ones manufd in the US and the No 6 is the one most commonly used (Ref 23, p 416). The fulminate in commercial and military detonators was first modified by mixing it with BkPdr, then with $K$ nitrate, and later with $K$ chlorate. The chlorate mixts soon atcained commercial importance and by 1910 had largely displaced straight MF. These were "single componeat caps" which are described under "BLASTING CAP" in Vol 2 of Encycl, p B185-R. They are known in Gt Britain as "Plain Detonators", as mentioned in Vol 4, p D737, under "Nonmilitary Detonators". Most commonly used mixts have been $\mathrm{MF} / \mathrm{KClO}_{3}-90 / 10$ and $80 / 10$ and weightit by weight they are more bri sant than straight MF, when determined by Sand Test (See Table on $p 417$ of Ref 23). These mixts are more hygroscopic than straight MF, but are cheaper and slightly safer to handle and to load. Plain detonators have been largely (but not wholly) displaced during and a fter WWII by Compound Detonacors, which are described as "Compound Caps" in Vol 2, p B185ff

There are in the USA two caps stronger than No 8: 1) US Army Special Blasting Cap, formerly known as "Special Army Engineer Cap" (Vol 2, p B188-R) and "Westem Big Inch Cap" (Vol 2, p B186-R). They are "compound caps" but do not contain MF

When MF is mixed with inert materials and/or fuels, such as antimony sulfide $\left(\mathrm{Sb}_{2} \mathrm{~S}_{3}\right)$, it merely rapidly burns (deflagrates) and can be used (especially if some $K$ chlorate is also included) for igaiting propellants, etc (See "Mercuric Fulminate and Its Mixtures and Qualitative \& Quantitative Analyses", described after AddnIRefs for SF)

As already mentioned, MF was largely (and now wholly) displaced since 1930 by LA (Lead Azide) and also by DAzDNPh (Diazodinitrophenol), Cyanuric Triazide and LSt (Lead Styphnate). This took piace first in 
Germany, than elsewhere in Europe and finally in the USh

Specification Requirements and Tests of US Amed Forces are covered by JAN-M219(1945). It is discussed after AddnlRefs for SF (Silver Fulminate) undet "Mercuric Fulminate and Its Mixtures; Qualitative and Quantitative Analyses and Specification Requirements and Tests"

\section{Mercuric Fulminate-Sulfur Compound,} $\mathrm{C}_{2} \mathrm{H}_{4} \mathrm{~N}_{2} \mathrm{O}_{2} \mathrm{~S}$; mw 121.14, N 23.13\%; crysts, mp - deflagrates below $100^{\circ}$; sol in eth.\& alc; insol in water, was prepd by heating MF in abs ether \& hydrogen sulfide Refs: 1) Beil 1,723 2) Steiner, Ber 8, 1177 (1875); 9, 779 (1876)

Mercuric Pyrofulminate or Pyrofulmin. An expl solid of empirical formula $\mathrm{Hg}_{6} \mathrm{O}_{5} \mathrm{C}_{8} \mathrm{~N}_{12}$ with $\mathrm{Hg}$ content $77.77 \%$; prepd by P.Y. Narayana [Current Sci 13, 313-15(1944) \& CA 39, 4227 (1945)] by heating MF for 64 hours or until gases $\mathrm{CO} \& \mathrm{CO}_{2}$ ceased to erolve. The compd was stable to at least $125^{\circ}$. It is identical with Pyrofulmin previously prepd by $A$. Langhans [SS 17, 9-11, 18-21 \& 26-28(1922) \& CA 16, 2603(1922)]

Narayana presumed that 3 mols of MF polymerized in the mannex characteristic of cyanogen compds and then decompd according to equations:

$$
\begin{aligned}
& 3 \mathrm{Hg}(\mathrm{ONC})_{2} \rightarrow \mathrm{Hg}_{3}\left(\mathrm{O}_{2} \mathrm{~N}_{2} \mathrm{C}_{2}\right)_{3} \text { (hypothetical } \\
& \text { and unstable) } \\
& 2 \mathrm{Hg}_{3}\left(\mathrm{O}_{2} \mathrm{~N}_{2} \mathrm{C}_{2}\right)_{3} \rightarrow \mathrm{Hg}_{6} \mathrm{O}_{5} \mathrm{C}_{8} \mathrm{~N}_{12}+3 \mathrm{CO}_{2}+\mathrm{CO}
\end{aligned}
$$

Potassium Fulminate, KONO, $\mathrm{mw} 81.11, \mathrm{~N}$ $17.27 \%$; crysts (from alc); very hy groscopic; sp gr 1.80; mp - expl; expl also by the action of flame. Can be prepd by shaking $K$ amalgam with $M F$ either in methanol or abs ethanol. Expln temp in 5 secs $225^{\circ}$ (See Ref 1, p [777] \& Ref 23, p 411)
Potassium-Silver fulminate, $\mathrm{KAg}(\mathrm{ONC})_{2}$, mw 231.01, N 12.13\%; mp - expl; sol in 8 parts of w. Can be prepd accdg to Daniel (1902), p 319 by adding $\mathrm{KCl}$ to a hot aq soln of SF. When treated with dil nitric acid, a ppt of Acid Potassium Fulminate is formed which is also explosive (See also Ref $1, \mathrm{P}$ 722 \& Ref 23, p 413)

Silver Fulminate (Fulminate d'argent in $\mathrm{Fr}$; Knallsilber in Ger; Fulminato d'argento in Ital; Fulminato de plata in Span and Gremucheye Serebro in Russ), AgONO, mw 149.90, N 9.34\%; wh crysts or amorphous aggregates; darkens on exposure to light; mp - expl at $170^{\circ}$ in $5 \sec ($ Ref 23, p 411); soly in 0.0075 parts in $100 \mathrm{ml}$ at $13^{\circ}$, 0.018 at $30^{\circ}$ and 0.25 at $100^{\circ}$; insol in nitric acid and is decompd by $\mathrm{HCl}$

Preparation of SF

Caution: Due to its extreme sensitivity to mechan ical action, it should be prepd only in very small quantities. When working in the lab, do it under a hood behind a safety glass or plastic, while for the plant production a room with good ventilation is required;

a barricade, and an arrangement for remote control

Accdg to Davis (Ref 23, p 405), E. Howard, after successfully prepg MF in 1799-1800, attempted to prep fulminates of $\mathrm{Au}, \mathrm{P}_{\mathrm{L}} \mathrm{Sb}$, $\mathrm{Sn}, \mathrm{Cu}, \mathrm{Fe}, \mathrm{Pb}, \mathrm{Ni}, \mathrm{Bi}, \mathrm{Co}, \mathrm{As}, \mathrm{Mn} \& \mathrm{Ag}$, but only with $A g$ had any success. In 1802 , L. Brugnatelli worked out a satisfactory method, which consisted in pouring onto 100 grains of powdered Ag nitrate, first an ounce of alcohol and then an ounce of nitric acid. After the ppt was fomed, the slurry was immediately diluted with water (to prevent the dissoln of SF) and immediately filtered

Because SF is extremely sensitive to

friction and heat it quickly became an object of amateur interest and public wonderment; one of the standard exhibits of street fakirs, etc. J. von Liebig (1803-1873) saw, when he was a boy, a demonstration of SF in the market place at Darmstadt and leamed how 
exploded on a surface of a silver spoon, a blow like a musket was heard and this punched a hole thru the spoon

FG is not suitable for practical use on acct of its extreme sensitiveness to shock, friction or heat, and also to its high cost (Ref 5, p 568 (Compare this compd with Auric Imidoamide or Gold Amidoimide, described in Encycl under AMIDES, IMIDES AND DERIVATIVES on $P$ A169-L of Vol I. It seems that the compd there was erroneously named Fulminating Gold) Refs: 1) Daniel (1902), 313-14 2) A. Lang hans, SS 25, Sonderdruck 70 (1930)(Explosianen, die man nich krwarten) 3) Stettbacher (1933), 330-31 4) Davis (1943), 400-01 5) Pérez $\mathrm{Ara}(1945), 567-68$

Fulminating Mercury or Mercury Nitride. Accd g to Marshall (Ref 1 ), its formula is $\mathrm{HggN}_{2}, \mathrm{mw} 629.85, \mathrm{~N} 4.45 \%$ and it can be prepd by treating mercury oxide with ammonia. It is very sensitive and must not be confused with Mercury Fulminate

Accdg to Davis (Ref 2), Fourcroy, by digesting red oxide of mercury $(\mathrm{HgO})$ in ammonia water for 8 to 10 days, prepd a material which became white and finally assumed the form of crystalline scales. The dried product exploded loudly from fire, but underwent spontaneous decompn when left alone. At slightly elevated temp it gave off ammonia and left a residue of mercury oxide

In the Journal de Physique for 1779 the French apothecary Bayen described a fulminating mercurial compd of a different kind. It was obtd by mixing 30 parts of precipitated $\mathrm{Hg}$ oxide(washed and dried) with 4 or 5 parts of sulfur. This mixt exploded violently when struck with a heavy hammer or on being heated on an iron plate

Accdg to Pérez Ara (Ref 3), there exist two nitrutos de mercurio (Mercury Nitrides) one is mercurous, while another is mercuric

None of the above listed expls found applicatioa in commercial or military primary or detonating compns, but they are interesting from an historical point of view

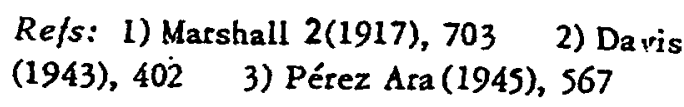

\section{Fulminoting Platinum (FP) (PIatine fulminarit in $F_{t}$ )}

Accdg to Daniel (Ref 1), when a soln of platinic oxide in sulfuric acid was treated with an excess of aq ammoniz; a black ppt of platine fulminant was obtd. When dry it detonated violently by shock, friction and heat (at $160^{\circ}$ ). Some scientists consider it as being identical with the nitride (azoture, in $F_{r}$ )

Accdg to Davis (Ref 4, p 402), FP was first prepd by Davy (Sir Humphry, 1778 to 1829) about 1825 , by adding ammonia water to a soln of $\mathrm{Pt}$ sulfate, boiling the ppt with a soln of potash, washing, and allowing to dry. It was exploded by heât, but not easily by percussion or friction. No formula is given

Accdg to Jacobson (Refs $2 \& 3$ ), the compd of the formula (HO) ${ }_{5} \mathrm{PtNH}_{3} \mathrm{Pt}(\mathrm{OH})_{5}$ was prepd by him by treating dichloroplatinic acid with an excess of ammonia. The soln first umed dark and then a brownish ppt appeared, which could be separated and dried. When heated, it blackened and detonated violently yielding $\mathrm{Pt}$, $\mathrm{N}_{2}, \mathrm{O}_{2}$ and $\mathrm{H}_{2} \mathrm{O}$ vapor. Dichloroplatinic acid was obed in $80-90 \%$ yield by boiling Ag tetrachloroplatinate in water

A compd of similar props, (HO) ${ }_{5} \mathrm{PtC}_{5} \mathrm{H}_{5} \mathrm{NPt}(\mathrm{OH})_{5}$, was obtd by the action of pyridine on dichloroplatinic acid Refs: 1) Daniel (1902), 313 \& 314(Platine fulminant) 2) J. Jacobsen, CR 149, 574-77 (1909) \& CA 4, 1002(1910) 3) Clift \& Fedoroff 2(1943), P FG 4) Davis (1943), 402

Fulminating Powder of Forsyth. Under this name Newman (Ref) lists the mixture of $K$ chlorate, sulfur $\&$ charcoal which could be detonated by percussion. It was invented at the beginning of the 19th century by the Scotch clergyman, A. Forsyth. It was replaced later by the mirture consisting of $K$ chlotate, MF \& powdered glass

Ref: J.R. Newman, "Tools of War", Doubleday-Doran \& Co, NY (1943), p 42 


\section{$\therefore$}
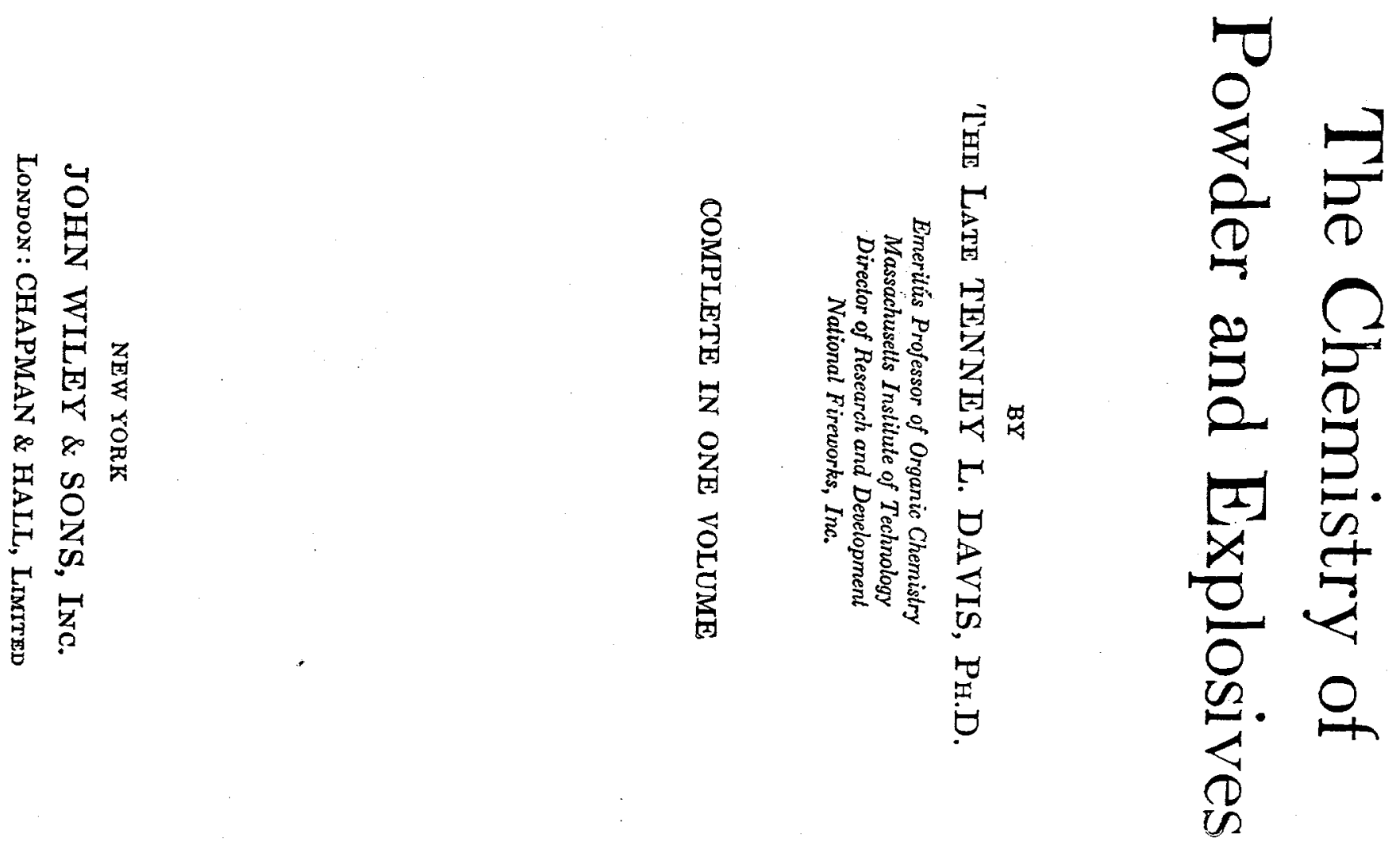


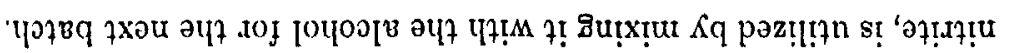

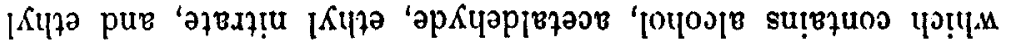

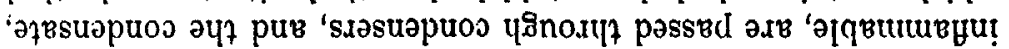

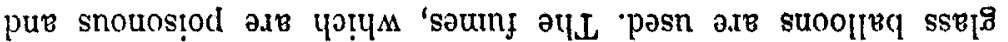

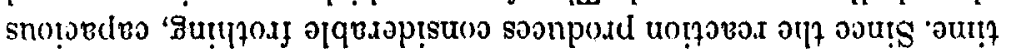

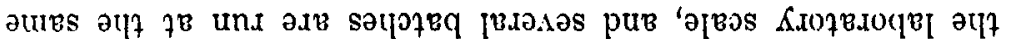
to Kl[ jo sur.ds 009 do paxpuny $ә$ I!.

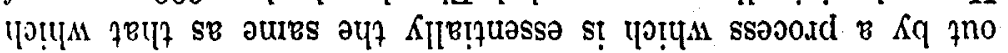

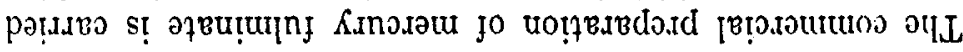

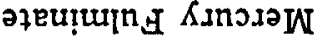

$\cdot \sin x \cdot 4$

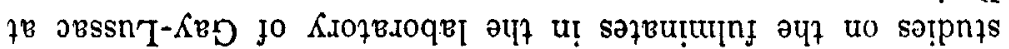

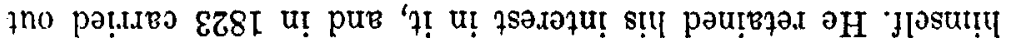

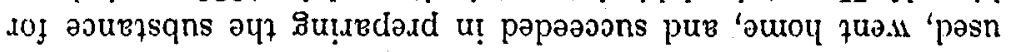

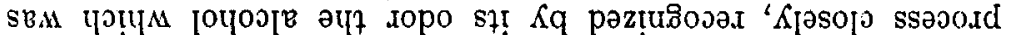

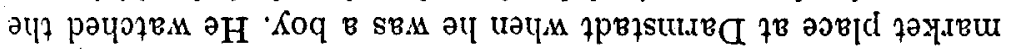

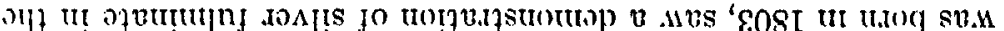

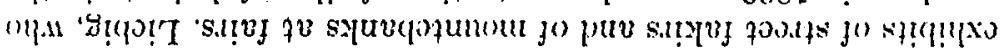

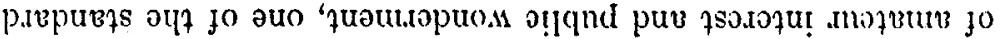

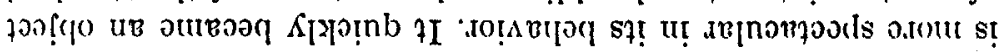

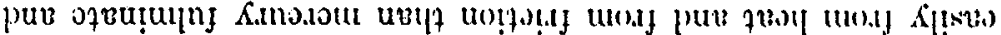

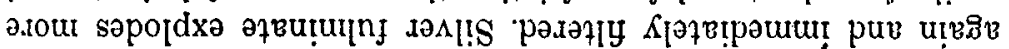

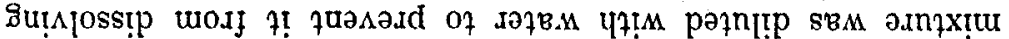

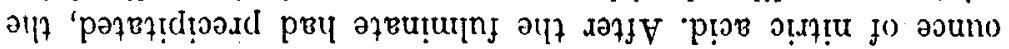

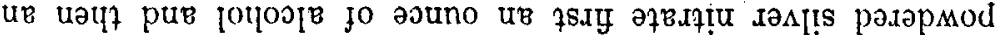

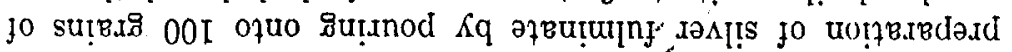

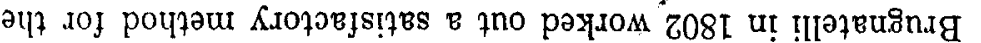

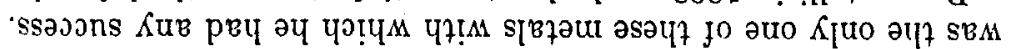

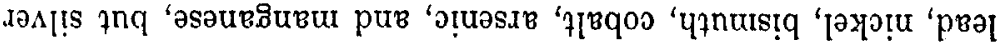

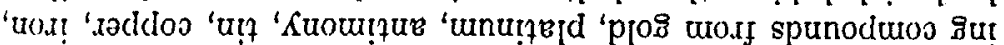

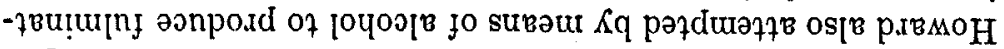

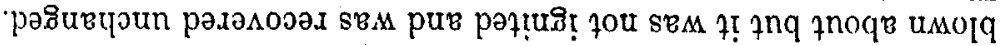

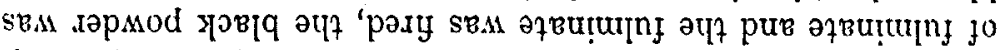

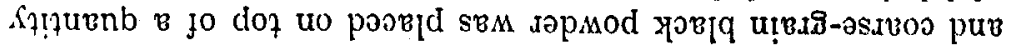

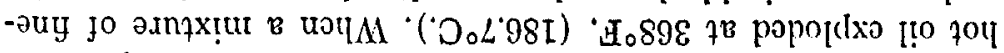

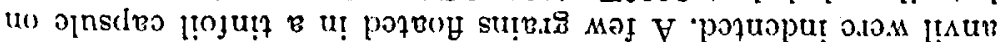

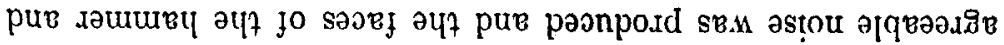

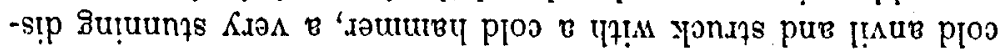

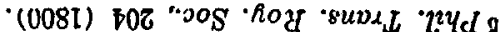

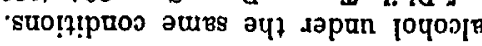

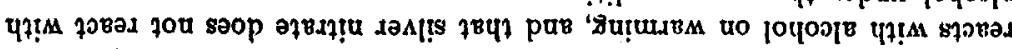

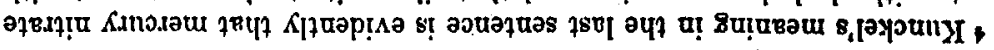

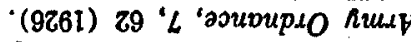

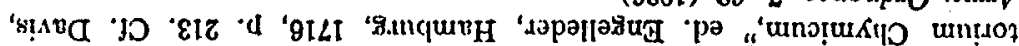
-ชमoqช T .

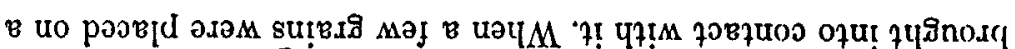

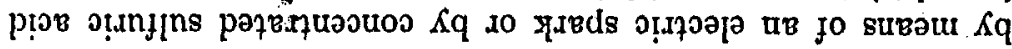

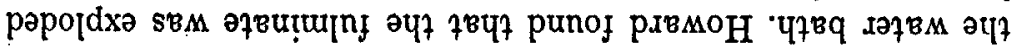

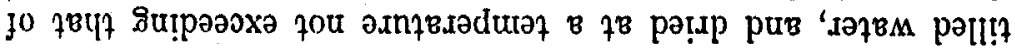

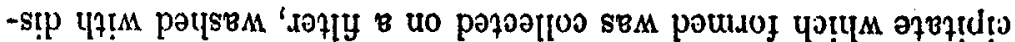

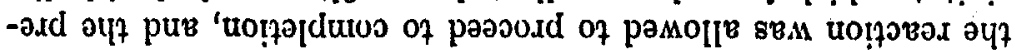

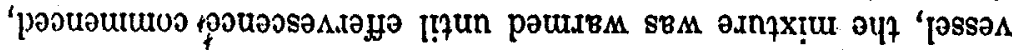

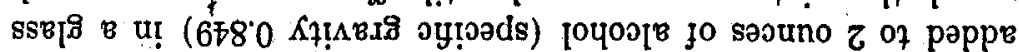
рuв рәтоо sвм uo!fn

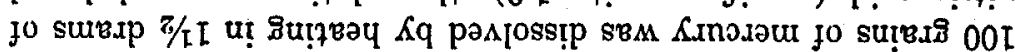

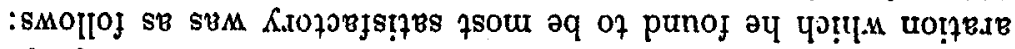

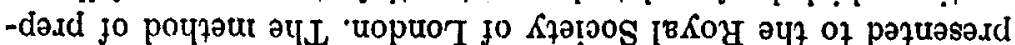

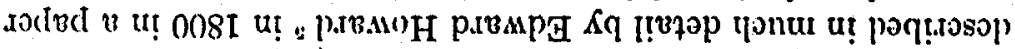

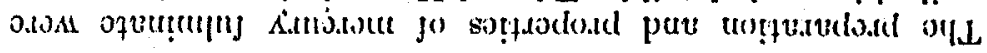

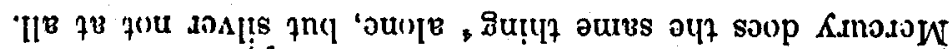

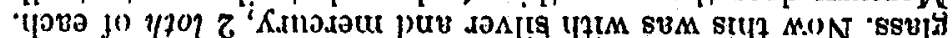

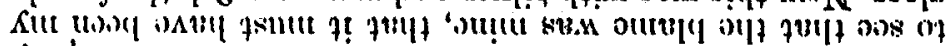

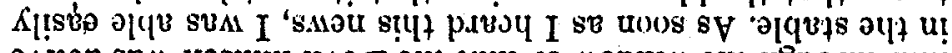

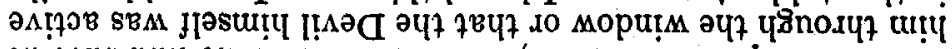

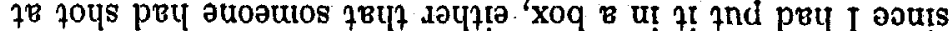

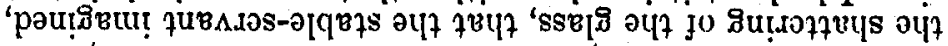

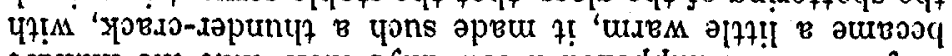

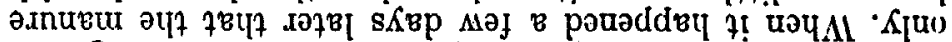

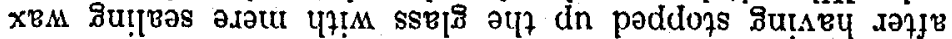

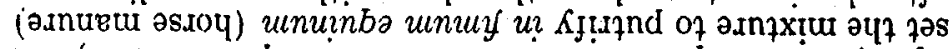

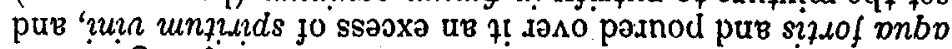

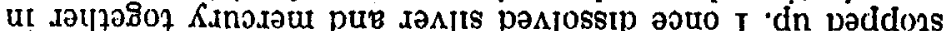

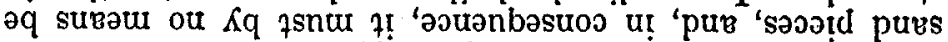

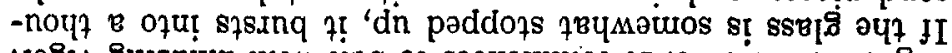

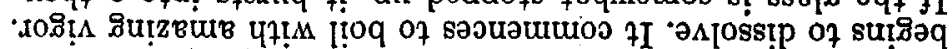

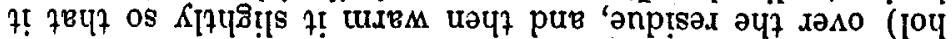

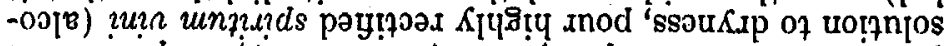

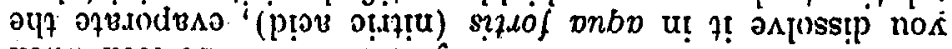

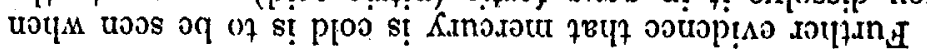

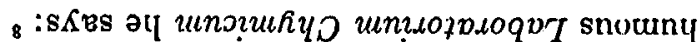

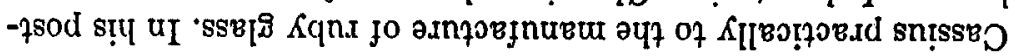

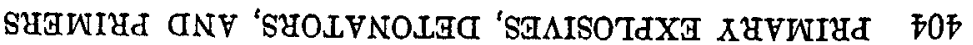




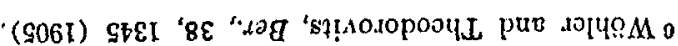

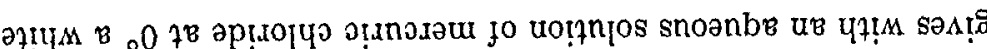

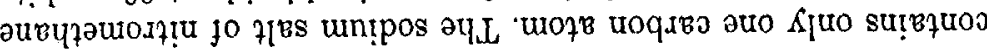

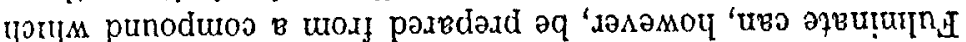

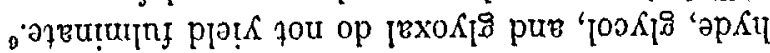

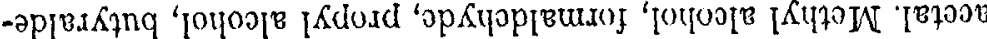

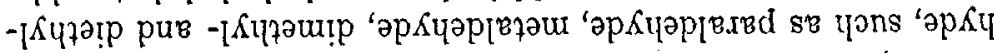

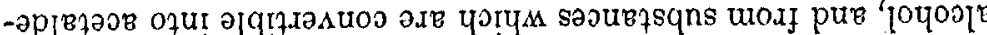

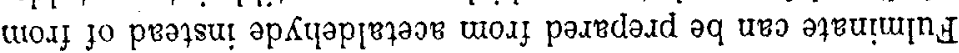

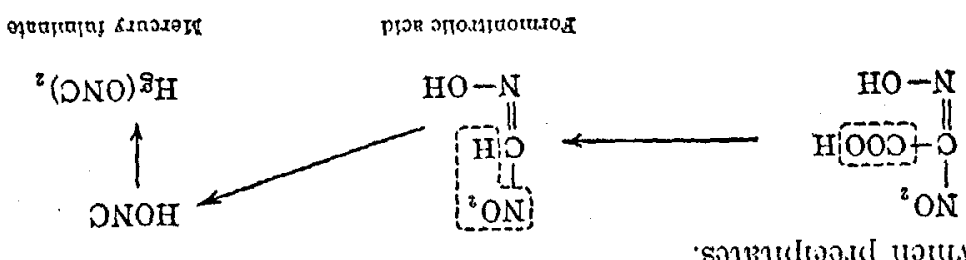

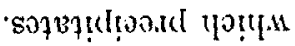

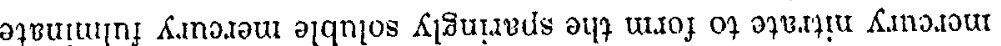

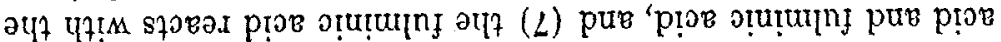

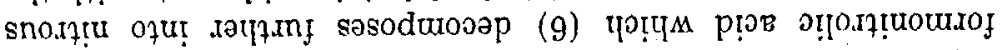

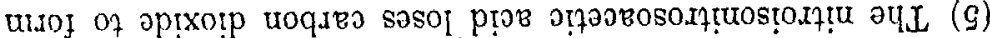

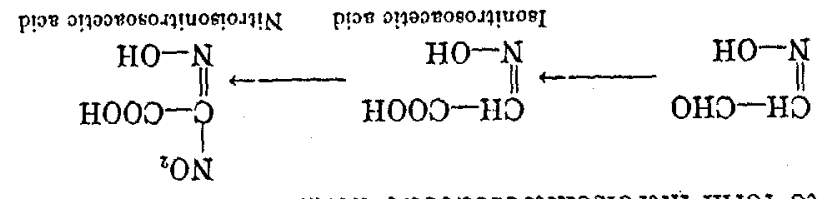

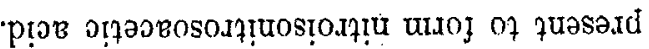

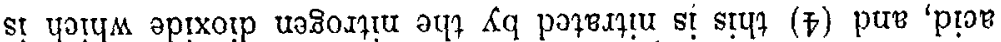

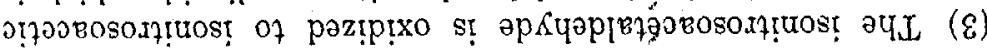

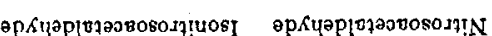

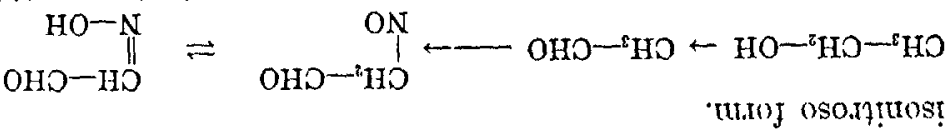

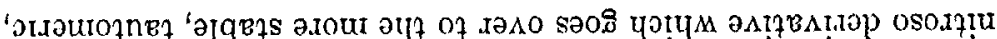

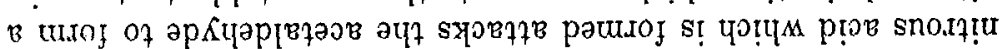

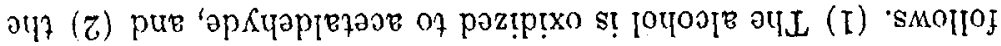

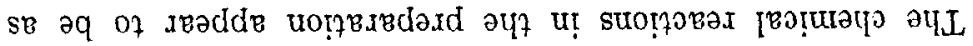

$$
\text { . }
$$

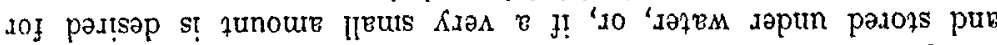

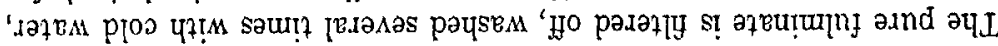

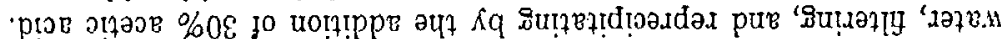

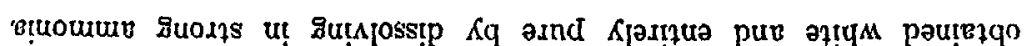

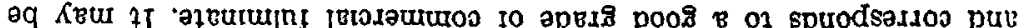
'speis $\delta$ so Molp

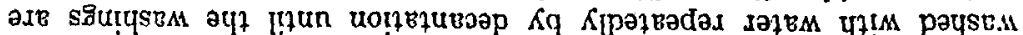

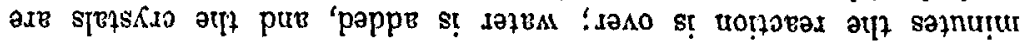

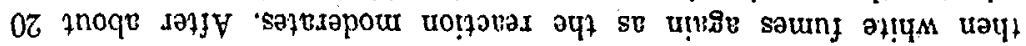

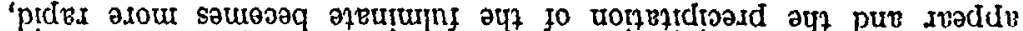

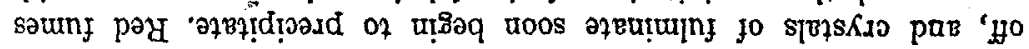

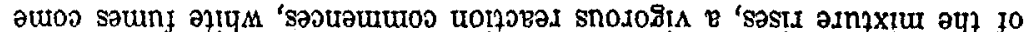

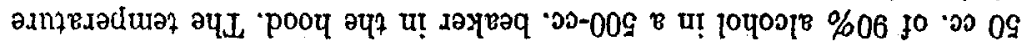

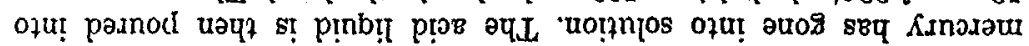

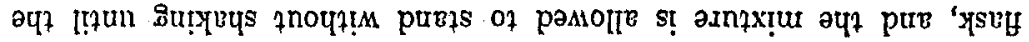

1

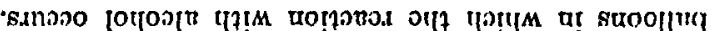

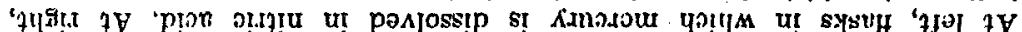

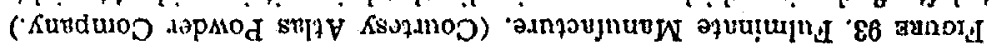

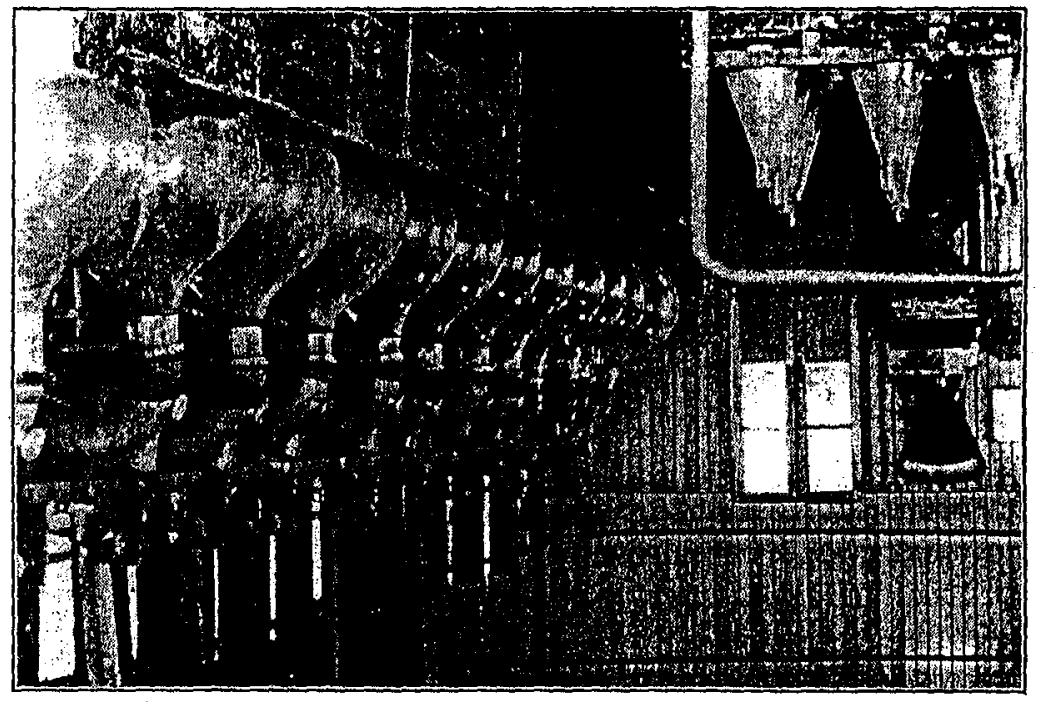

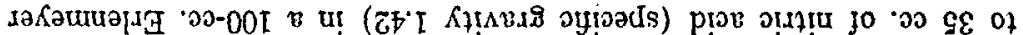
pappe s! Kinoxəu fo suiesi әА!

†вtrozeu

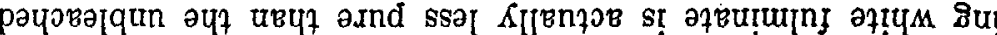

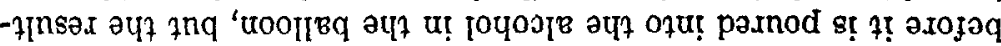

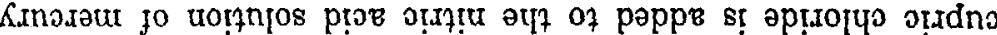
jo qunour

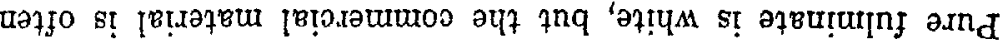

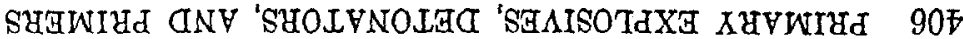




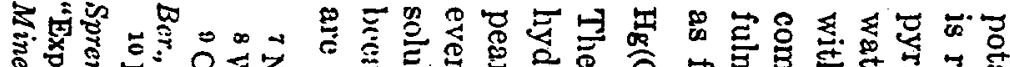

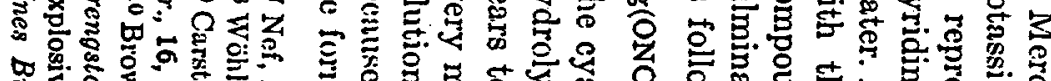

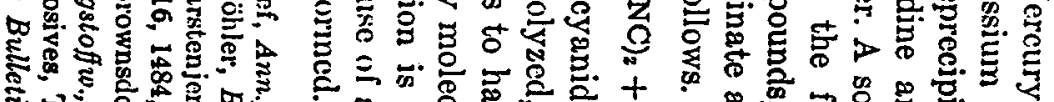

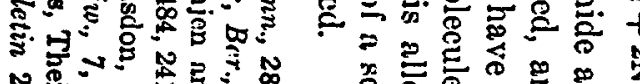

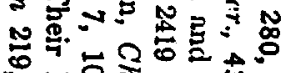

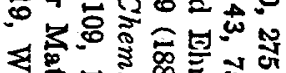

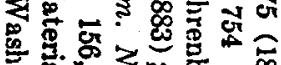

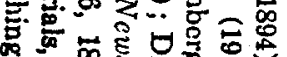

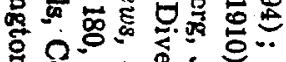
छ

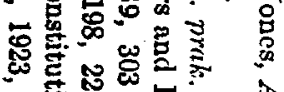

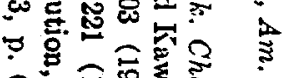

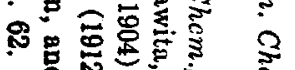

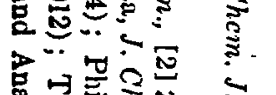

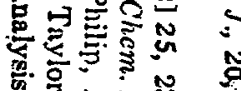
$=N \tilde{D}_{\mathrm{N}}^{0}$

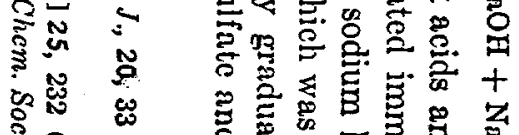

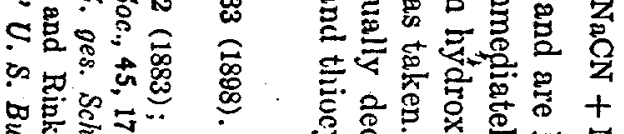

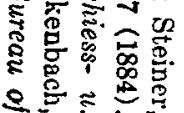

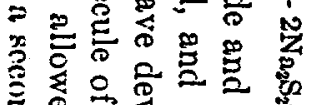
范吉要

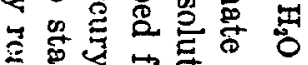

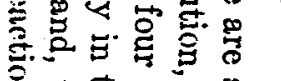

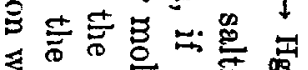

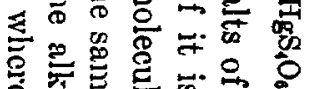

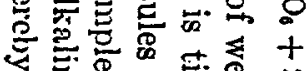

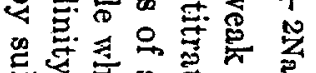

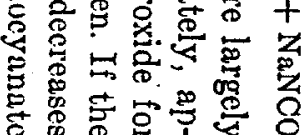

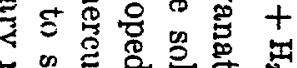

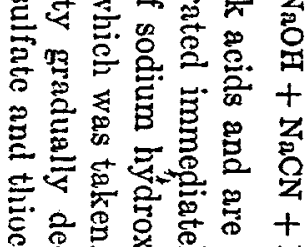

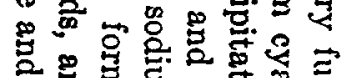

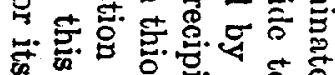

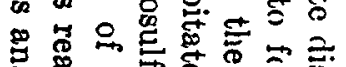

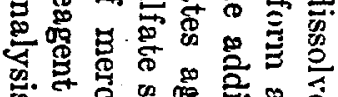

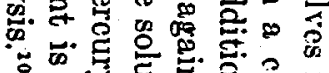

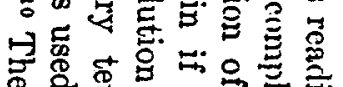

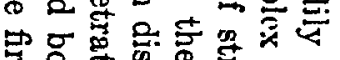

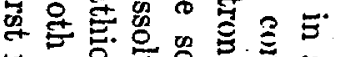

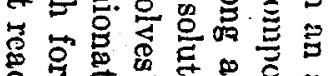

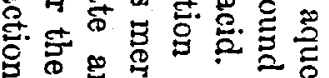

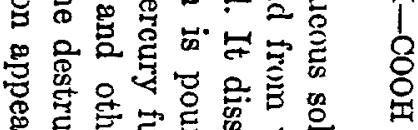

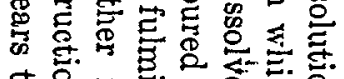
ธ욤

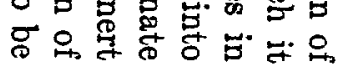

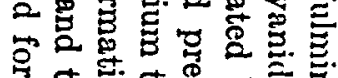

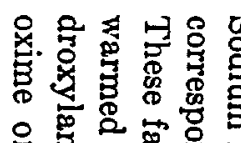

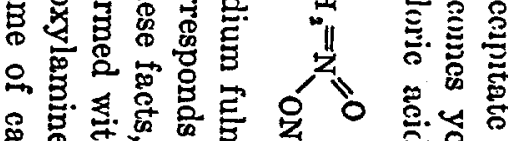

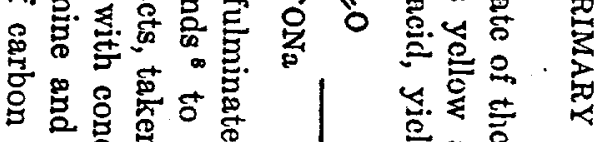

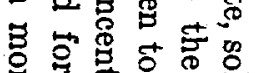

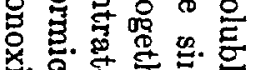

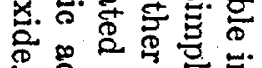
喀. 记芯芯

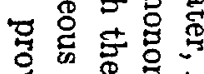

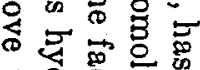

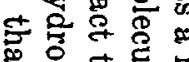

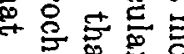

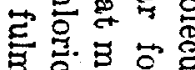

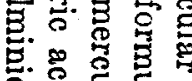

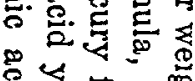

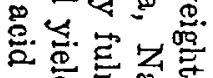

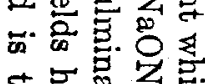

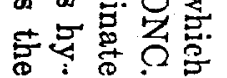

क्ष

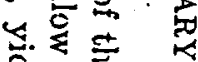
कิ

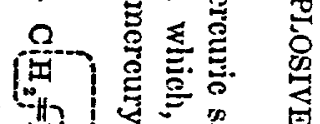
이 og 造

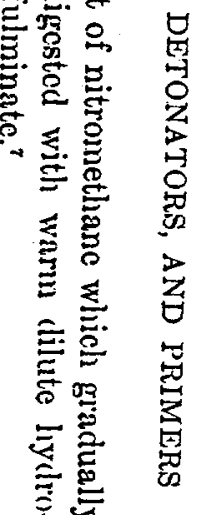
娄 $\vec{\Xi}$

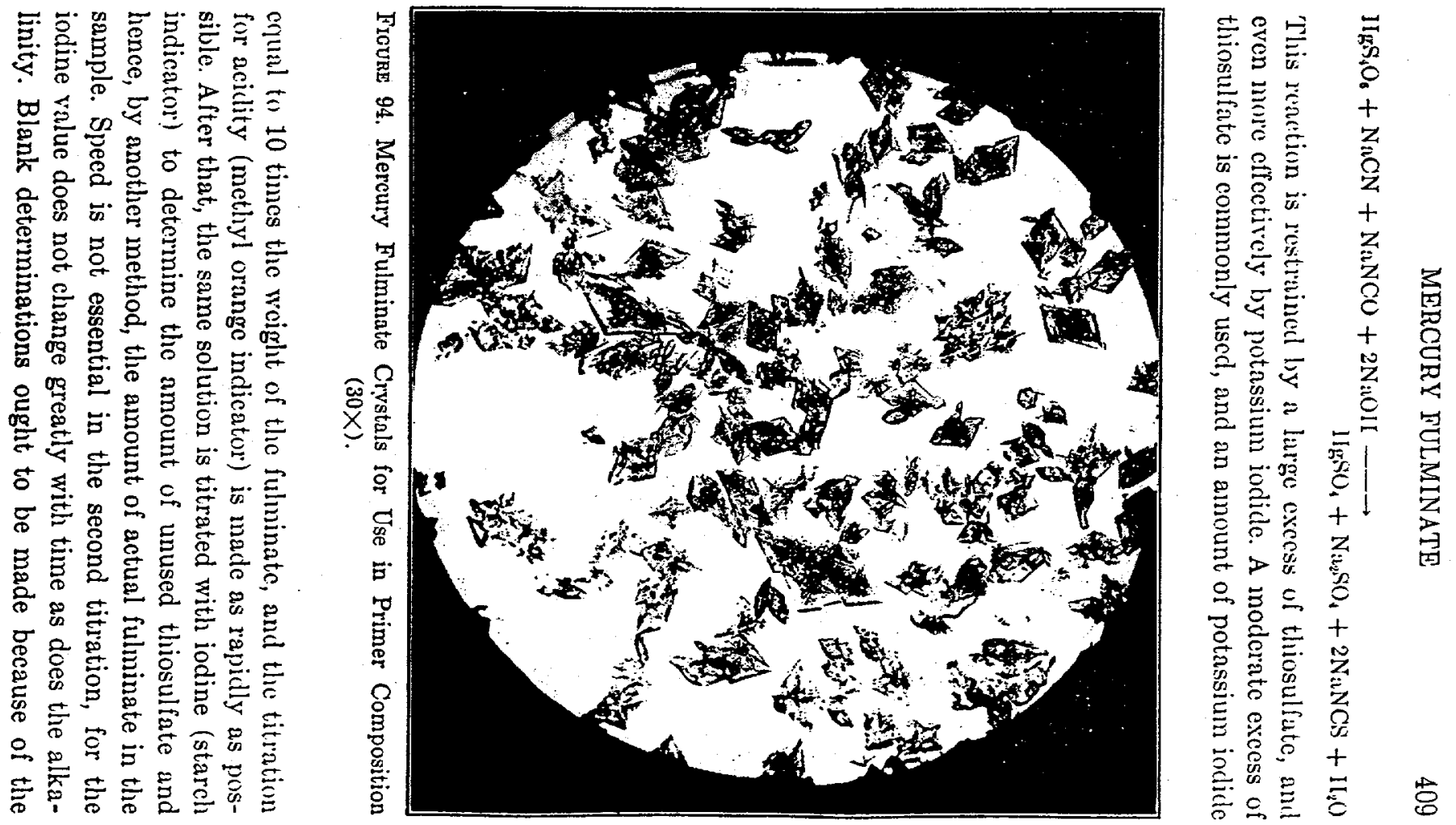




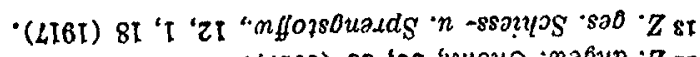

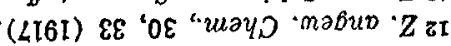

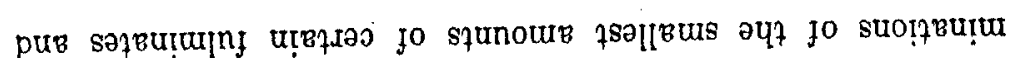

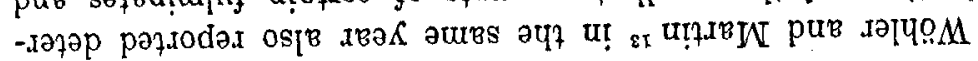

\begin{tabular}{|c|c|}
\hline & \\
\hline & 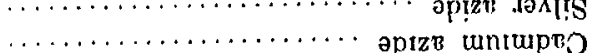 \\
\hline & $\begin{array}{l}\text { ptze un } \\
\cdots \\
\cdots \text { aptr }\end{array}$ \\
\hline & apize snosn \\
\hline & optzes \\
\hline & p!ze əs: \\
\hline & әp!zr \\
\hline & optzos \\
\hline & eptze u \\
\hline & әртzв \\
\hline & әp!zв \\
\hline & $\ldots \ldots \ldots \ldots \ldots \ldots \ldots$ \\
\hline & 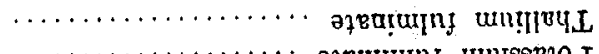 \\
\hline & $\cdots \cdots \cdots$ өq \\
\hline & trumpy \\
\hline & Ilug uminupr: \\
\hline & 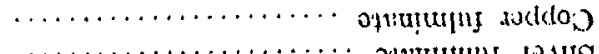 \\
\hline & . \\
\hline & \\
\hline
\end{tabular}

savilug so

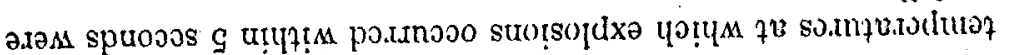

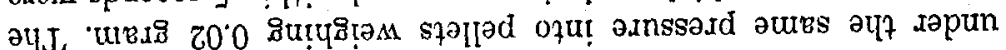

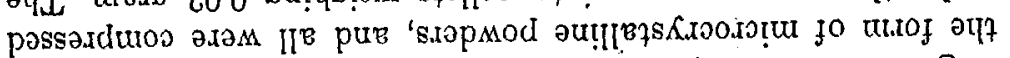

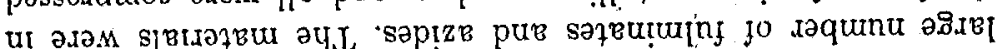

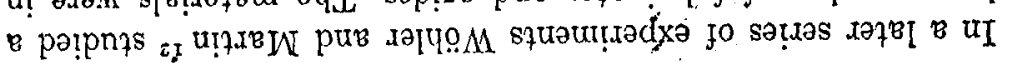

\begin{tabular}{|c|c|}
\hline $.09 \mathrm{I}$ & $\theta$ treqfat \\
\hline .068 & aptze da八I!S \\
\hline & әркчарів \\
\hline 000 & 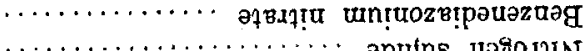 \\
\hline 06 & pylns uosod7!n \\
\hline & \\
\hline & $\operatorname{lng} \alpha$ \\
\hline
\end{tabular}

-smollof se osam postnooo suotsordxa yoty

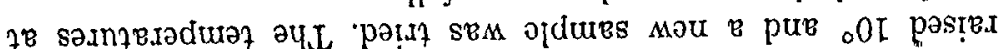

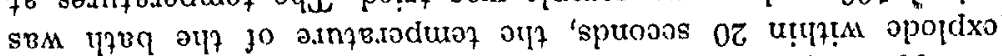

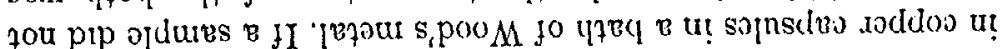

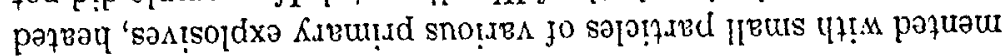

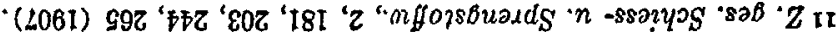

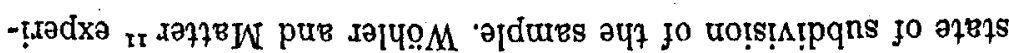

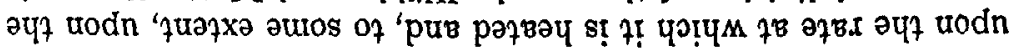

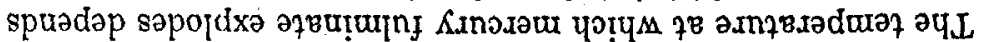

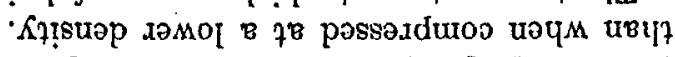

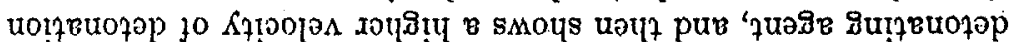

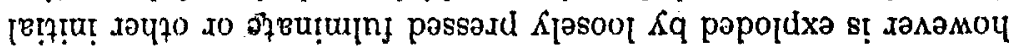

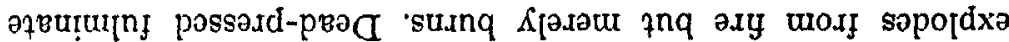

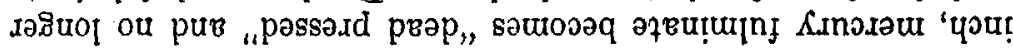

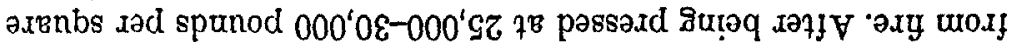

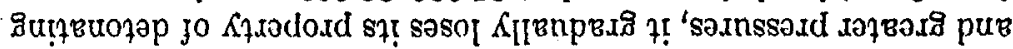

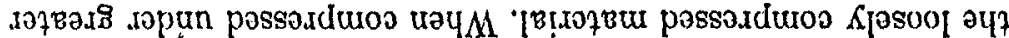

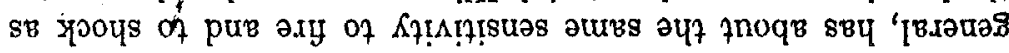
u! 'pue 'xגeds в urody sopoldxa 'puooas dad staqaux 0007 znoqe jo

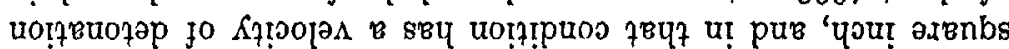

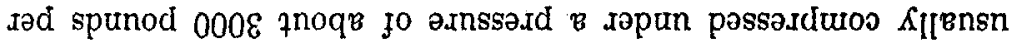

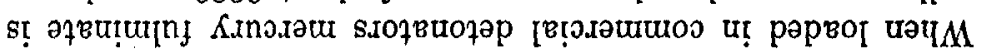

'uo!znjos ә78j[nsotyz unțpos u! әтqnjosu!

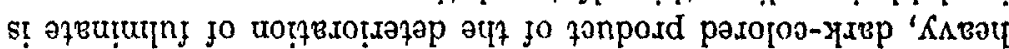

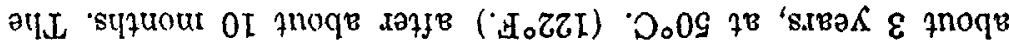

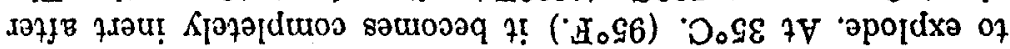

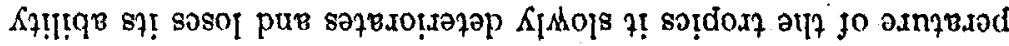

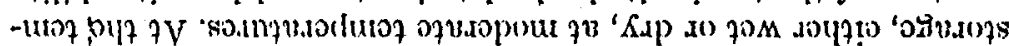

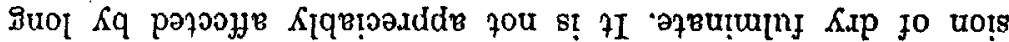
-o[dxә әчl $K q$ pəpold

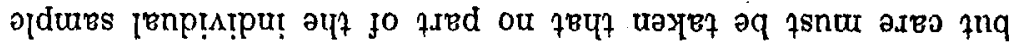

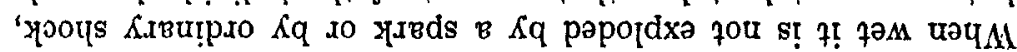

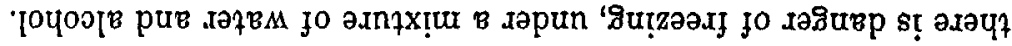

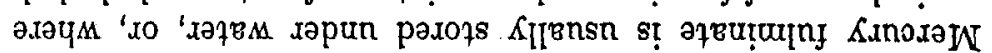

sure.so $\angle 2$ o00t

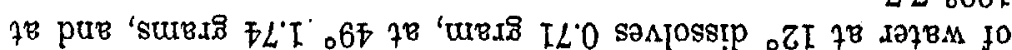
xә7!I әu० 'snoxp

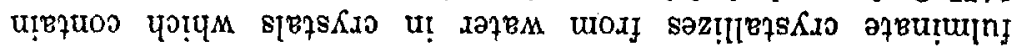

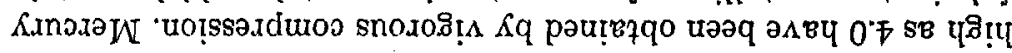

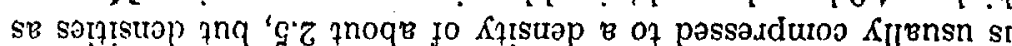

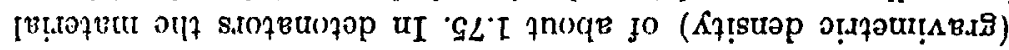

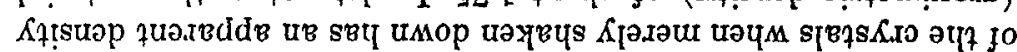

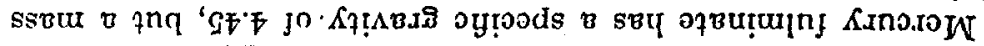

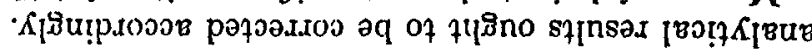

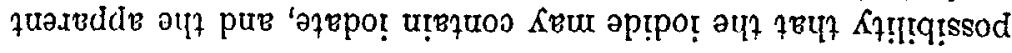




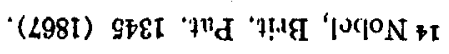

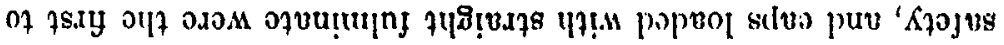

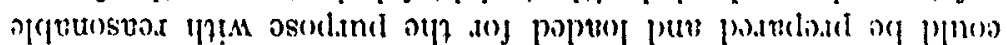

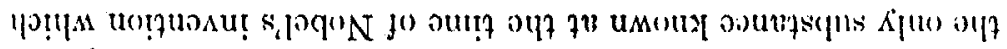

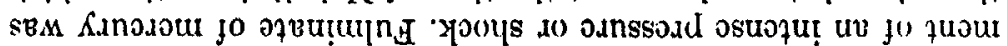

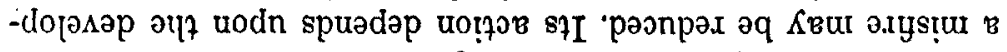

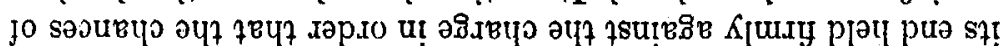

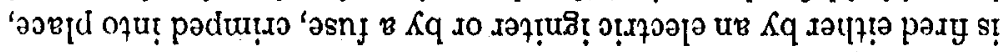

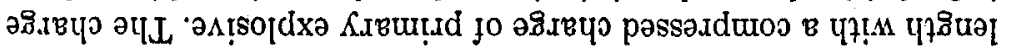

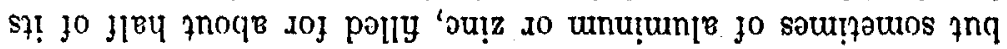
doddos jo $\Lambda$ [ן

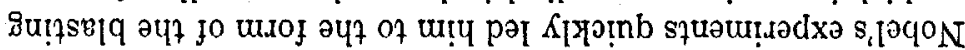

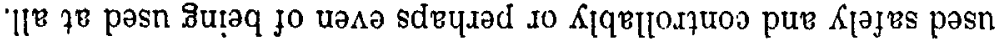

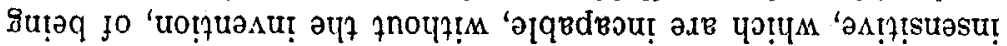

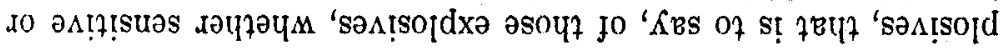

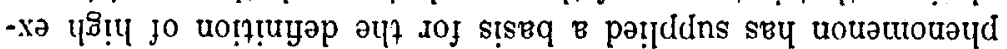

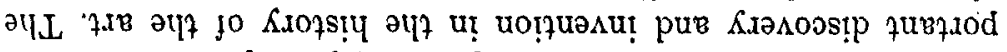

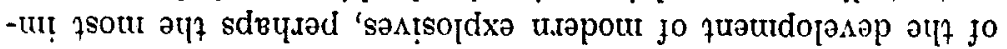

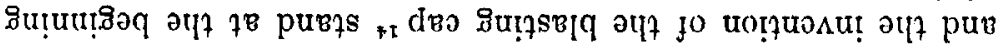

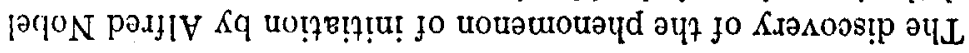

s107etrofod

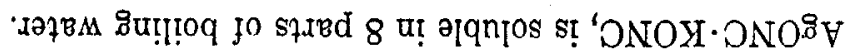

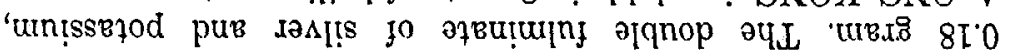

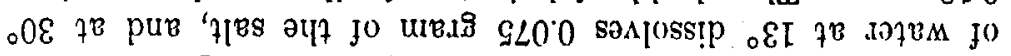

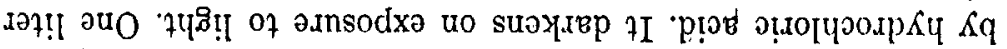

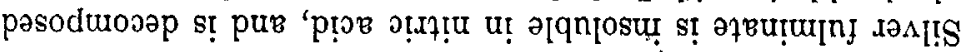
-s.JOABf Jeftutits pur

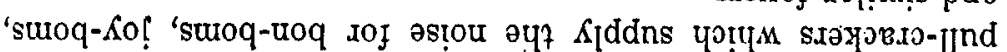

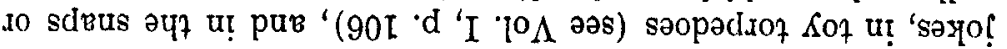

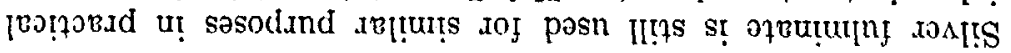

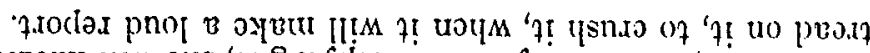

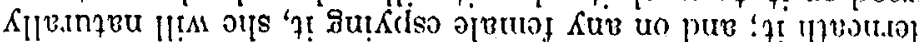
- (III . . os

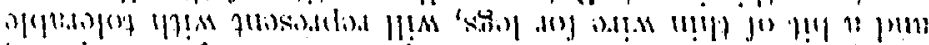

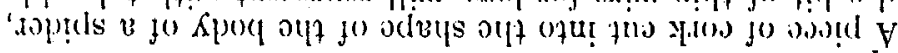
supp!dS

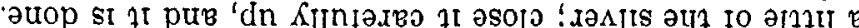

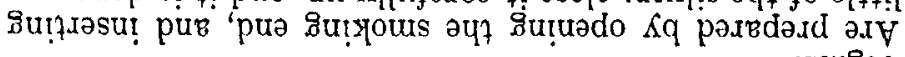
- S.IB.ిว

$$
\text { ... . . }
$$

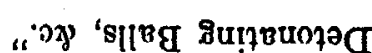

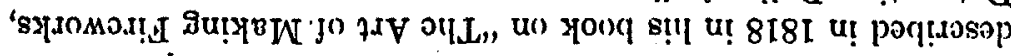

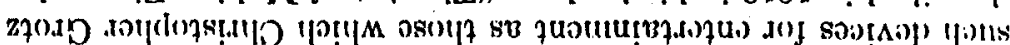

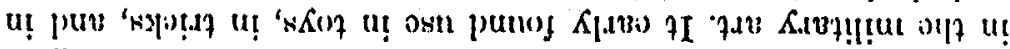

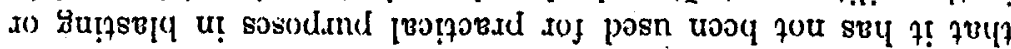

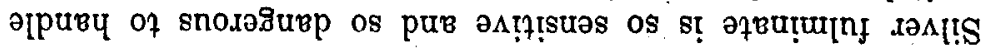
$\rightarrow$

әfeụurng

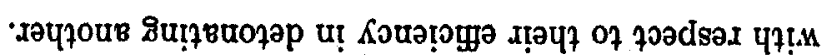

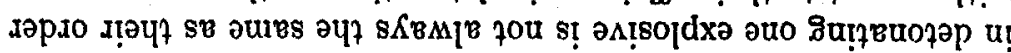

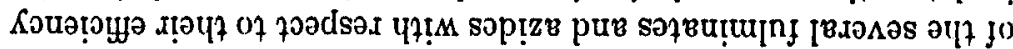

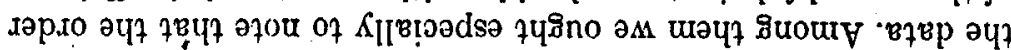

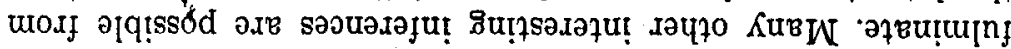

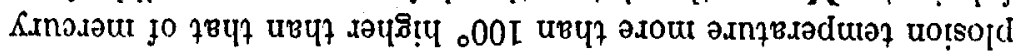

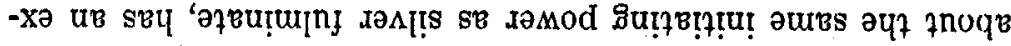

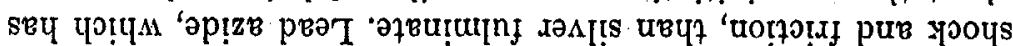

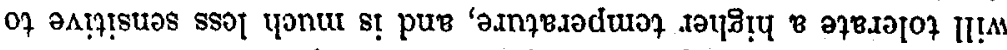

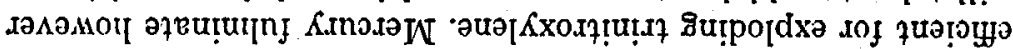

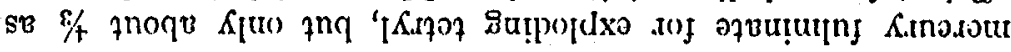

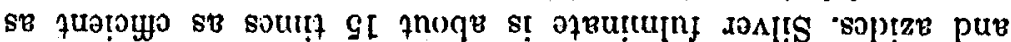

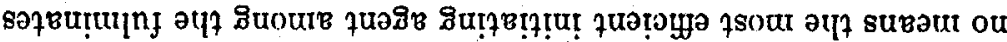

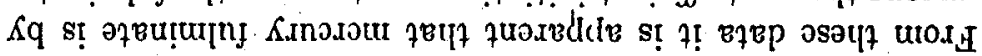

\begin{tabular}{|c|c|c|c|c|c|}
\hline . & $\cdots$ & & $\varepsilon \neq 0$ & $0 E^{\circ} 0$ & 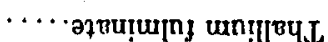 \\
\hline$O F \cdot 0$ & $\angle \varepsilon^{\circ} 0$ & $\theta \varepsilon^{\circ} 0$ & $0 \& \cdot 0$ & $6 z \cdot 0$ & 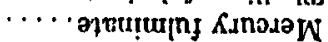 \\
\hline$\varepsilon \mp 0$ & $z \varepsilon^{\circ} 0$ & st. 0 & $80^{\circ} 0$ & $\$ 20^{\circ} 0$ & $\cdots$ aquu!uinj soddens \\
\hline $9 \varepsilon^{\circ} 0$ & $9 z^{\circ} 0$ & II 0 & 90.0 & $800^{\circ} 0$ & 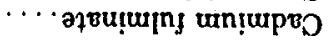 \\
\hline \multirow[t]{2}{*}{$0 \varepsilon^{\circ} 0$} & $\varepsilon Z^{\circ} 0$ & 960.0 & $90^{\circ} 0$ & $20^{\circ} 0$ & 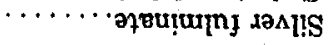 \\
\hline & & g\&\&.0 & SII 0 & $\angle 0^{\circ} 0$ & 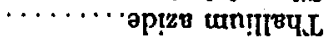 \\
\hline $09^{\circ} 0$ & $99^{\circ} 0$ & $\mathfrak{S E I} \Gamma^{\circ} 0$ & $S \angle 0^{\circ} 0$ & $S \notin 0^{\circ} 0$ & " әр!zв snomodəא \\
\hline \multirow[t]{2}{*}{$0 \% 0$} & $G \angle E^{\circ} 0$ & $\$ 60^{\circ} 0$ & $970^{\circ} 0$ & $920^{\circ} 0$ & $\cdots$ әp!zu snosdn \\
\hline & $8 z^{\circ} 0$ & $60^{\circ} 0$ & $980^{\circ} 0$ & $9 \approx 0^{\circ} 0$ & อp!zu pะor \\
\hline \multirow[t]{2}{*}{980} & $9 z \cdot 0$ & $20^{\circ} 0$ & $980^{\circ} 0$ & 600 & 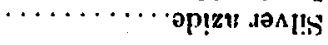 \\
\hline & 1.0 & 50.0 & $80 \%$ & $10^{\circ} 0$ & $\cdots \cdots \cdots$ ə|p!zv un!̣upvo \\
\hline 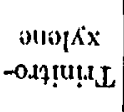 & 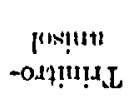 & 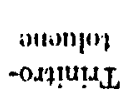 & $\begin{array}{l}\text { 1!\%V } \\
\text { o!̣o!d }\end{array}$ & {$[\mathbf{A} \mathbf{l}] U_{\mathbf{L}} \mathrm{L}$} & 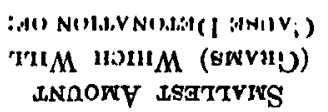 \\
\hline
\end{tabular}

-səs!so[d

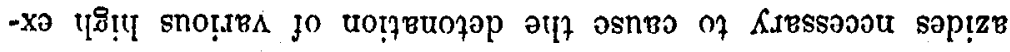

SYGWIYd GNV 'SYOLVNOL'G 'SHAISOTdXG XYYNIYd ZIF 


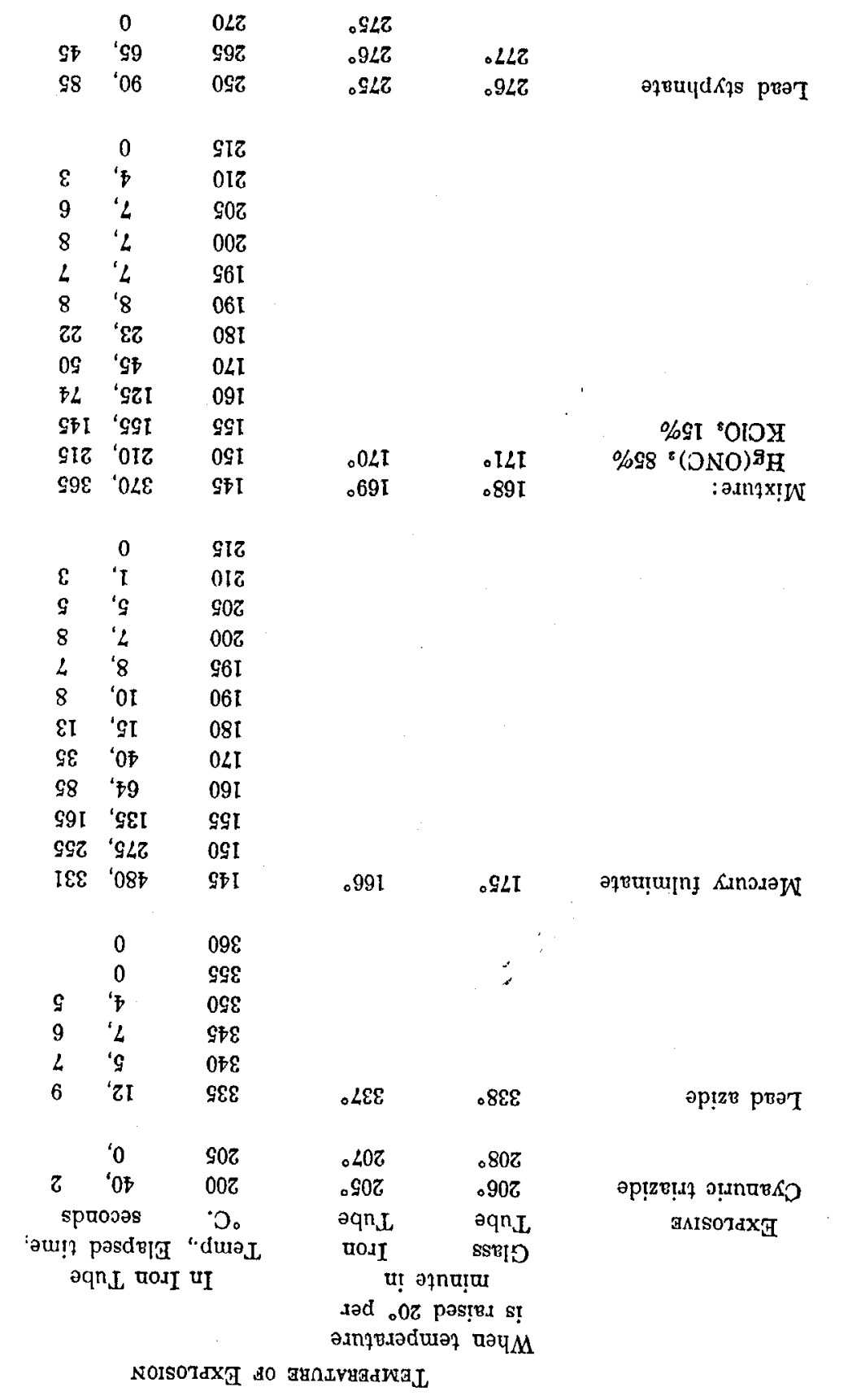

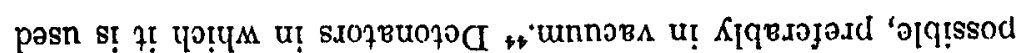

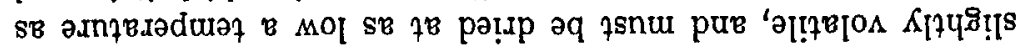

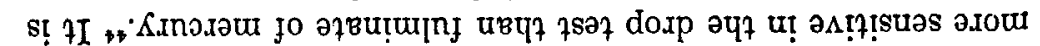

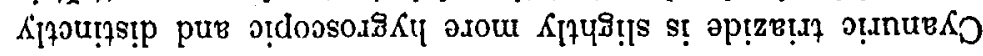

\begin{tabular}{|c|c|c|}
\hline 980 & gro & 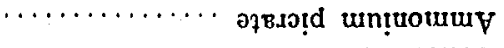 \\
\hline 070 & $60^{\circ} 0^{\circ}$ & 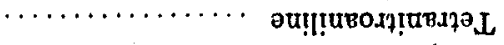 \\
\hline$\$ 20$ & 500 & $\cdots \ldots \ldots \ldots$ \\
\hline 160 & $90^{\circ} 0$ & 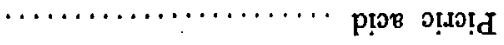 \\
\hline $9 z^{\prime} 0$ & oro & 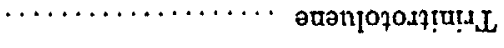 \\
\hline ә7вu!uring & әptzeg!: L L & बAISOTdXG HOtKL \\
\hline Siñגə) & ọ, & \\
\hline
\end{tabular}

GOUVHO DNILVILINI TONINIT

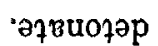

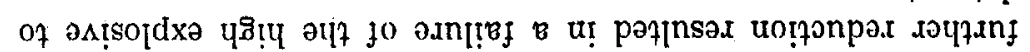

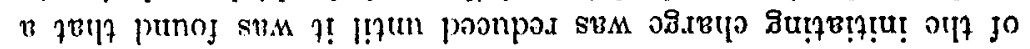

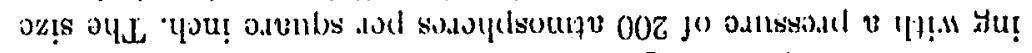

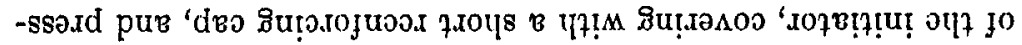

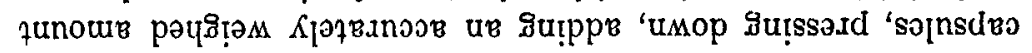

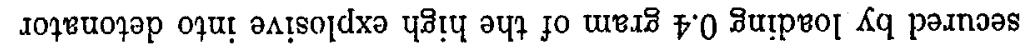

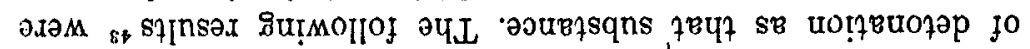

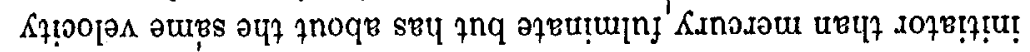

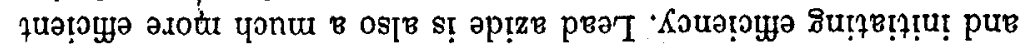

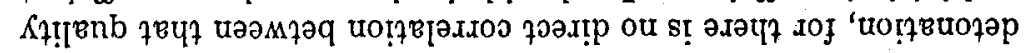

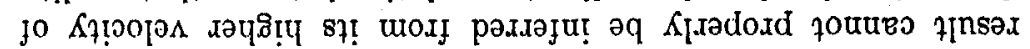

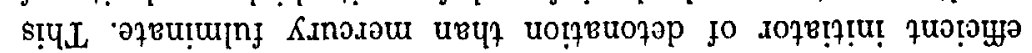

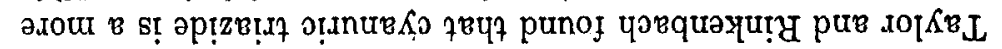

\begin{tabular}{|c|c|c|}
\hline 0067 & 97 & $\ldots \ldots \ldots \ldots \ldots$ \\
\hline 099 & I' $\varepsilon$ & 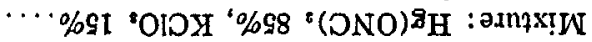 \\
\hline 0677 & $\varepsilon \varepsilon$ & 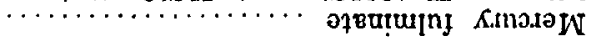 \\
\hline 0097 & $8 \varepsilon$ & әptze priar \\
\hline $9 b 9 g$ & gIt & optzets' othuưs \\
\hline aNOOAS & XLISNB & GATSOTdXG \\
\hline Had s4guaIN & & \\
\hline ROLVNOLA $\alpha$ & & \\
\hline 0 גLIOOTI $\Lambda$ & & \\
\hline
\end{tabular}

${ }_{\text {:5. S. }}$.

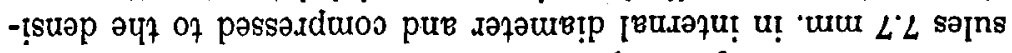

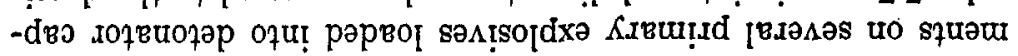

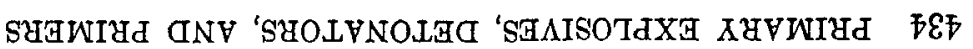




\section{APPENDIX C}

Sourceš for Explosive Literature 



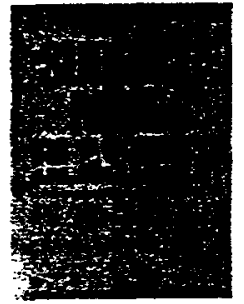

\section{SUREACE MUNE BLASTIVG}

by Carl E. Pavetto

Training manual for MSHA Certification. Covers major types of explosives, initiation systems, and shot checking systems in surface coal mining. Tools to meet certification requirements. Soft cover, 1989,317 pp. MAN09891

\section{TXST METHODS FOR EXPLOSTVES}

Muhamed Suceska, Treats the experimental methods used to determine the physical properties of explosives \& explosions - physical principles, operating procedures and evaluation of results. 1995, 225 pp. ISBN 0387945555.

\section{UNDERGROUND BLASTING WORKSHOP}

Edited by Trevor Little

Proceedings of the Underground Blasting Workshop conducted by the Blasting Research Group of the Western Australia School of Mines, Curtin University of Technology. Softcover, 1992 PRO02911
DEMOLITION SAFETY MANUAX

The bible of the demolition industry for safe work practices. Describes safety measures to be followed before the demolition work actually begins. MAN20000

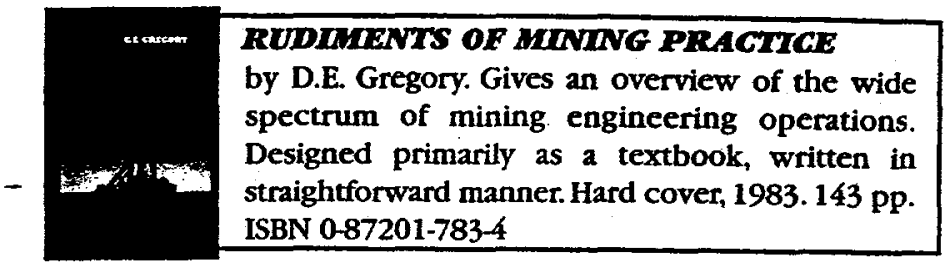

Ul FEGK INTERNATTONAC SECURTY PRODUCT DENTHIGATION GUIDE

The Federation of European Explosive Manufacturers has provided a product guide for explosives materials in a CD-Database format. Includes images of products. CDFEEM

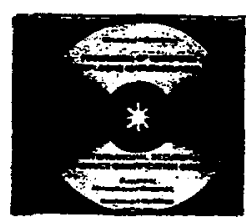

\section{"Blasters Library Price List}

Tile

Air Drilling Handbook

Applications of Directional Blasting

Applied Explosives Technology
BAl's High-Tech Seminar Proceedings 'a9

BAl's High-Tech Seminar Proceedings 90

BAl's Migh-Tech Seminar Proceedings '91

BAl's High-Tech Seminar Proceedings 492

BAl's High-Tech Seminar Proceedings '94

BAl's High-Tech Seminar Proceedings 45

Black Powder Handbook

Blast Damage \& Structural Cracking

Blast Design

Blast Vibration Analysis

Blast Vibration Monitoring \& Control

The Blaster's Guide

Blaster's Training Manual for Ranchers, Prospectors, etc.

Blasting Guidance Manual

Blasting in Ground Exc'ns \& Mines

Blasting In Hydraulic Construction

The Blasting Primer

Blasting Technique

Blasting Techniques I-III

Blasting Techn for Min \& Civ Engrs

Bombs And Bombing

Characteristics of Non-military Expl

Chemistry of Powder \& Explosives

Chemistry of Pyrotechnics

Complete Art of Firework Making

Compressed Air Systems

Construction Dewatering

Contemporary Hist. Of Industrial Expl

Construction Vibrations

\section{Detonator Board}

Demoltion Safety Manual

Dictionary of Blasting Technology

Drilling \& Blasting of Rocks

Dictionary of Mining, Mineral, and Related Terms

Emulsions Explosives

Engineering Design Mandbook

Engineering Geology

Encyclopedia of Explosives $10 \mathrm{Vol}$
Iten No.

HDKo7891

TXT05891

ISBN9179706347

TXT01989

TXT01990

TXT01991

TXT01992

TXT01994

TXX01995

ISBNo873491750

MANo991

ISBN0964956004

ISBN0809309513

ISBNO130781975

CU015994

MAN1991

MAN78913

ISBN9061919568

IT7150047

MANO4891

TXT02891

ISBN0940427033

ISBNO86840294X

ISBNO39BO022453

REP04791

ISBN10913022004

ISBNO824774434

ISBN0929931092

MAN07789

ISBN4716501853

Colo8791

ISBNO13299108X

\section{TXT3965}

MAN20000

ISBN3527263454

ISBN9054101997

ISBN0922152365

TXT04991

ARM5557

ISBN0471544248

AD257189
Member Price Non-Member Price

$\$ 15.95 \quad \$ 34.00$

$28.00 \quad 42.00$

$82.50 \quad 103.00$

$40.00 \quad 55.00$

$45.00 \quad 60.00$

$50.00 \quad 65.00$

$55.00 \quad 70.00$

$80.00 \quad 95.00$

$60.00 \quad 75.00$

$32.50 \quad 41.00$

$27.00 \quad 33.60$

$65.00 \quad 81.00$

$15.00 \quad 20.00$

$55.00 \quad 68.75$

$5.00 \quad 7.00$

$90.00 \quad 112.50$

$9.95 \quad 21.25$

$103.50 \quad 129.50$

$30.00 \quad 37.50$

$19.50 \quad 29.00$

$165.50 \quad 206.25$

$85.00 \quad 106.00$

$40.65 \quad 50.80$

$49.50 \quad 62.00$

$16.50 \quad 21.00$

$27.00 \quad 33.75$

$120.00 \quad 150.00$

$18.00 \quad 23.00$

$31.00 \quad 38.75$

$82.50 \quad 103.00$

$18.95 \quad 24.00$

112.00

140.00

$75.00 \quad 90.00$

$174.00 \quad 217.00$

$135.00 \quad 168.75$

$150.00 \quad 175.00$

$88.80 \quad 111.00$

$16.00 \quad 20.00$

$104.00 \quad 130.00$

$\begin{array}{ll}525.00 & 638.00\end{array}$ 


\section{OBDER FOBM}

\section{Order Information}

United States: Add $\$ 5.95$ per item and $\$ 3$ for each additional item. All orders shipped UPS. Allow 46 Weeks

Canada: Surface-Add $\$ 7.95$ per item and $\$ 5$ for each additional item. Allow 68 weeks. Air-Add $\$ 9.95$ per item and $\$ 9$ for each additional item. Orders shipped by air via reguhar mail or DHL. Allow 46 weeks for delivery.

All other Countries: All items shipped by International Air Only unless otherwise instructed.Add $\$ 20$ per item. For orders with 4 or more items, contact ISEE for shipping charges. Allow 46 weeks. Delivery guaranteed.

\section{Restrictions}

- You must be at least 21 years old to order.

- Quantities are limited, special offers valid only while supplies last.

- All orders must be prepaid. Prices are subject to change without notice and are quoted and payable in U.S. Dollars. Bank draft or money order must be drawn on a U.S. bank.

- Intemational customers call for surface rates. (not guaranteed)

- Libraries and Booksellers call for prices and availability.

Name (Please Print)

Member Number Company

Street Address

City State Fax Zip Country

Phone E-mail

Shipping Address: (we cannot ship to P.O. Box)

Name

Company

Address

City State Postal Code (Zip) Country

Our Guarantee... Review any book you order for 30 days. If il doesn't meet your needs, retum it for a full retund or credit. For more information or TO ORDER, call, fax or mail this form to International Society of Explosives Engineers $\bullet 29100$ Aurora Road - Cleveland, Ohio 44139 - USA - Tel: (440) 349-4004 • Fax: (440) 349-3788 • E-mail: isee@isee.org, or - website: www.isee.org 


$$
\begin{aligned}
& 1 \text { - mazuas. } \\
& \text { I- ATPAZ10 } \\
& 1=4 / 0200 \\
& \int D_{1} D \text {. Hunten }
\end{aligned}
$$

\section{Encyclopedia of Explosives and Related Items on CD-ROM}

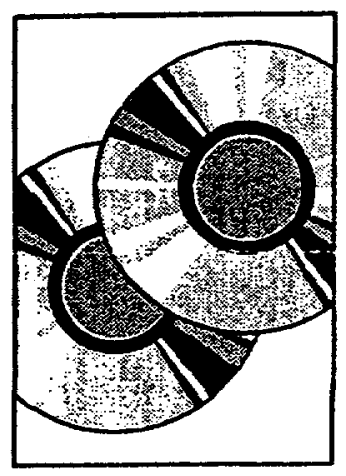

The classic, definitive reference on the field of explosives and pyrotechnics is now available as a two CD-ROM set from the National Technical Information Service. All 9,000 pages of the original 10-volume encyclopedia are included as it was published by the U.S. Army Picatinny Arsenal. The original printed edition was prepared by B. T. Fedoroff, O. E. Sheffield, and S. M. Kaye - over a 23-year period and it is now considered "the final word" for anyone involved in the chemistry of explosives and related research.

:

Now with all 10 volumes on a two-CD-ROM set, you can quickly and easily:

- Search all 9,000 pages for chemical name, descriptive phrase, or keyword.

- View or print an entry with valuable embedded diagrams and figures.

- Copy and paste text into word processing documents.

- Look up terms and chemical names alphabetically using the Table of Contents.

Comprehensive Coverage From $\mathrm{A}$ to $\mathrm{Z}$

This complete, technical reference on the entire field of explosives and pyrotechnics contains entries on:

- Military and industrial explosives, explosive compositions, propellants and pyrotechnic compositions;

- Explosives and explosive compositions which have not been used for military or industrial purposes;

- Analytical procedures for the more common explosives, propellants, and pyrotechnic compositions;

- Compounds which deflagrate or may possibly explode because of the presence of plosophoric groups;

- Ammunition items, such as projectiles, bombs, grenades, detonators, fuses, etc.;

- Calibers of weapons and projectiles used in the United States and worldwide;

- Brief definitions of ordnance terms;

- Names of scientists who made important contributions in the fields of explosives, ammunitions, and weapons.

\section{Detailed Entries Pull So Much Information into One Place!}

Entries contain information on the chemistry, synthesis and preparation of explosives. Analytical methods, and handling, physical and explosive properties of specific chemicals and compositions are described. Entries also outline the history and background of the development and use of explosives. Every effort was made to include references to the parent compound of azido, nitro and nitroso derivatives, and intermediate non-explosive derivatives. These references are important for the proper preparation of explosive derivatives. 


\section{Encyclopedia of Explosives and Related Items on CD-ROM}

Just Released!

\section{A "Must Have" for Engineers, Chemists, and Manufacturers of Explosives}

This thorough treatment of the field of explosives and pyrotechnics was

painstakingly prepared by experts at the U.S. Army Picatinney Arsenal. Now it's available on CD-ROM, so you can use the latest text search software to lookup pertinent information in seconds from this voluminous reference. Find all entries citing a substance and jump to the next reference electronically. Once you find the answer, simply print it, or cut and paste the text into a word processor for inclusion in reports or procedures.

\section{System Requirements:}

Runs on Windows, $3 . X$, Windows 95 or higher, and Windows NT, with 8 MB RAM and 5 to $10 \mathrm{MB}$ hard disk space. Runs on Macintosh with a minimum of a 68020 processor with 3.5 MB RAM and version 7.1 system software. Search software provided.

\begin{tabular}{|ccc|}
\hline http://www.ntis.gov & NTIS SALES DEsK: $\begin{array}{c}\text { 1-800-553-NTIS (6847) } \\
\text { or (703) 605-6000 }\end{array}$ & $\begin{array}{r}\text { ORDER BY FAX: (703) 605-6900 } \\
\text { IDD: (703) 487-4639 }\end{array}$ \\
\hline
\end{tabular}

Yes, Enter my order for the Encyclopedia of Explosives and Related ltems on CD-ROM.

SHIP TO ADDRESS (please print or type)

\begin{tabular}{l|l|l}
\hline CUSTOMEA MASTER NUMBER (IF KNOWN) & DATE \\
\hline ATTENTHON I NAME
\end{tabular}

\begin{tabular}{l|l|l|}
\hline ORGANIZATION & OIVISION/ ROOM NUMBER \\
\hline
\end{tabular}

\begin{tabular}{l|l|l}
\hline CINT & STATE & ZIP CODE \\
\hline PROVINCE / TEARITOAY & INTERNATIONAL POSTAL CODE \\
\hline
\end{tabular}

COUNTAY

\begin{tabular}{l|l}
\hline PHONE NUMBEA & $\left(\begin{array}{l}\text { FAX NUMEER } \\
(1)\end{array}\right.$ \\
\hline CONTACT NAME & INTERNET E-MAIL AODRESS \\
\hline
\end{tabular}

D BIL ME (U.S. Canada, and Mexico only - $\$ 10$ additional tee)

A request to be billed must be on a purchase order or company letterhead.

Order Via E-Mail: orders@ntis.fedworld.gov

For internet security, register your credit card at NTIS; call (703) 605-6070.

Order by Mail:

NTIS - 5285 Port Royal Road • Springfield. VA 22161

RUSH Service is available for an additional fee. Call NTIS Sales Desk for details

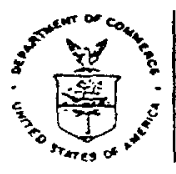

U.S. DEPARTMENT OF COMMERCE

Technology Administration

National Technical Information Service

Springtield. va 22161

nitp.j/wmw.ntis.gov

\begin{tabular}{|c|c|c|}
\hline atr & PRICE & $\begin{array}{l}\text { NTIS PRODUCT NUMBER } \\
\text { Encyciopedia of Explosives and Related Items, } \\
\text { PB99-500076LBG, Single User, } \$ 375 \text { per copy } \\
\text { (outside U.S. Canada, and Mexico. } \$ 500 \text { ) }\end{array}$ \\
\hline & & $\begin{array}{l}\text { Encyclopedia of Explosives and Related Items, } \\
\text { PB99-500076LBG, Up to } 5 \text { concurrent users, } \$ 975 \\
\text { per copy (outside U.S., Canada, and Mexico. } \$ 1,295 \text { ) } \\
\text { For more information on concurrent users, call NTIS. }\end{array}$ \\
\hline & 5 & TOTAL \\
\hline & $S \quad \mathbf{5 . 0 0}$ & HÀNOLING FEE PER TOTAL ORDER (Outside North America - S10.00) \\
\hline & $S$ & $\begin{array}{l}\text { For international airmail service, Canada and Mexico } \\
\text { add \$4 per ilem; other countries add } \$ 8 \text { per item. }\end{array}$ \\
\hline & $s$ & GRAND TOTAL \\
\hline
\end{tabular}

METHOD OF PAYMENT (please print or type)

O VISA O MasterCard a American Express D Discover

\begin{tabular}{l|l|l}
\hline CREDIT CARO NUMBEA & EXPIRATION OATE \\
\hline
\end{tabular}

D NTIS Deposit Account Number.

G Check/Money Order enclosed for \$ (PAYABle TO NTIS IN U S DOLLARS) $9901 \mathrm{H}$ 
ATTACHMENT 2 


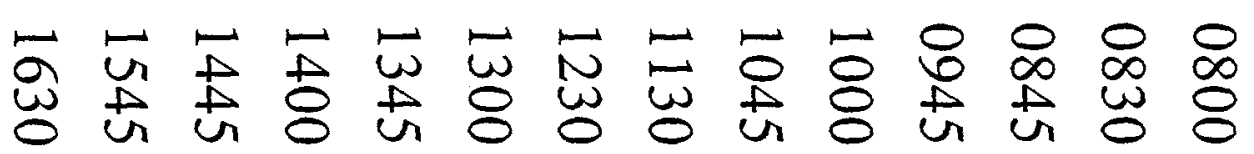

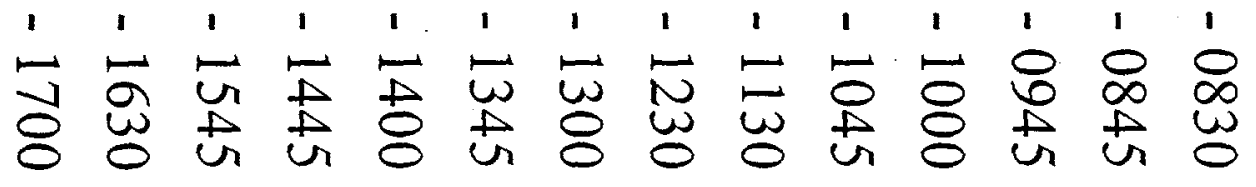

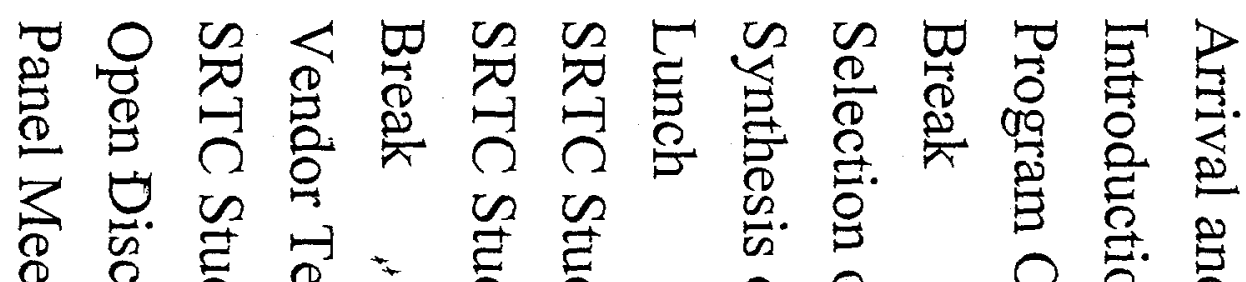

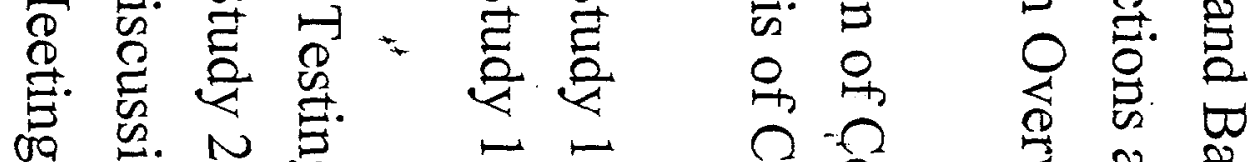

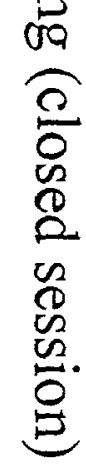

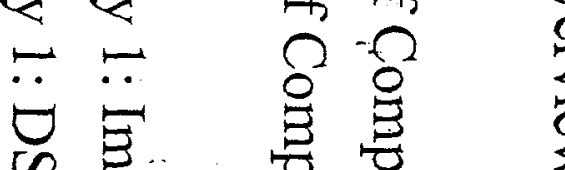

它

$\Omega$ D

$\square$

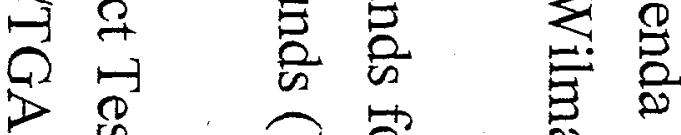

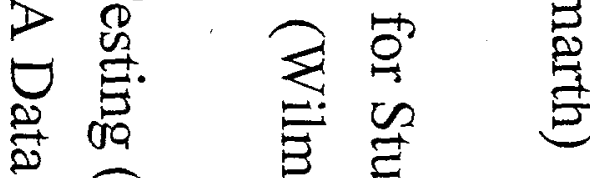

D 

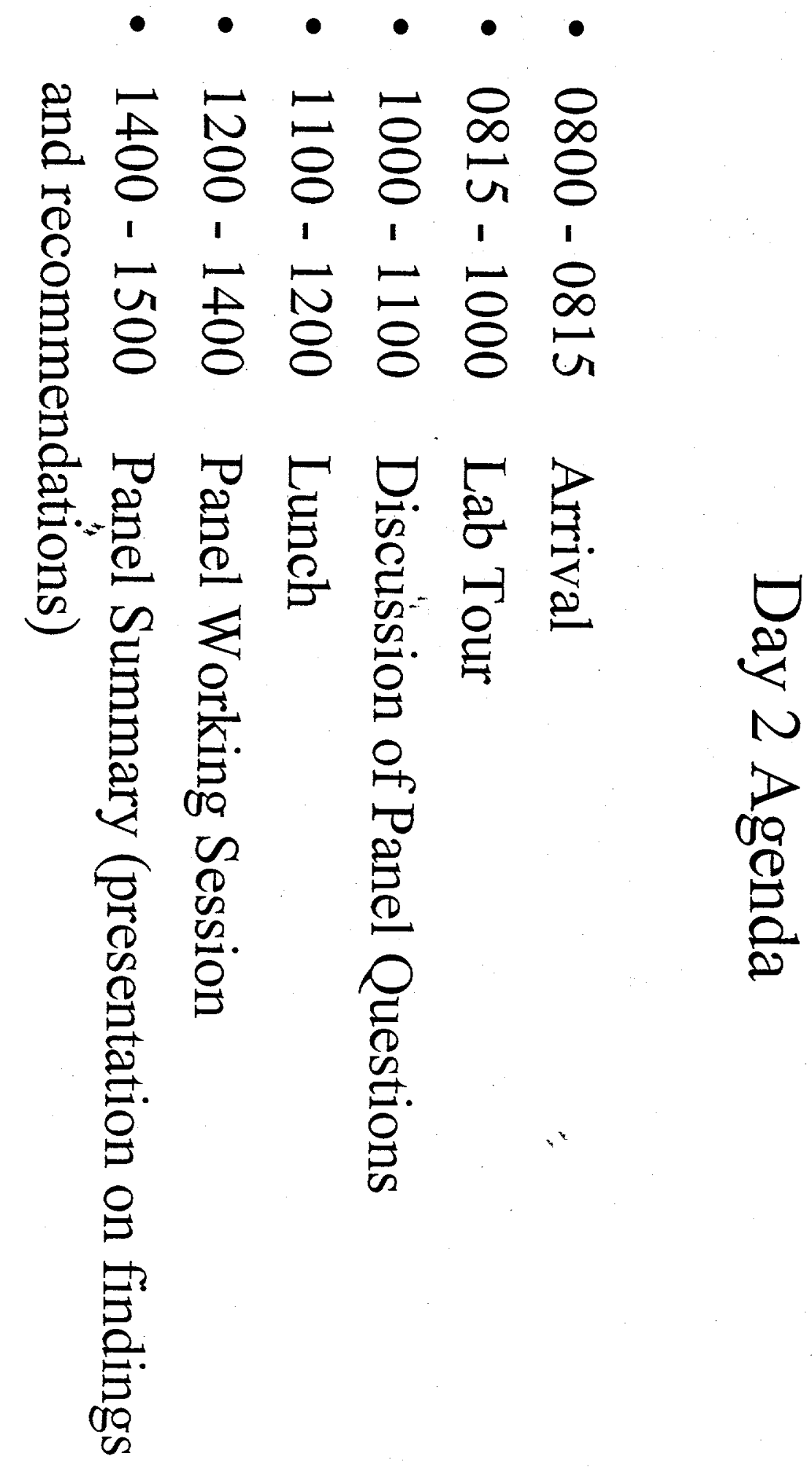


\section{Dry Sludge Impact Tests}

- All Impact Tests were run at $6 \mathrm{~kg}$ weight and $50 \mathrm{~cm}$ height (maximum for our Impact Tester)

- Tests run on

- Mercury Fulminate

- Mercury Oxalate

- Basic Sludge Simulant (1-A)

- Basic Sludge Simulant with Organics (7-D)

- Basic Simulant with Mercury Oxalate $(\sim 6$ wt \%, $\sim 15$ wt $\%$ mixed dry)

- Basic Simulant with Mercury Oxalate ( $\sim 6$ wt $\%, \sim 15$ wt \% mixed wet)

- Basic Simulant with Organics and Mercury Oxalate ( $\sim 6 \mathrm{wt} \%, \sim 15 \mathrm{wt} \%$ mixed dry)

- Basic Simulant with Mercury Fulminate $(\sim 3 \mathrm{wt} \%, \sim 6$ wt $\%, \sim 15$ wt $\%$ mixed dry)

- Basic Simulant with Mercury Fulminate $(\sim 3$ wt \%, $\sim 6$ wt $\%, \sim 15$ wt $\%$ mixed wet)

- Basic Simulant with Organics and Mercury Fulminate ( $\sim 3$ wt \%, 6 wt \%, 15 wt\% mixed dry)

- Basic Simulant with Mercury, Silver and Organics

- Results

- Both fulminate and oxalate standards gave positive results (smoke) at amounts of 1-3 $\mathrm{mg}$

- No sludge simulants (with or without standards) gave positive results

- Some evidence of degradation of standards in sludge 
- Problems

- Impact tester not on completely stable base (some bouncing

- Samples not ground to uniform particle size (sticky samples and concerns about setting off standards)

- Masses used not entirely uniform (sticky samples made weighing difficult

- Sample material ejected from sample cup during impact 
imalar test matix provided y ting vasis slude aimulal 6. Jac mostic fen aptfitue une polon

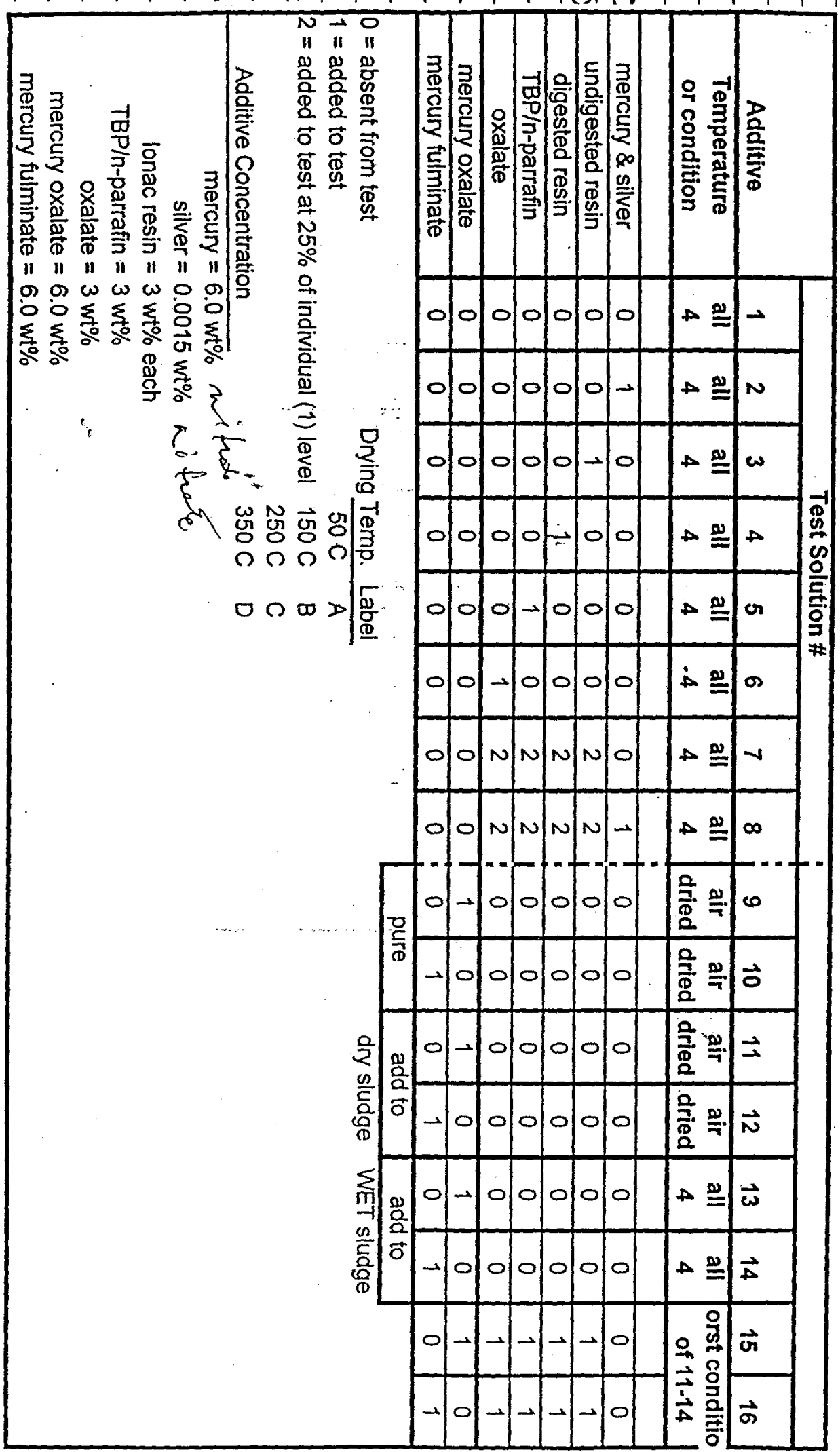

FID IRITING UNDER⿳- TH TMSFRT 10 TRITING UNOOK \# 98.00238

6 


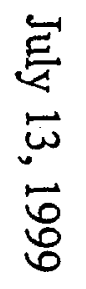

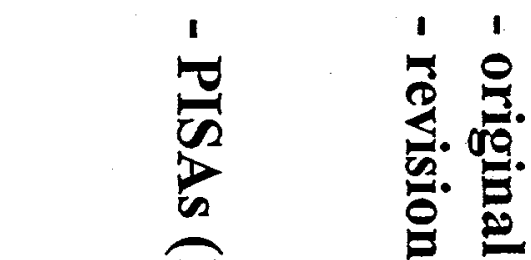

0
1
1
1
6
0
8
8
8
0

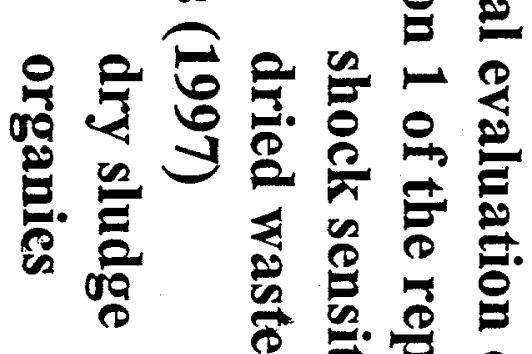

충 융

능흥

这

2

F

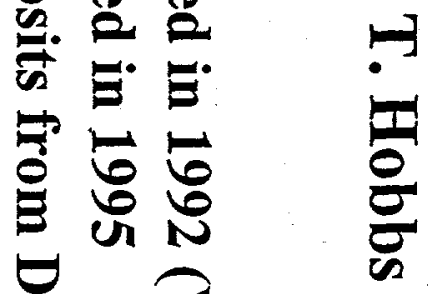

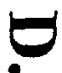

[-]

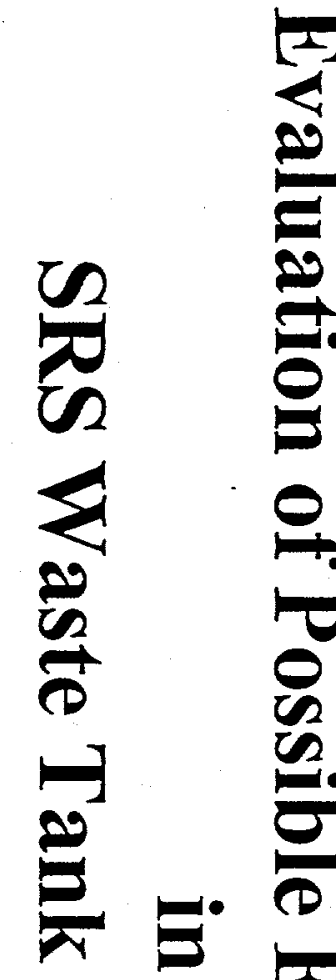

8

퍼

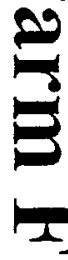

2

2

$\underline{ }$

Ag

ㅂ.

룽

8

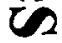

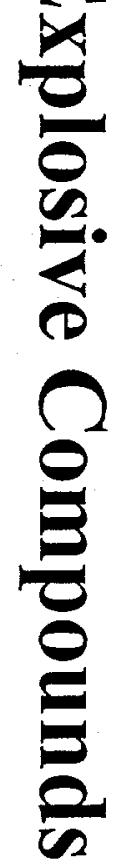




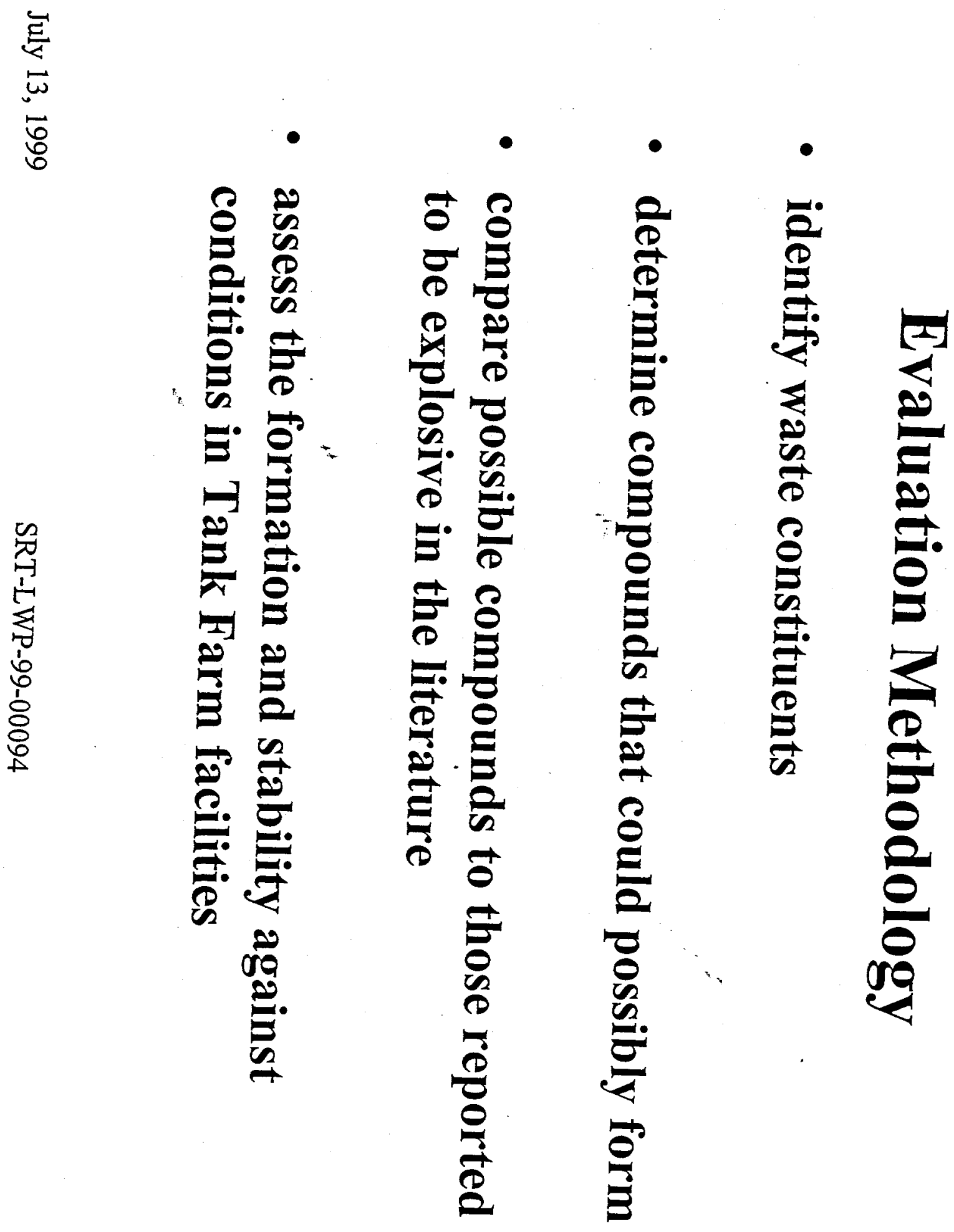




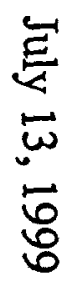
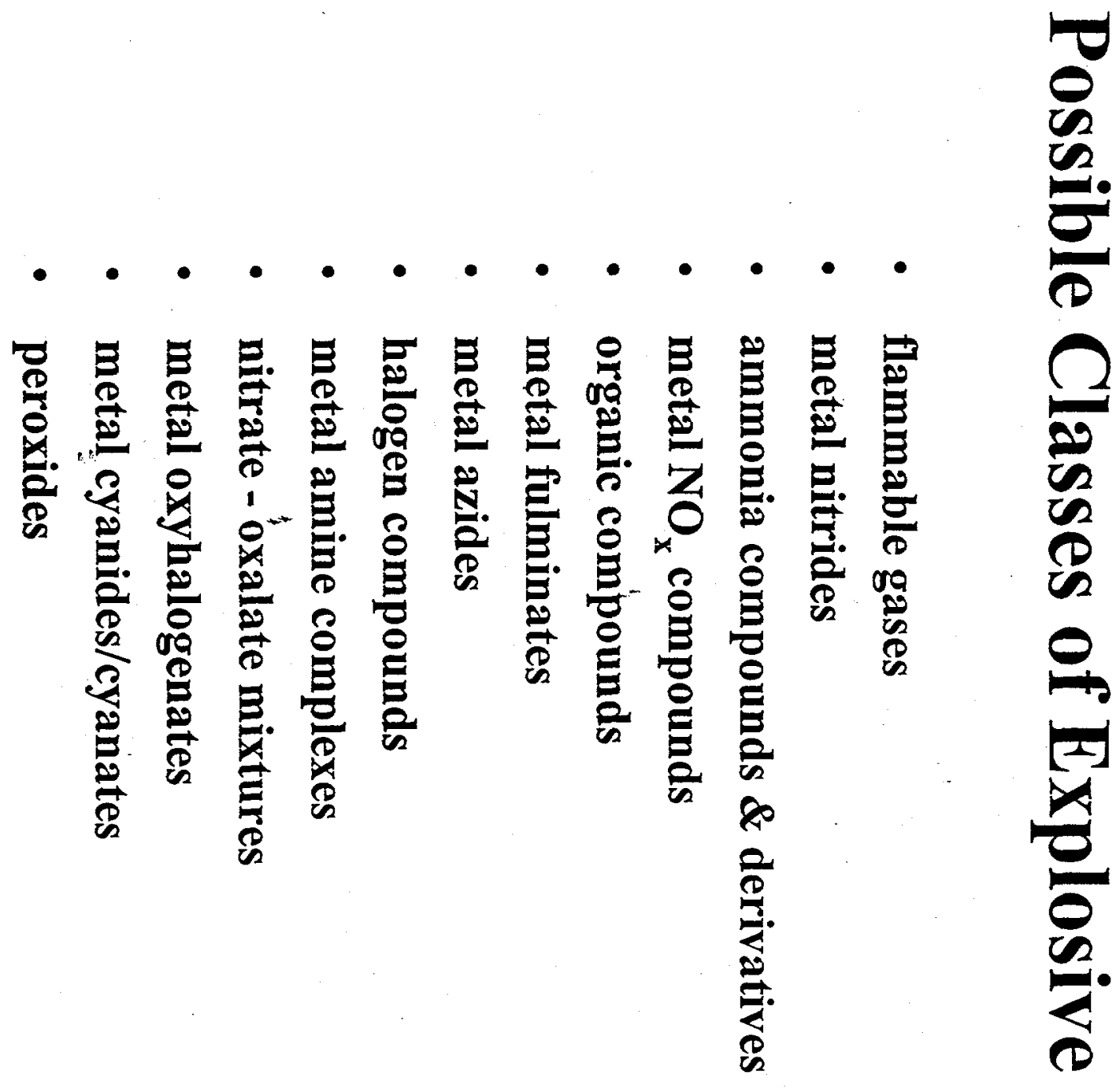

0
0
1
8
8
8
8
8

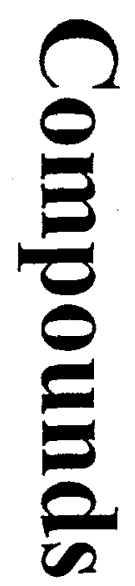


$\vec{g}$
$\overline{5}$
$\overline{0}$

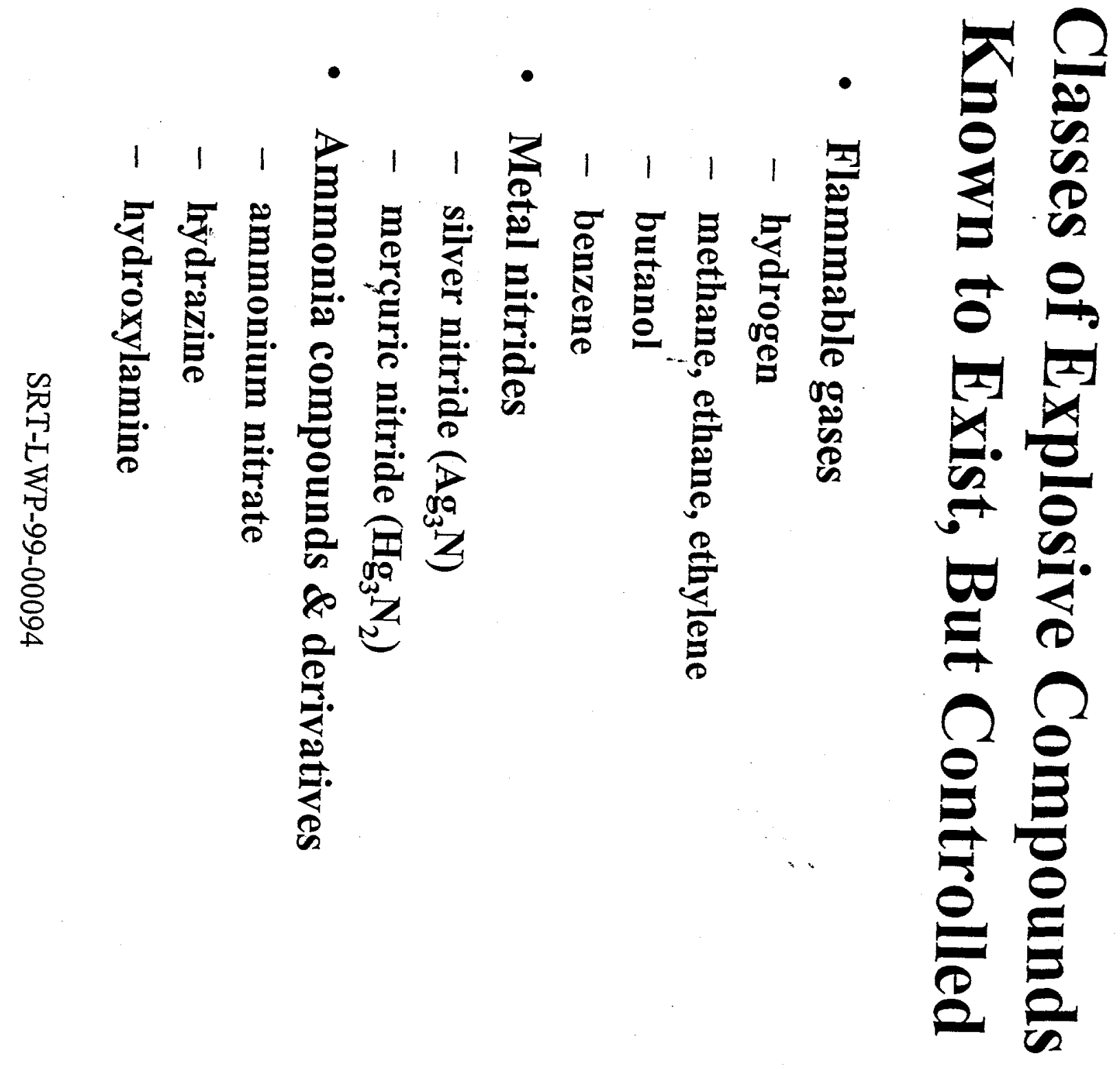




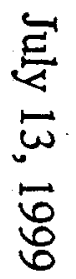

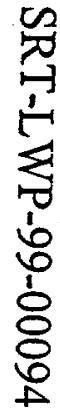

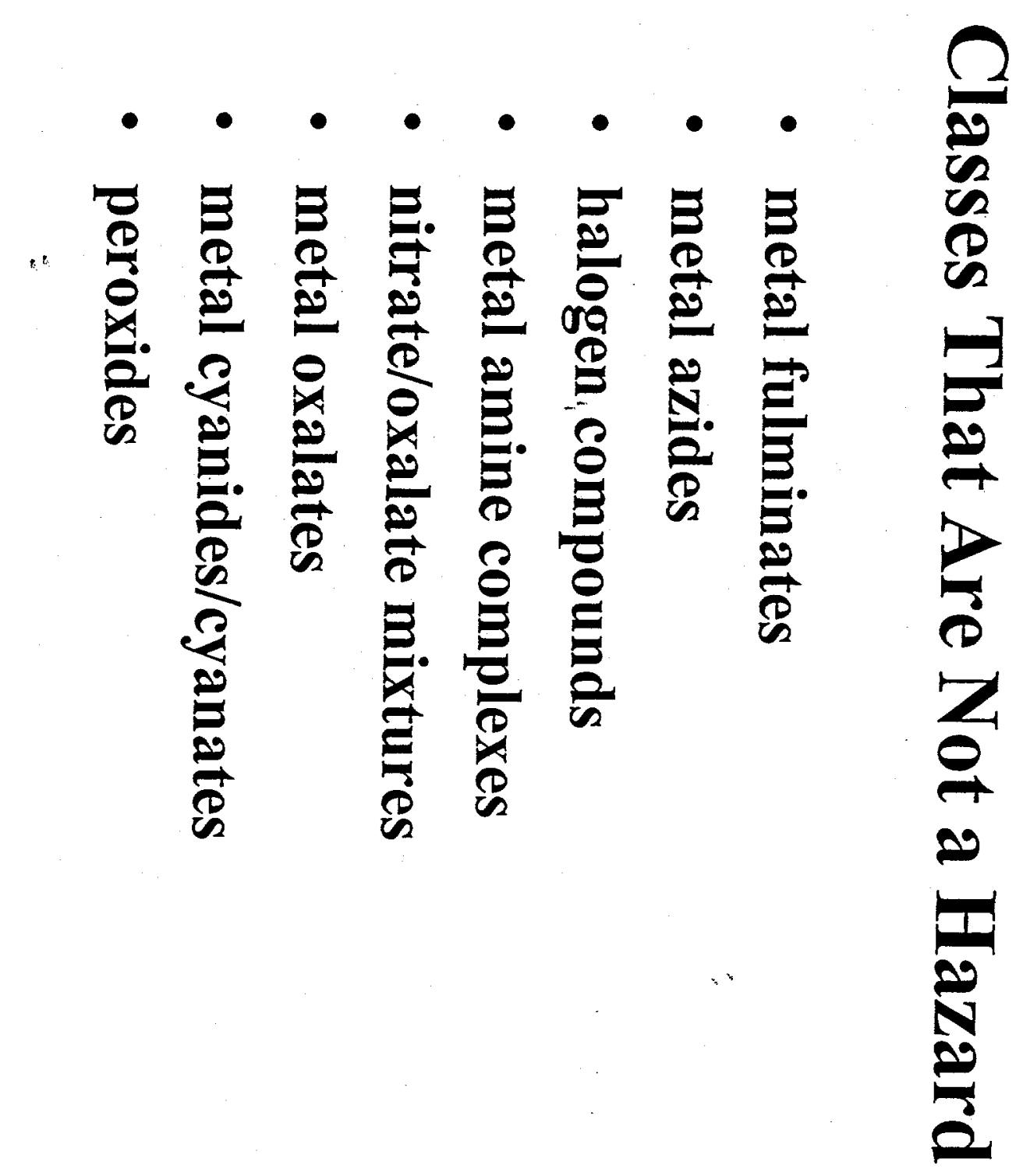




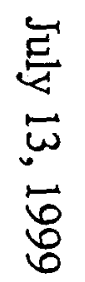

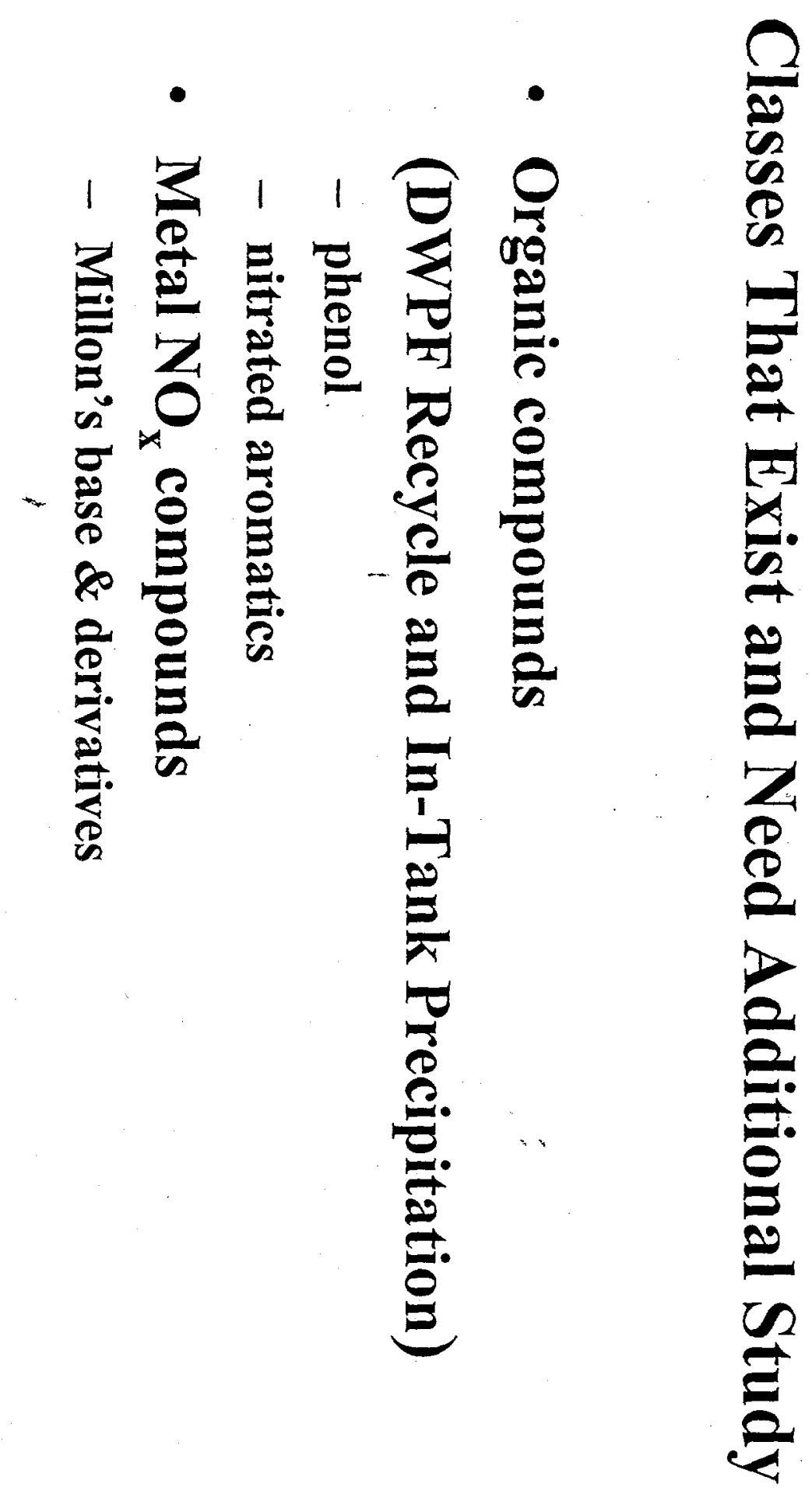

a) 


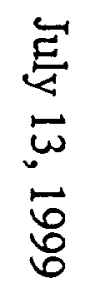

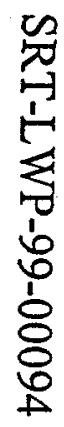
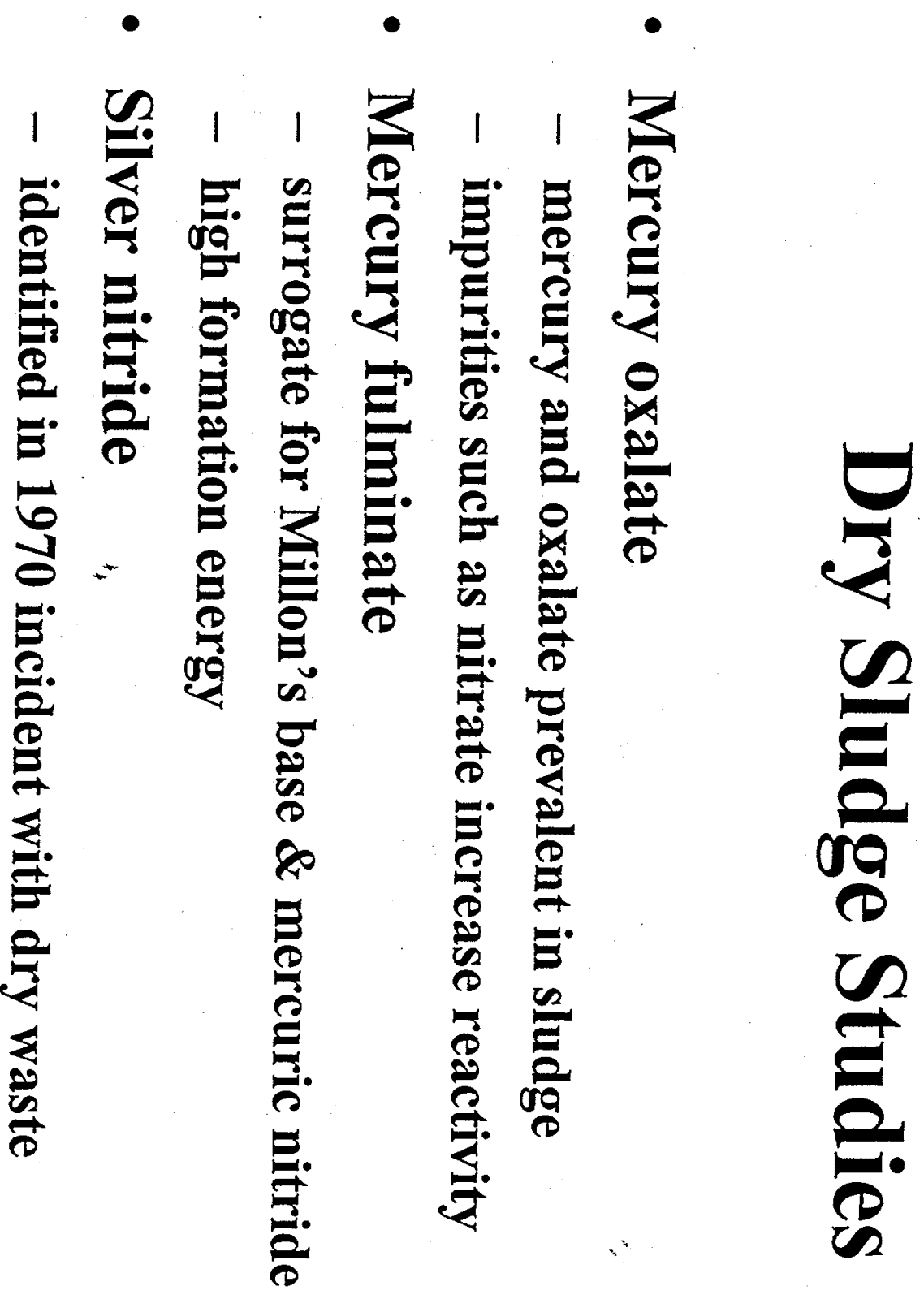

를

ora

(1)

$\frac{c}{2}$

D

E 


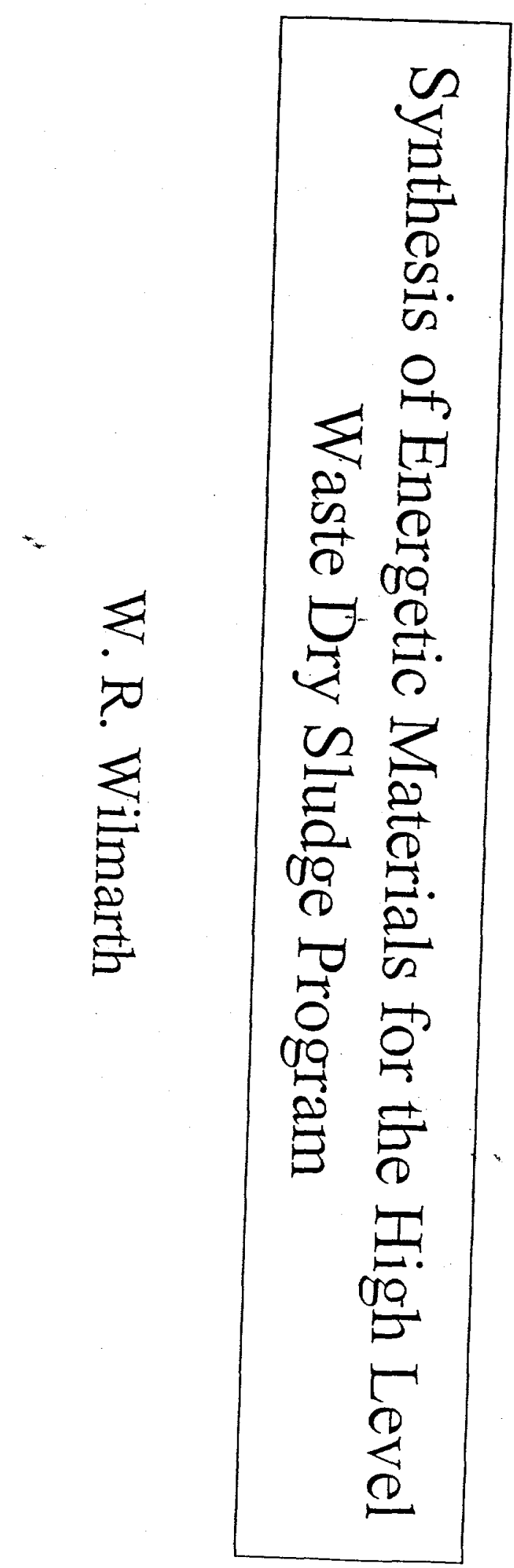




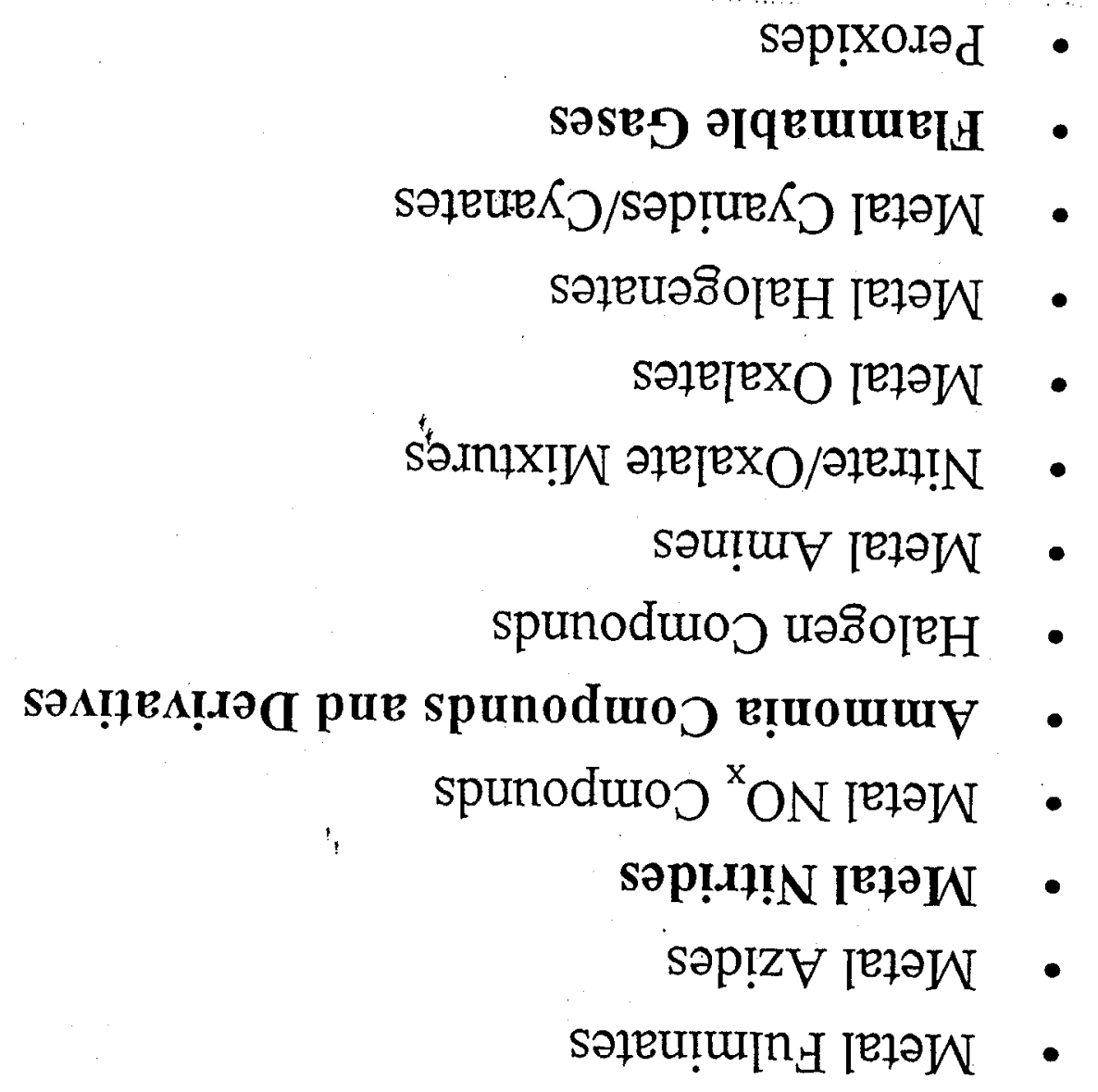

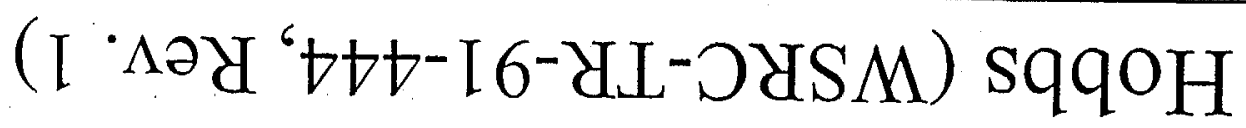

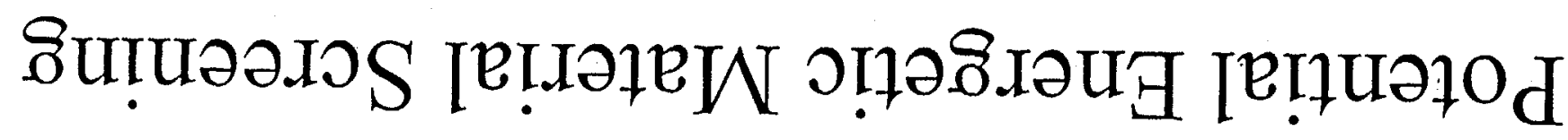




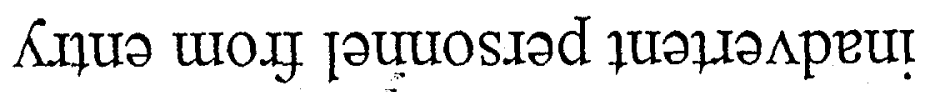

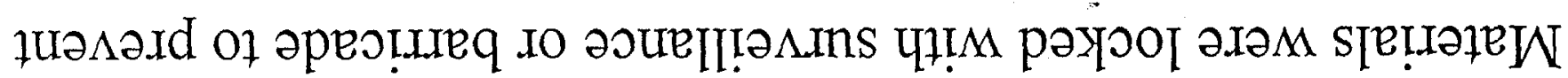

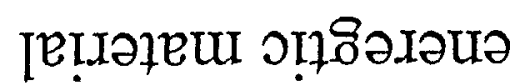

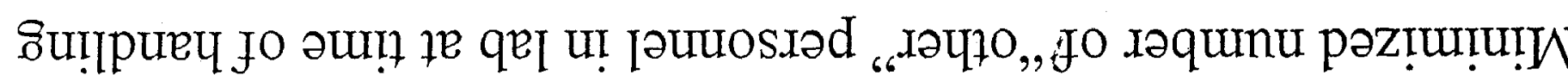

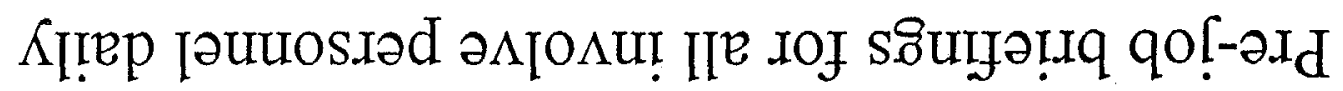

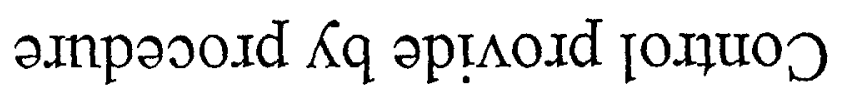

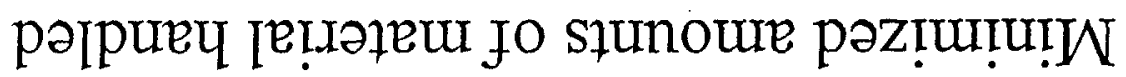
OLYS

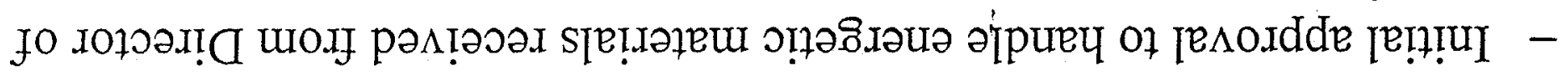

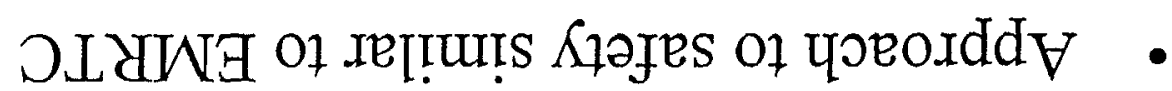

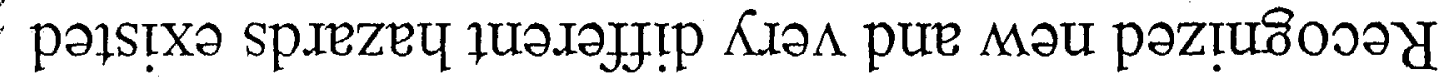

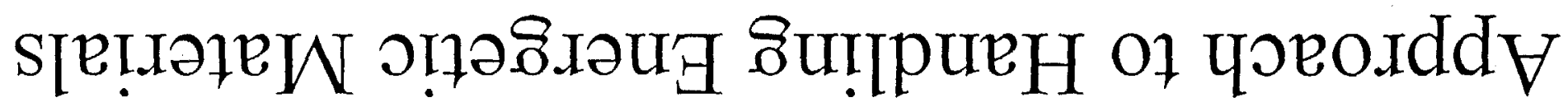




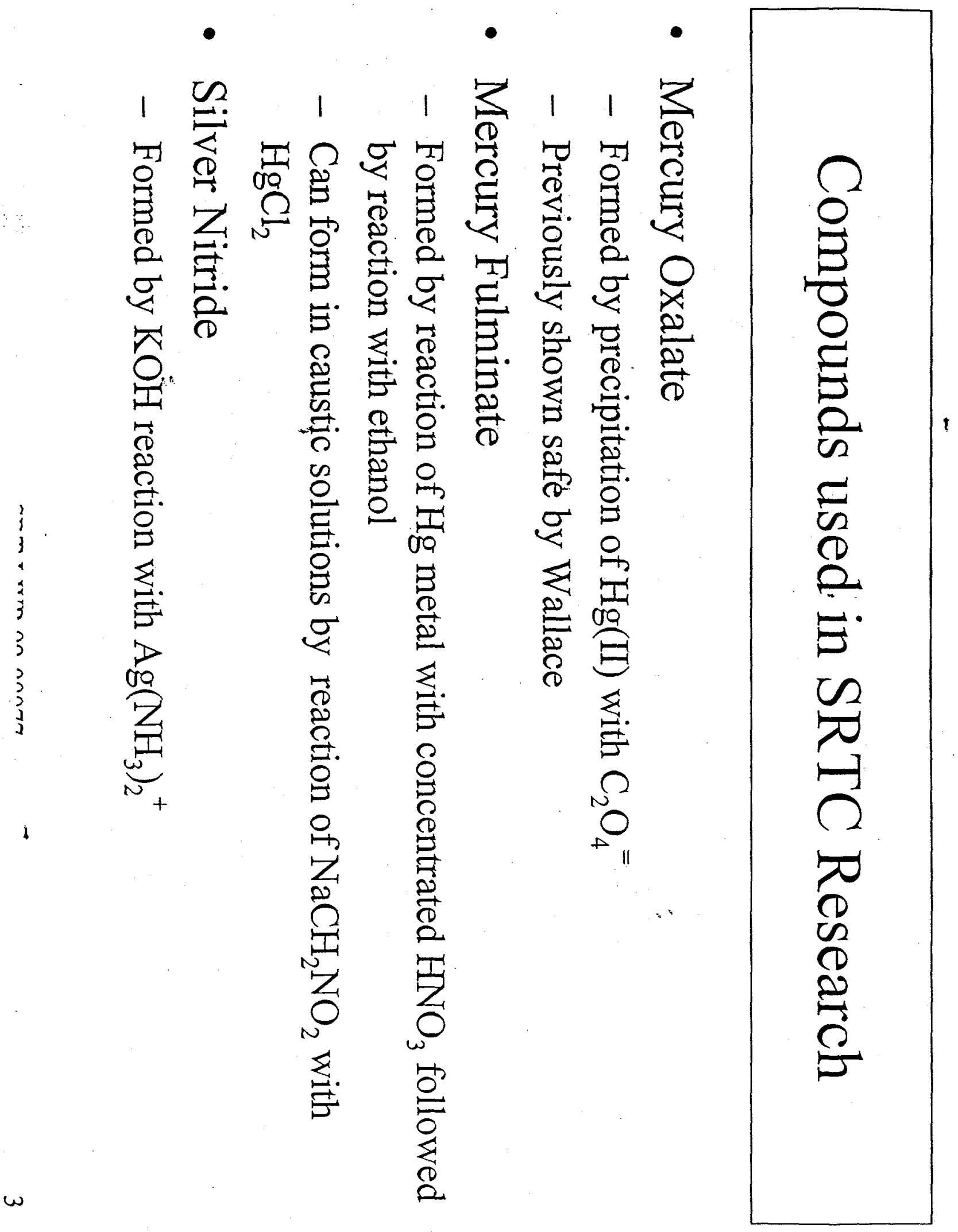




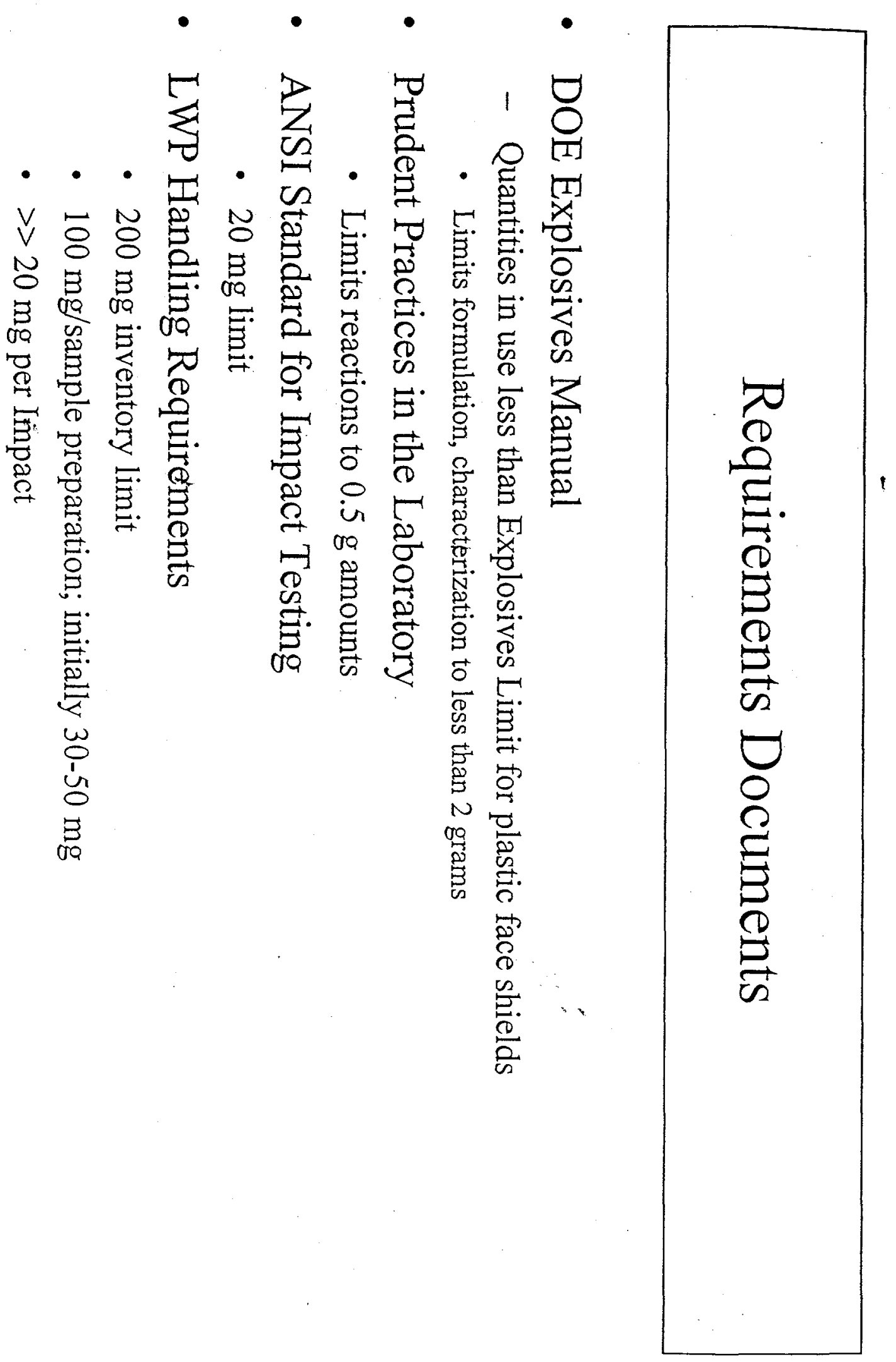




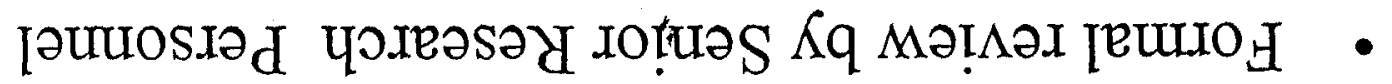

surdung 'uo!̣ezrodsuext 'ump

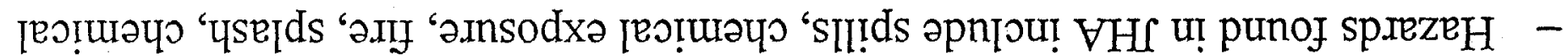
StSKjeUY pIezeH qor •

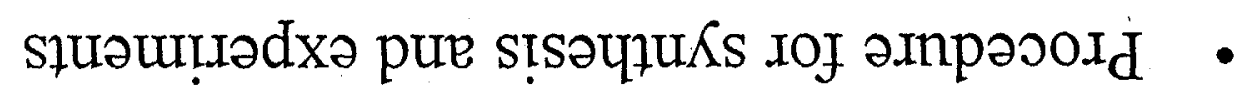

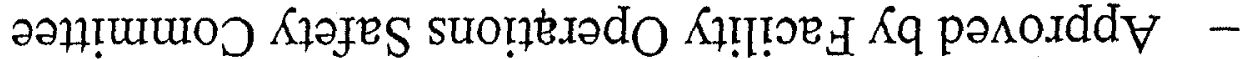

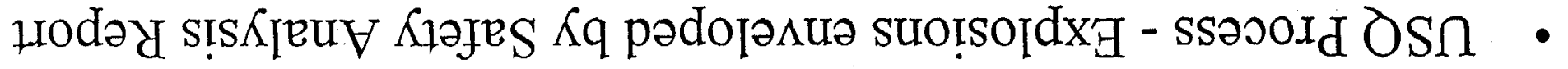

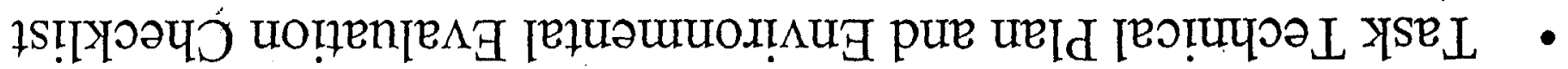

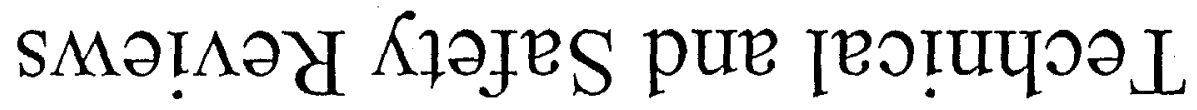




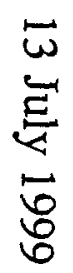

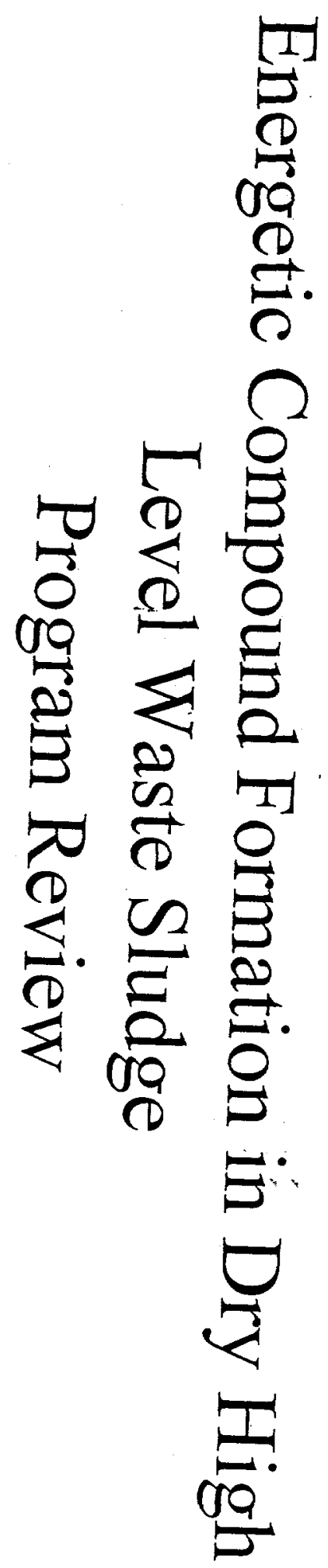

$\stackrel{8}{\circ}$.

0
0
0
0
0
0
0 


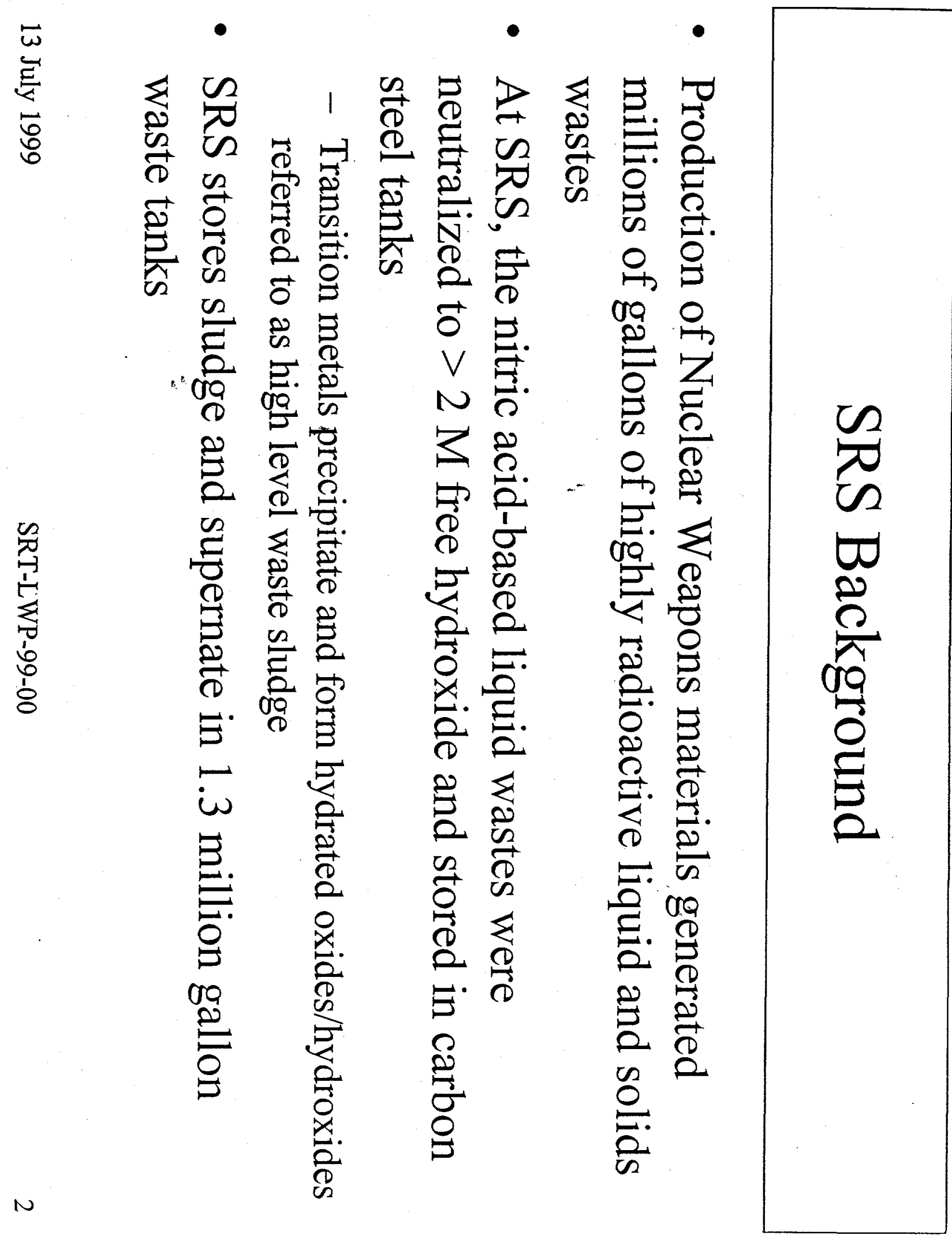




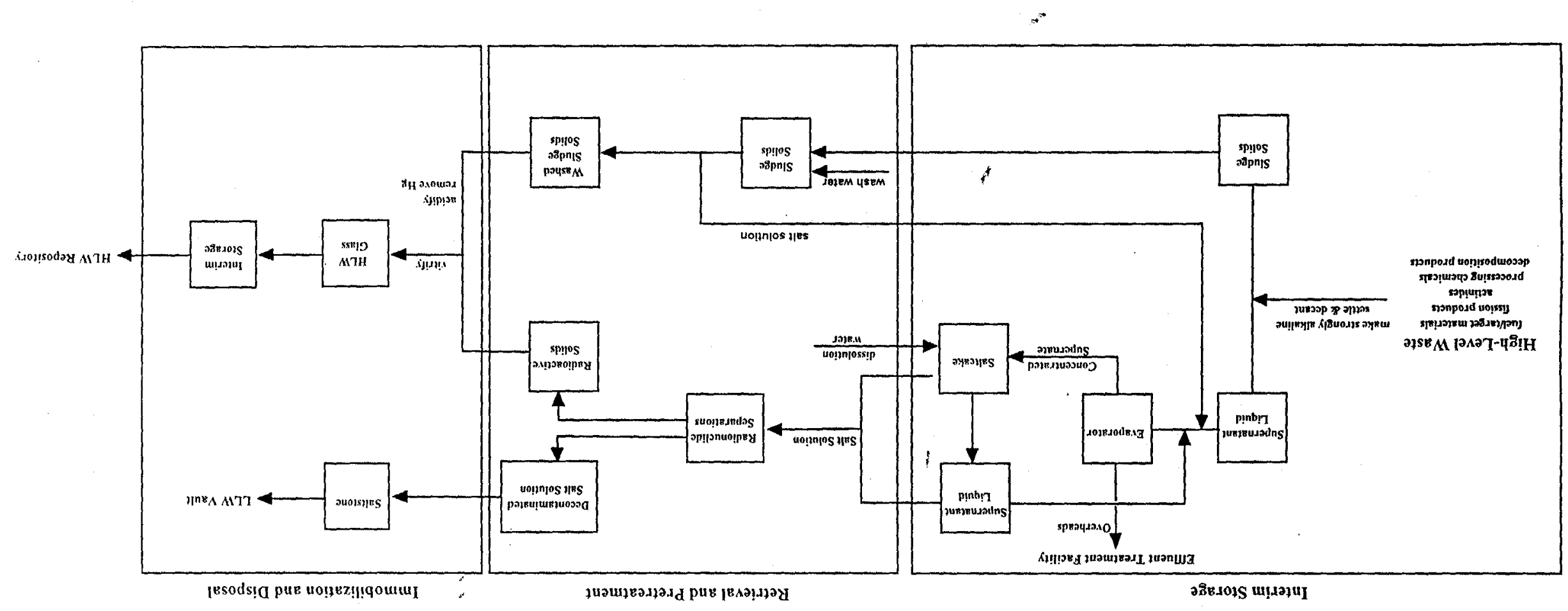

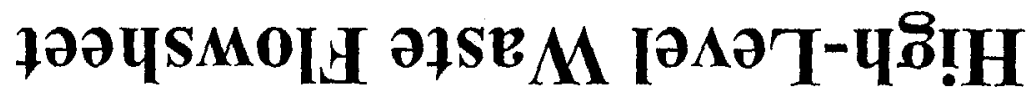




\section{Sludge Processing.}

- Currently, sludge processed into glass in the Defense Waste Processing Facility

- Two waste tanks officially closed pre CERCLA protocol

- Over 500 canisters produced to date

- Extended Sludge Process washes the sludge with $0.1 \mathrm{M}$ $\mathrm{NaOH}$ to remove entrained salts

- Sludge is combined with glass formers and vitrified

- Ultimate disposal is to National Repository 


\section{Salt/Supernate Processing}

- Original plans were to dissolve salt and precipitate radio-cesium with sodium tetraphenylborate and remove radio-strontium and actinides with monosodium titanate

- $430 \mathrm{kgal}$ processed in 1985 demonstration

- During initial batch processing in the In-Tank Precipitation (ITP) process, benzene generation rates observed'

- Research program identified active transition metal catalyst that likely originated from sludge entrained solids

- Systems Engineering approach used to identify replacement process

- Three candidate processes undergoing final selection

- Tetraphenylborate process using engineered safety features

- Crystalline silicotitanate ion exchange

- Grout 


\section{Problem Statement}

- Authorization Basis for Tank Farm assumes sludge remains wet

- Release fraction and respirable fraction possibly higher for dry tank

- 5 tanks dry at start of program

- 2 tanks have been re-wetted (Tank 6Fand 8F)

- Tank $15 \mathrm{H}$ has cracks that may preclude efforts to re-wet

- Potential Inadequacy in Safety Analysis (PISA) declared

- Establishes schédule to revise SAR as necessary

- Hazardous chemical formation during dry process could lead to shock sensitive compound formation

- Sludge contains $\sim 4 \mathrm{wt} \% \mathrm{Hg}$ and $\sim 1 \mathrm{wt} \% \mathrm{Ag}$ 


\section{Investigation Approach}

- Use DSC/TGA, Impact (ASTM) testing and Friction testing to test for energetic behavior

- Parallels LANL's approach for ferrocyanide-bearing Hanford tanks

- Examine archive tank samples located in SRTC facilities from previous experimentation

- Prepare simulate sludge at range of worse case conditions to ensure experimental methods would detect energetic behavior

- organic components, drying temperature, high mercury and silver content

- Test behavior at larger scale $(\sim 10 \mathrm{~g})$

- Review results with independent consultants to guide program 


\section{Program Evolution}

- Initial work by WPT focused on proving safety of sampling operations

- Performed impact tests on simulated sludges with energetic materials

- Energetic standards selected and prepared

- Radiological safety concèrns preclude safe sampling operations

- Cracks in Tank 15 preclude wetting

- Emphasis change caused research to shift to ensuring safety of sludge containing energetic materials

- Demonstrate low probability of compound formation

- Demonstrate short lifetime 


\section{H-Area Evaporator Incident}

- In July 1970, operators noticed "popping” sounds during work near the $2 \mathrm{H}$ high level waste evaporator

- Investigation by SRL suggested silver nitride

- Limited XRD data corroborated identification

- Large quantities of silver discharged to the tank farm prior to incident

- Later, silver blended to limit recurrence

- Wallace previously addressed $\mathrm{Hg}$ and Ag oxalate safety for Tank $16 \mathrm{H}$

- Concluded oxalates safe especially if maintained wet

- Impact and heat caused decomposition when dry 


\section{Archived Sludge .}

- Differential Scanning Calorimetry analysis, of archived samples from Tanks $8 \mathrm{~F}, 12 \mathrm{H}$, and $15 \mathrm{H}$ showed no exothermic behavior to temperatures as high as $400{ }^{\circ} \mathrm{C}$

- Chemical analysis of Tank $12 \mathrm{H}$ and $15 \mathrm{H}$ sludge showed materials experienced pre-treatment prior to DSC test

- Chemical analysis of Tank 8F sludge showed no evidence of pre-treatment. 


\section{Impact Testing}

- Impact testing (780 psi) of simulated sludge samples showed no visible reaction (i.e., smoke or spark) at conservative mercury and silver concentrations

- Tests containing pure explosives showed positive

- Smoke and sparks observed

- Small masses required for positive tests ( $3 \mathrm{mg} \mathrm{HgC}_{2} \mathrm{O}_{4}, 2 \mathrm{mg} \mathrm{Hg}(\mathrm{CNO})_{2}$ )

- Impact testing with mixtures of sludge and explosive (14.9 wt $\% \mathrm{HgC}_{2} \mathrm{O}_{4}$ or $\left.21.5 \mathrm{wt} \% \mathrm{Hg}(\mathrm{CNO})_{2}\right)$ showed no visible signs of reaction per standard protocol 


\section{Calorimetric Studies}

- Mixtures of dry, simulated sludge and mercury oxalate (14.9 wt \%) showed no net exothermic behavior

- Oxalate decomposition occurs at temperature overlapping an endotherm in the sludge

- Wet mixtures suggest oxalate may decompose during drying process

- Mixtures of dry, simulated sludge and mercury fulminate (21 wt \% fulminate) exhibit exothermic reaction at the decomposition temperature of the fulminate

- Across the entire temperature range, the net heat flow is endothermic

- Calorimetric studies of simulants containing oxalate/fulminate do not show signs of propagating into doped organic material 


\section{Effects of Radiation and Caustic Exposure}

- Studies have shown very short lifetimes for mercury oxalate in both alkaline environments or during exposure to gamma radiation

- Lifetimes for similar exposures are lengthened for mercury fulminate

- Synergism between radiation and alkaline exposure significant reduces fulminate lifetime 


\section{Preliminary Conclusions}

- Studies do not preclude the formation of energetic compounds as High Level Waste sludge dries

- Simulate sludge prepared in similar heat treatments do not show energetic behavior

- Mixtures of simulated sludge and energetic compounds do not exhibit a net exothermic reaction when heat to temperatures near $400{ }^{\circ} \mathrm{C}$

- Organic compounds within simulated sludge does not enhance behavior

- Impact studies of energetic compounds within sludge matrices do not show energetic behavior

- Vendor studies at larger scale show similar behavior for fulminate containing sludge

- Radiation and caustic stability indicate expected lifetimes of oxalate and fulminate are sufficiently low to ensure these energetic materials will not survive under real waste conditions 


\section{RESEARCH TEAM}

Mark Barnes

Mike Hay

Tom Nance

Tom Britt

\section{SRTC}

Lee Dworjanyn

David Hobbs

Rob Swingle

\section{CST}

Greg Hutchens
Fernando Fondeur

Mark Geeting

Bill Wilmarth

Rahn Ross 


\section{MERCURY FULMINATE STABILITY (LITERATURE REVIEW)}

- DeComposition temperature function of EXPOSURE at TEMPERATURE (FIgURE 10)

-12 MIN AT $132^{\circ} \mathrm{C}$

- INSTANT AT $277^{\circ} \mathrm{C}$

- Decomposition temperature

- DECREASES WITH INCREASING SAMPLE SIZE

- INCREASES WITH HEATING RATE (TABLE 6)

- Deteriorates With Storage, $10 \%$ Loss in (P 9 )

-12 MONTHS AT $50^{\circ} \mathrm{C}$

- 2 DAYS AT $80^{\circ} \mathrm{C}$

- INTERNET: AVOID́ CONTAÇCT WITH ALUMINUM, COPPER, ZINC, LEAD (Z. ges. Schiess- $u$. Sprengstoffw. $1921,16,105)$ 


\section{DIFFERENTIAL SCANNING CALORIMETRY RESULTS}

- Vendor fulminAte deCOMPOSES AT $235^{\circ} \mathrm{C}$

- Peaks function of sample CONTAinment: lose, tight, CRIMPED

- Measured exotherm heat Variable, 21 to 96 Cal/g

- EXOTHERM HEAT MEASUREMENT IS COMPLICATED BY MERCURY VAPOR RECONDENSATION

- SRTC FULMINATE DECOMPOSES AT $175{ }^{\circ} \mathrm{C}$

- Decomposition temperature lowered in 10 WT \% MiX in CAUSTIC sludge

- VENDOR $182^{\circ} \mathrm{C}$

- SRTC $169^{\circ} \mathrm{C}$ 


\section{CARIUS SEALED TUBE THERMAL DECOMPOSITION}

- MAjor exotherm at $123^{\circ} \mathrm{C}, 10$ WT\% fulminate in 10-g CAustic sludge SAMple (Run 3)

- Not CONFIRMED BY RETESTING USING ORIgINAL SLUDge AND FULMINATE

- Not SEen IN 3-g CAUStic SLUdge or IN NEUTRAL SLUdge.

- Gas generation reduced by 2/3 in Caustic sludge, including 3-g Samples (TABle 7)

- Peak pressure developed in Sealed tube also reduced in CAUstic sludge.

- Re-tested July 99, 10 WT\% fulminate in 10-g Caustic Sludge Showed No Residula gas GENERATION.

- SUSPECT FULMINATE AGING AND FULMINATE DECOMPOSITION IN CAUSTIC SLUDGE. 


\section{VISUAL DECOMPOSITION IN CAPILlaRY TUBE (Melting Point Technique - Video)}

- STRC MERCURY OXALATE DECOMPOSES RAPIDLY, LEAVING MERCURY DEPOSITS IN THE LOWER CAPILLARY AND CRYSTALLINE DEPOSITS AT CAPILLARY END.

- SRTC MERCURY FULMINATE DETONATES, LEAVING AN ATOMIZED CLOUD OF MERCURY DEPOSITED TO THE END OF THE CAPILLARY.

- VENDOR FULMINATE DECOMPOSES SLOWLY, LEAVING A RESIDUE AND MERCURY DEPOSITS AT LOWER END OF CAPILLARY.

- Mercury oxalate in dry sludge mix decomposes at temperature, leaving mercury DEPOSITS ABOVE THE SLUDGE, CLEARLY INDICATING PRESENCE OF SENSITIVE MERCURY COMPOUNDS.

- A miX of SRTC, fulminate WITH DRY SLUDGe has NOT BEEN TESTED (DETONATION?). 


\section{UNRESOLVED ISSUES}

- SRTC Mercury fulminate decomposition In dRY Sludge mix (CAPILlary test)

- DETONATION VS. DECOMPOSITION

- SRTC vs. Vendor Mercury fulminate (IR, XRD)

- XRD, DSC, VISUAL DECOMPOSITION DIFFERENCES.

- REACTIVITY OF MERCURY FULMINATE WITH DRY CAUSTIC SLUDGe (DSC)

- AGING, EFFECT OF TEMPERATURE

- Flame propagation in dRy Sludge mix (BuRning test)

- IS DILUTE FULMINATE SAFE?

- IMPact test fúlminate,decomposition (USE hOt PLATE)

- DID HAMMER TESTING DECOMPOSE DILUTE FULMINATE, OR

- IS THE FULMINATE STABILIZED BY DILUTION? 


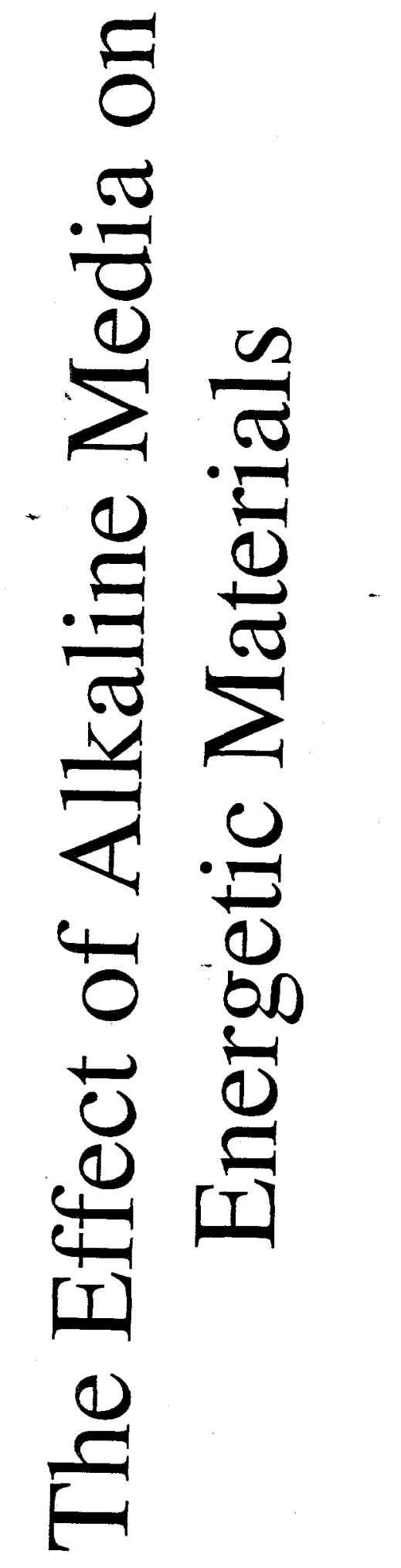




\section{Objective}

- Determine the lifetime of $\mathrm{HgC}_{2} \mathrm{O}_{4}$ and $\mathrm{HgC}_{2} \mathrm{~N}_{2} \mathrm{O}_{2}$.

- $\mathrm{HgC}_{2} \mathrm{O}_{4}$ and $\mathrm{HgC}_{2} \mathrm{~N}_{2} \mathrm{O}_{2}$ in $1.8 \mathrm{M}\left[\mathrm{OH}^{-}\right]$wet sludge.

- Dose rates of $23800 \mathrm{Rad} / \mathrm{hour}$ 


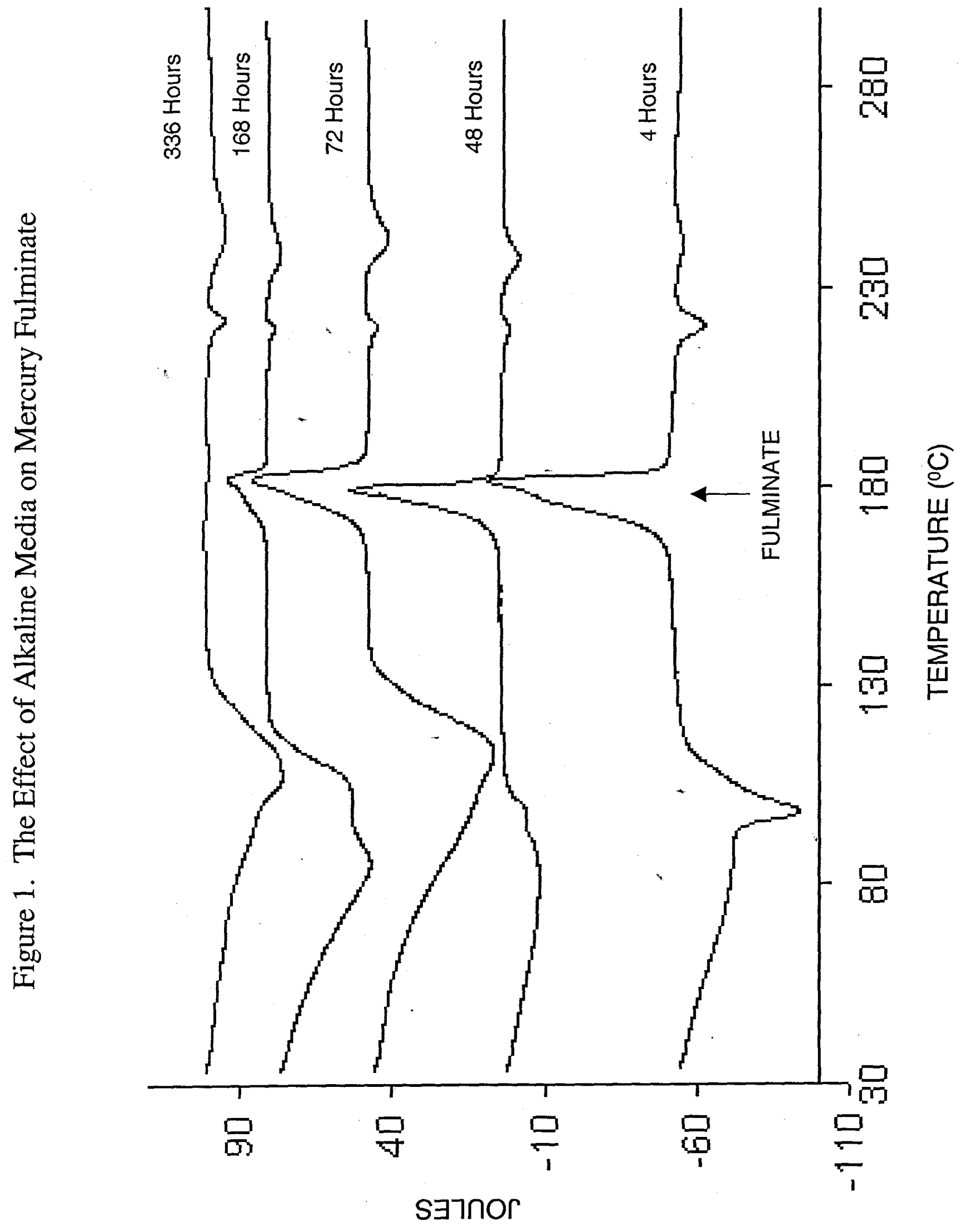


Figure 2. The Effect of Alkaline Media on the Energetic of Mercury Fulminate

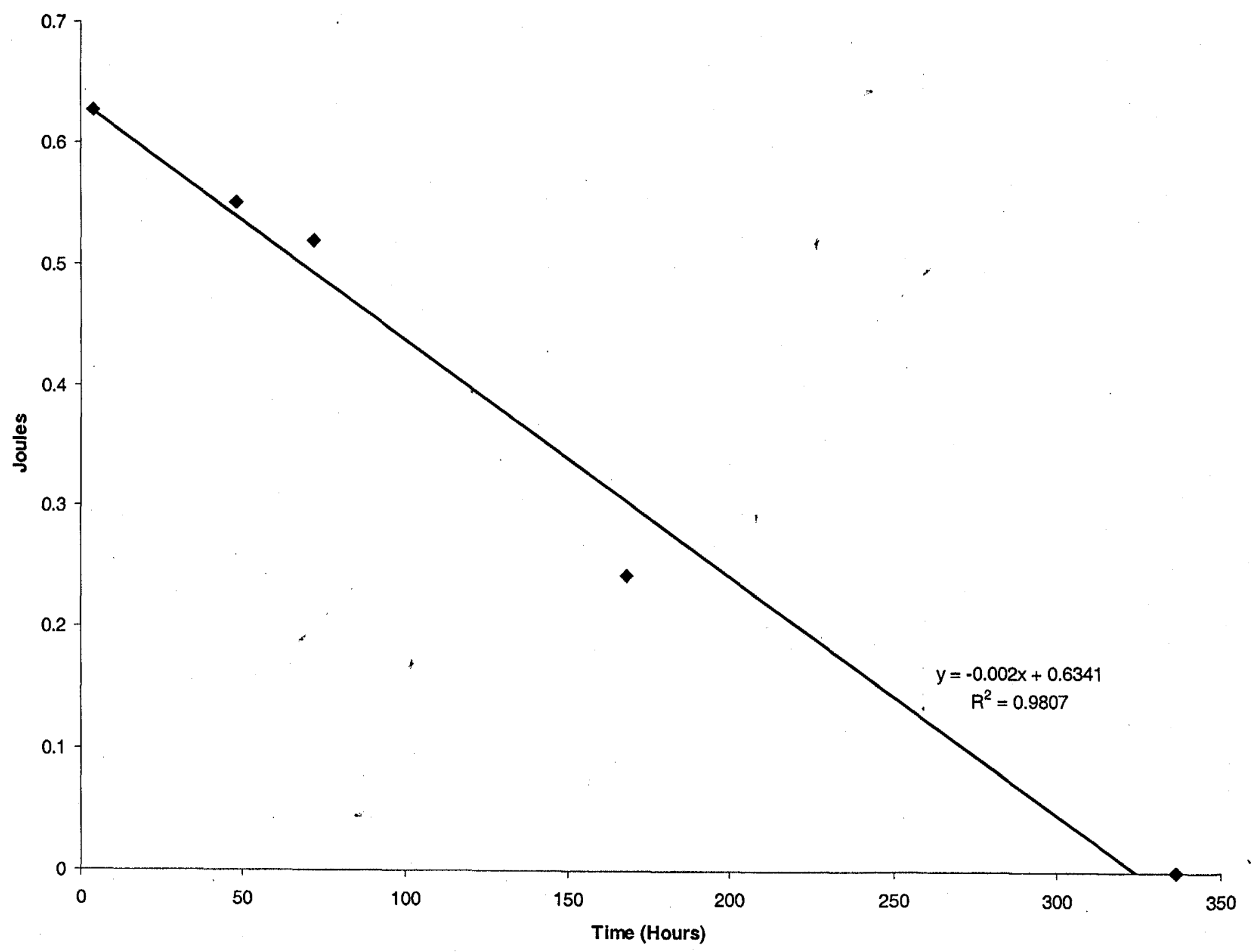


Figure 3. The Effect of Alkaline Media on the Energetic of Mercury Oxalate

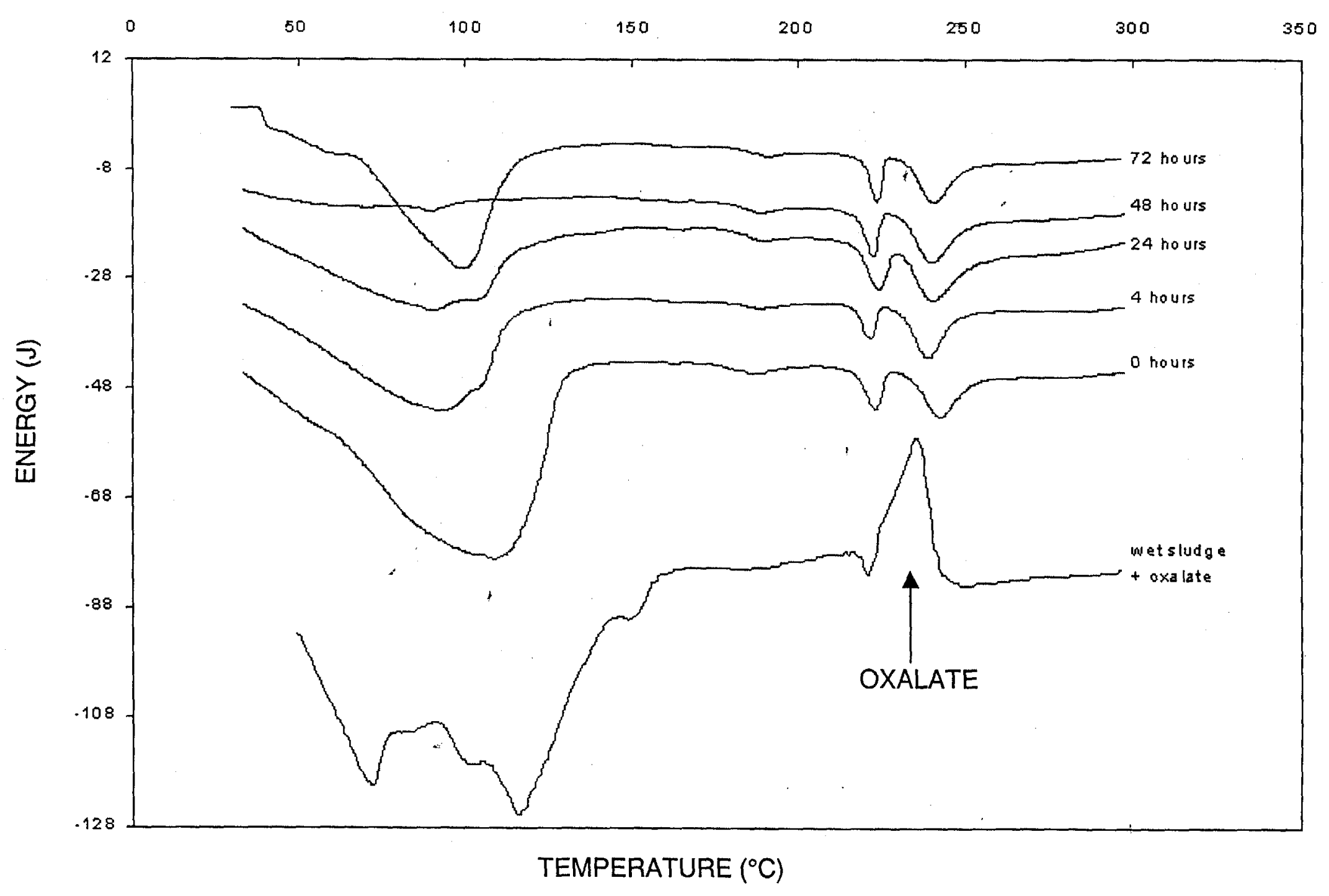




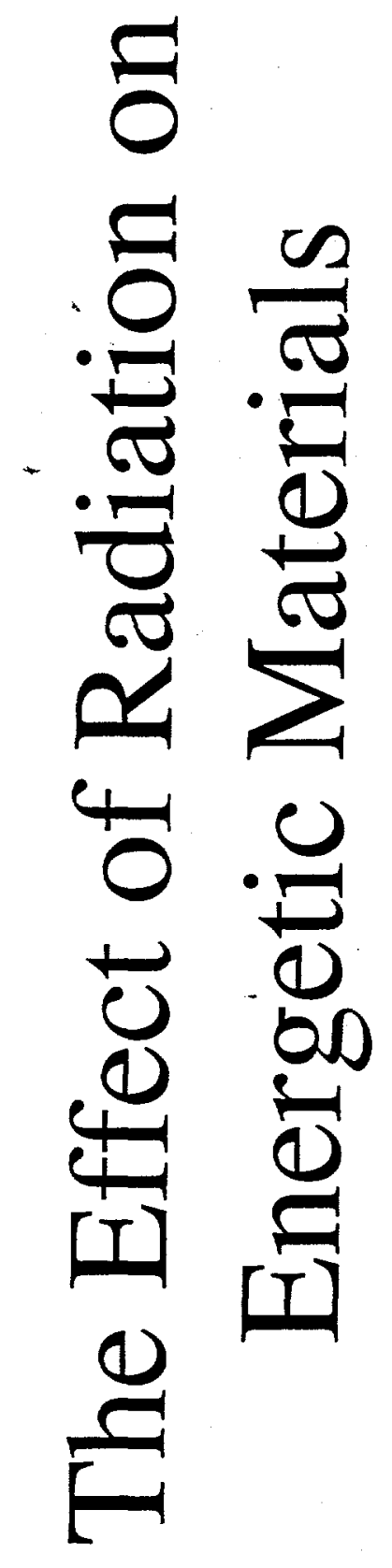




\section{Figure 4. Radiation Effects on Mercury Fulminate}

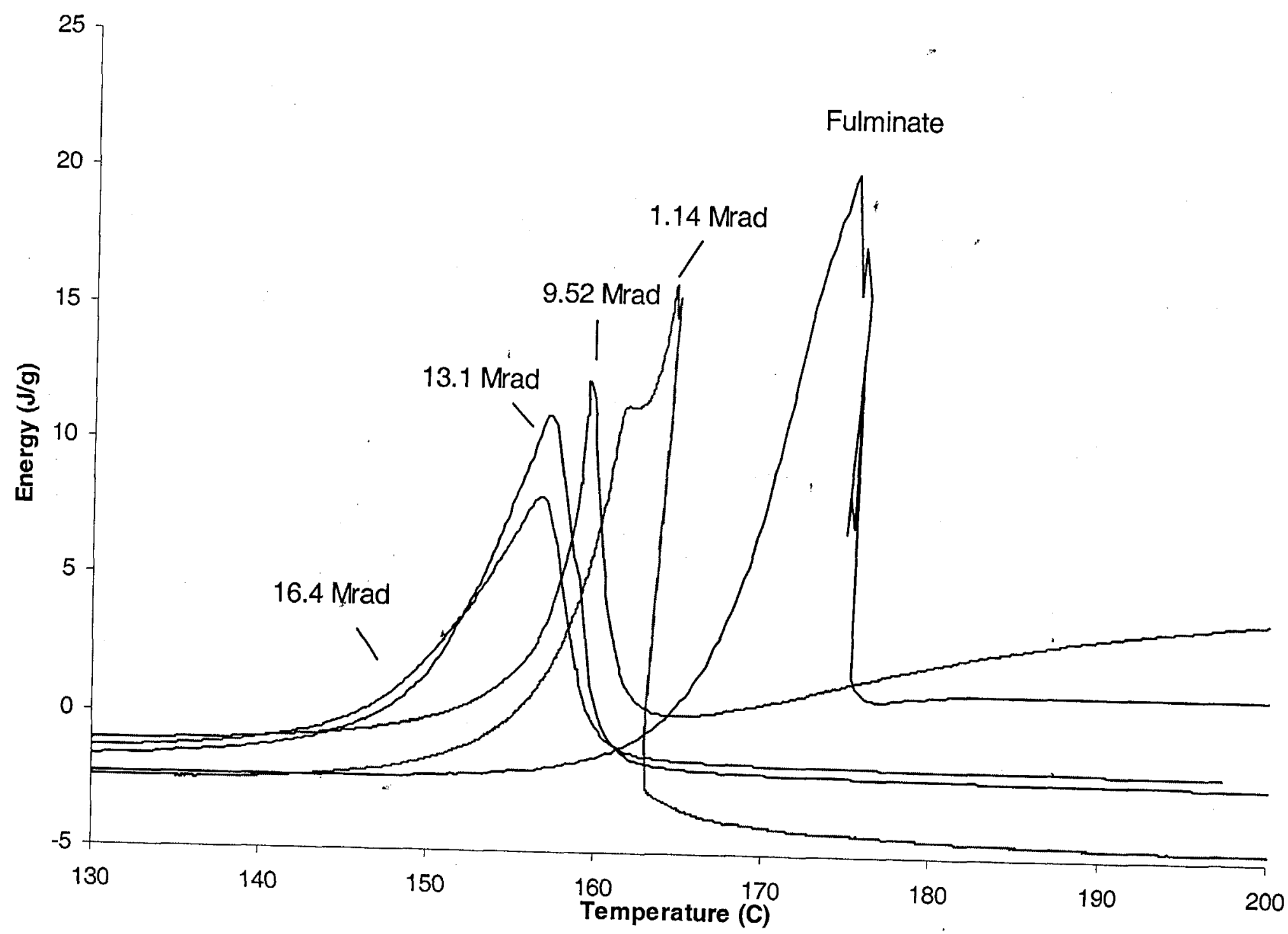




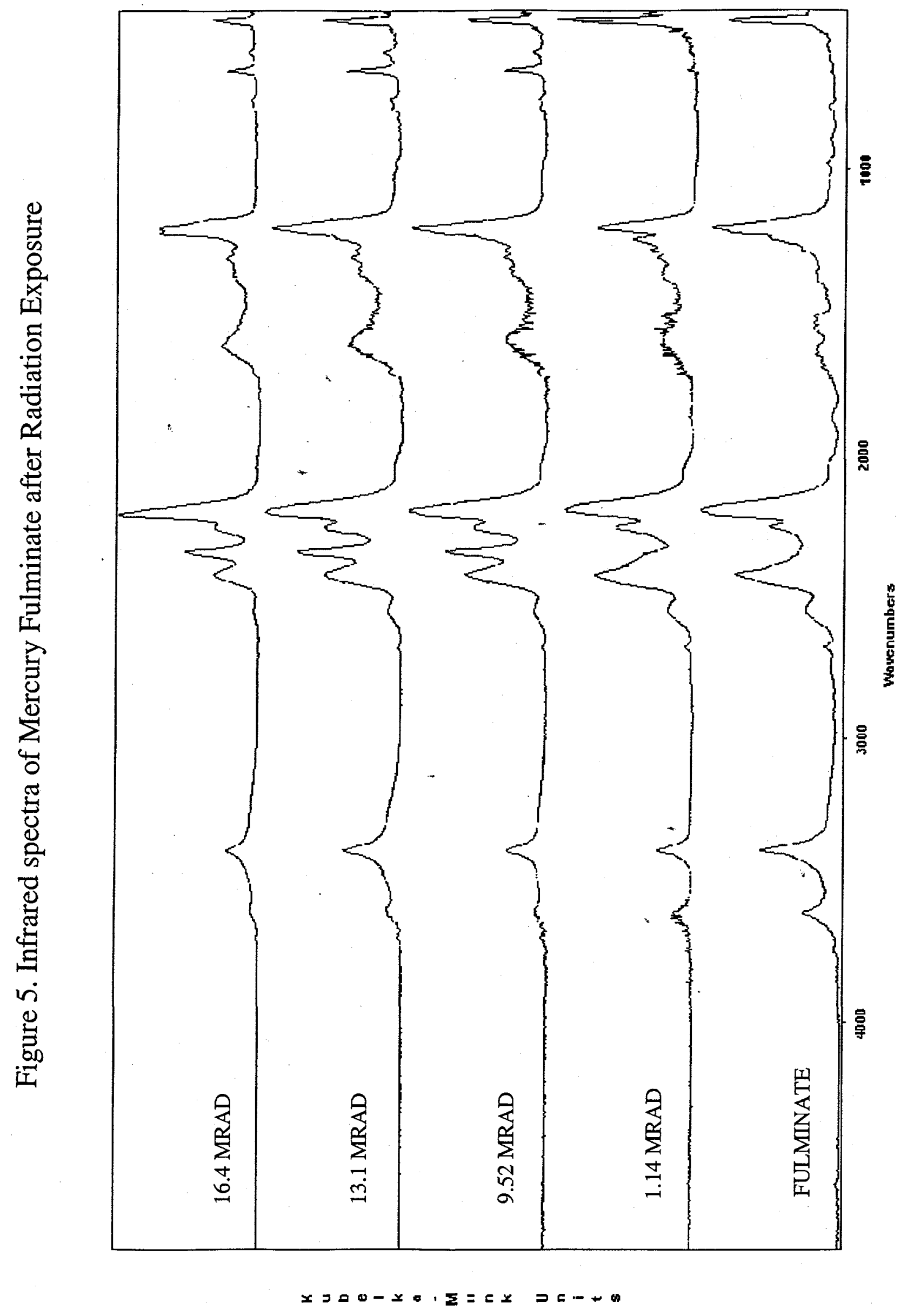




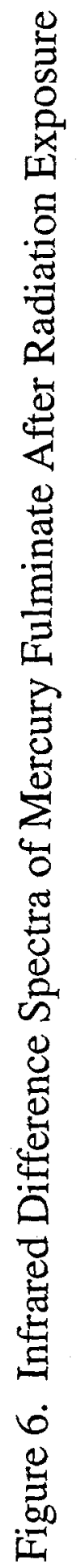

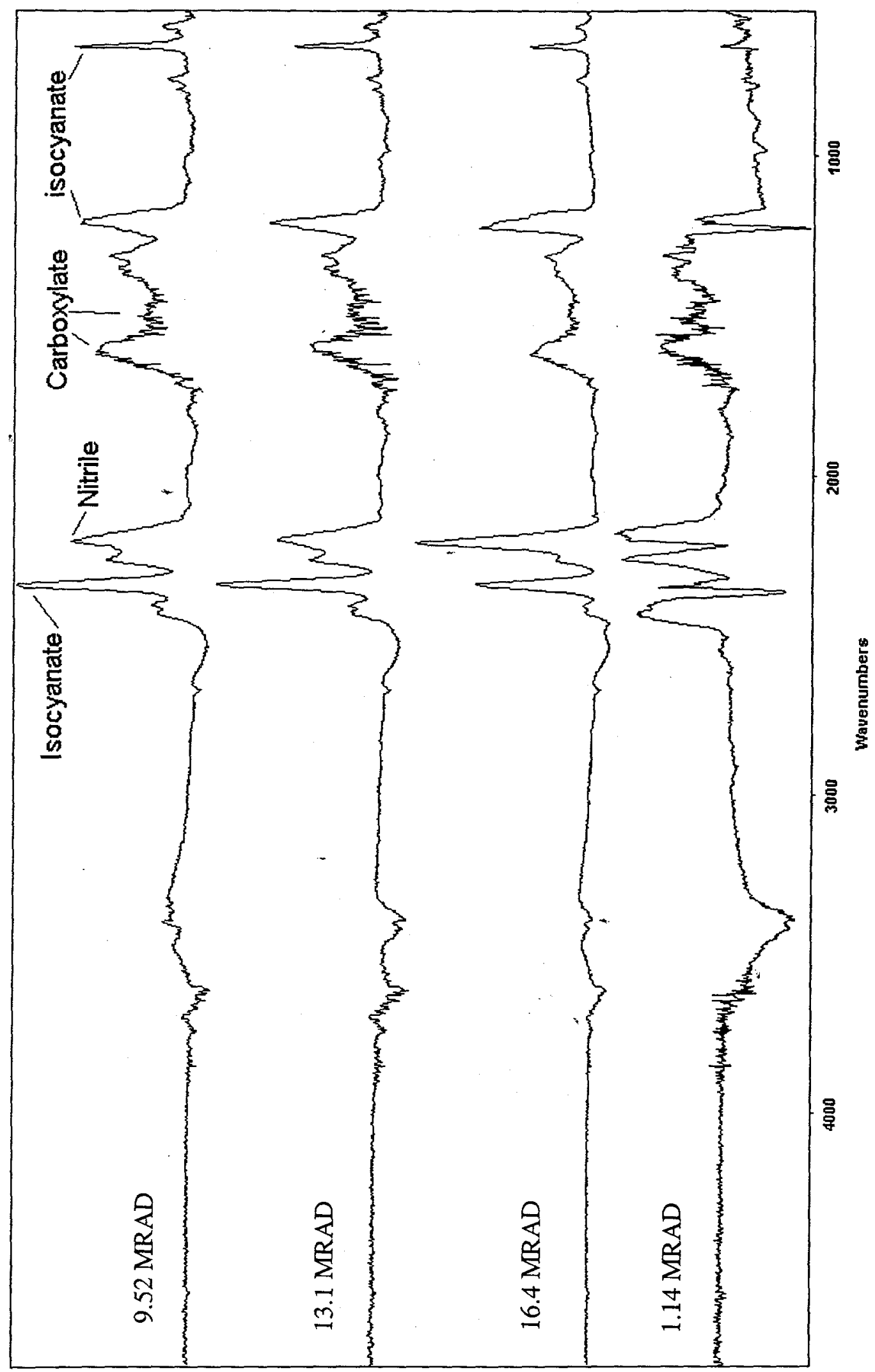

XNกW-VXTHgกY 


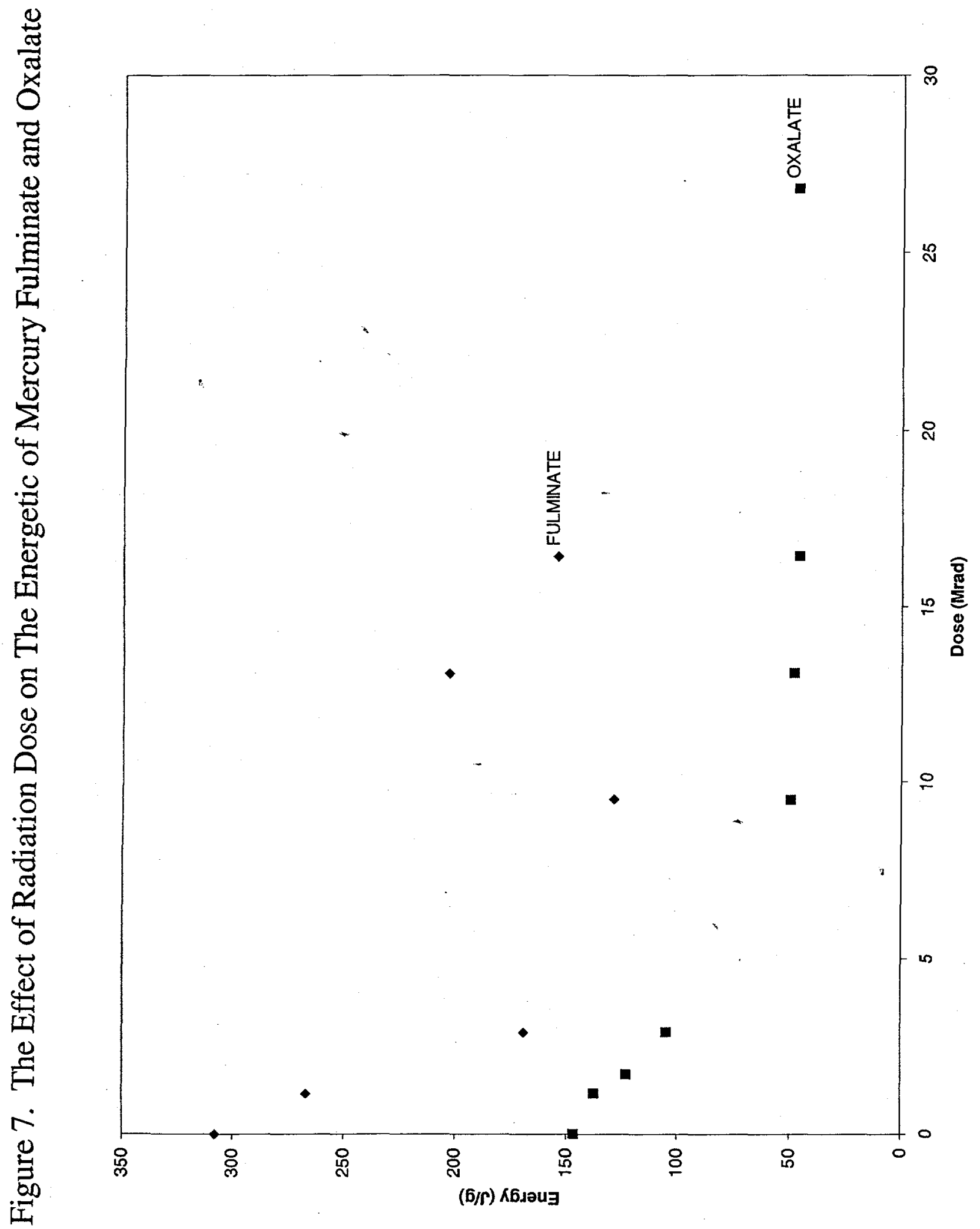


Figure 8. The Effect of Radiation Dose on The Onset of Decomposition of Mercury Fulminate and Oxalate

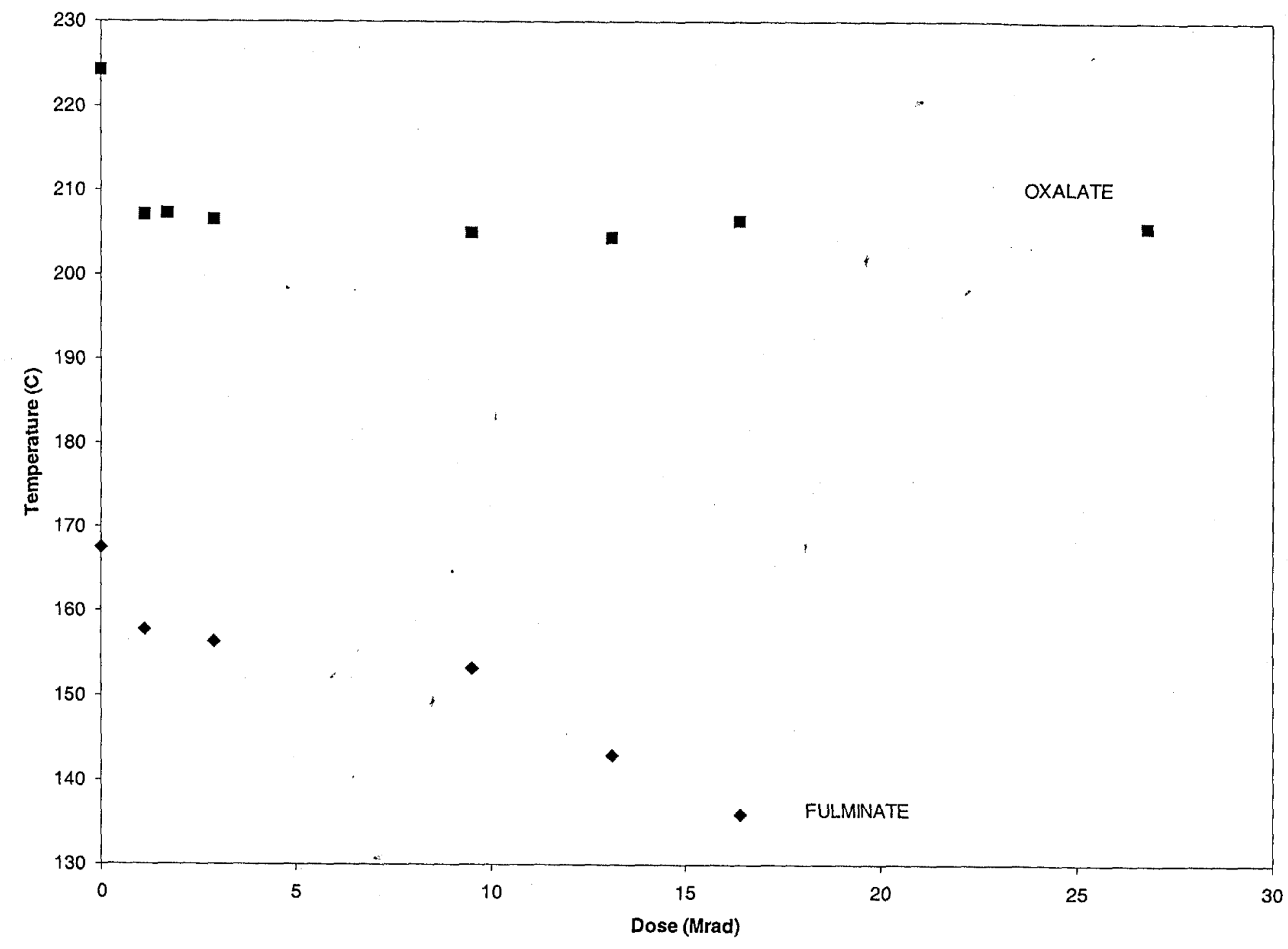


Figure 9. The Effect of Radiation Dose (23800 rad/hr)on the Differential Scanning Calorimetry spectrum of Mercury Oxalate

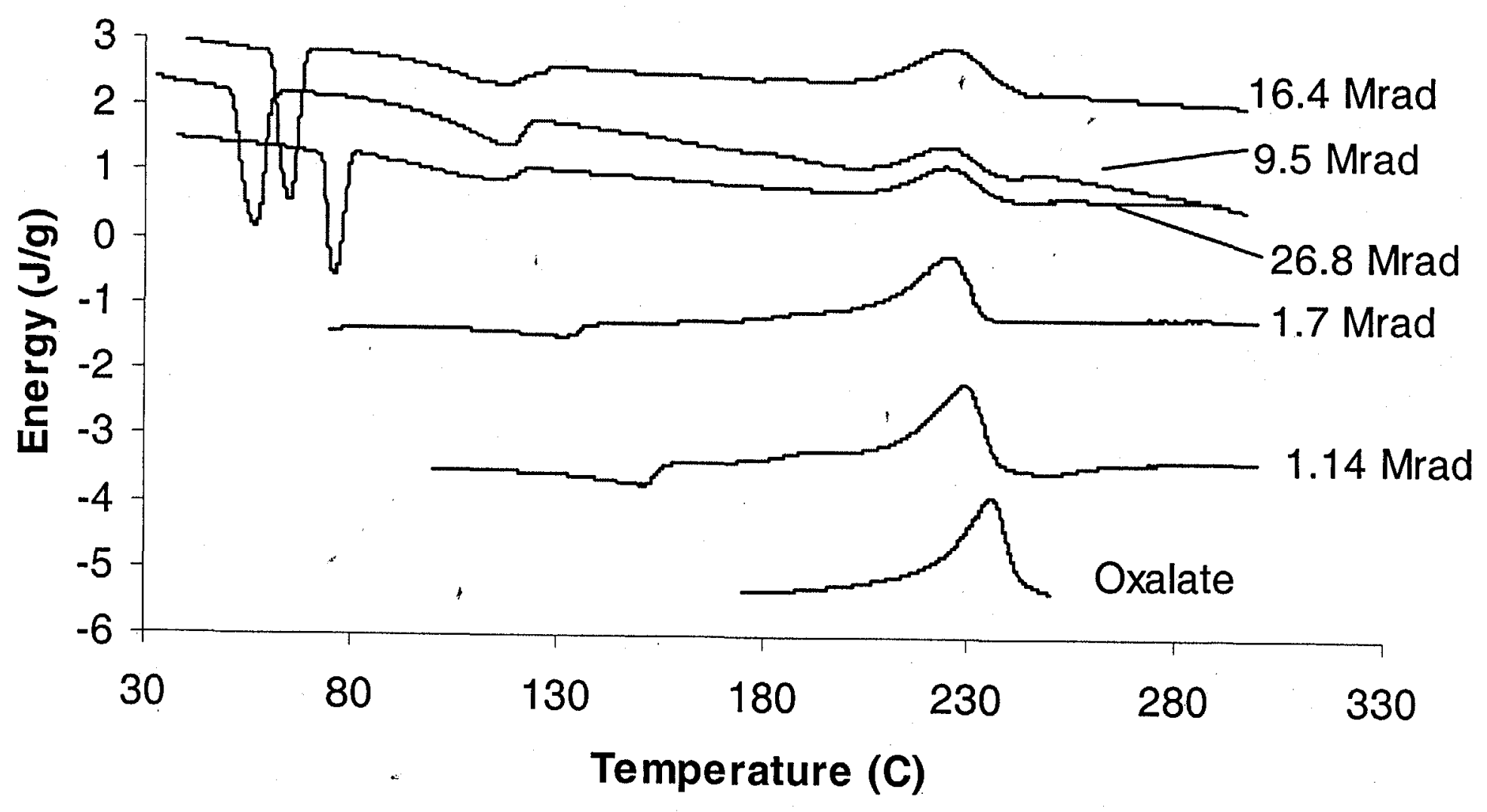




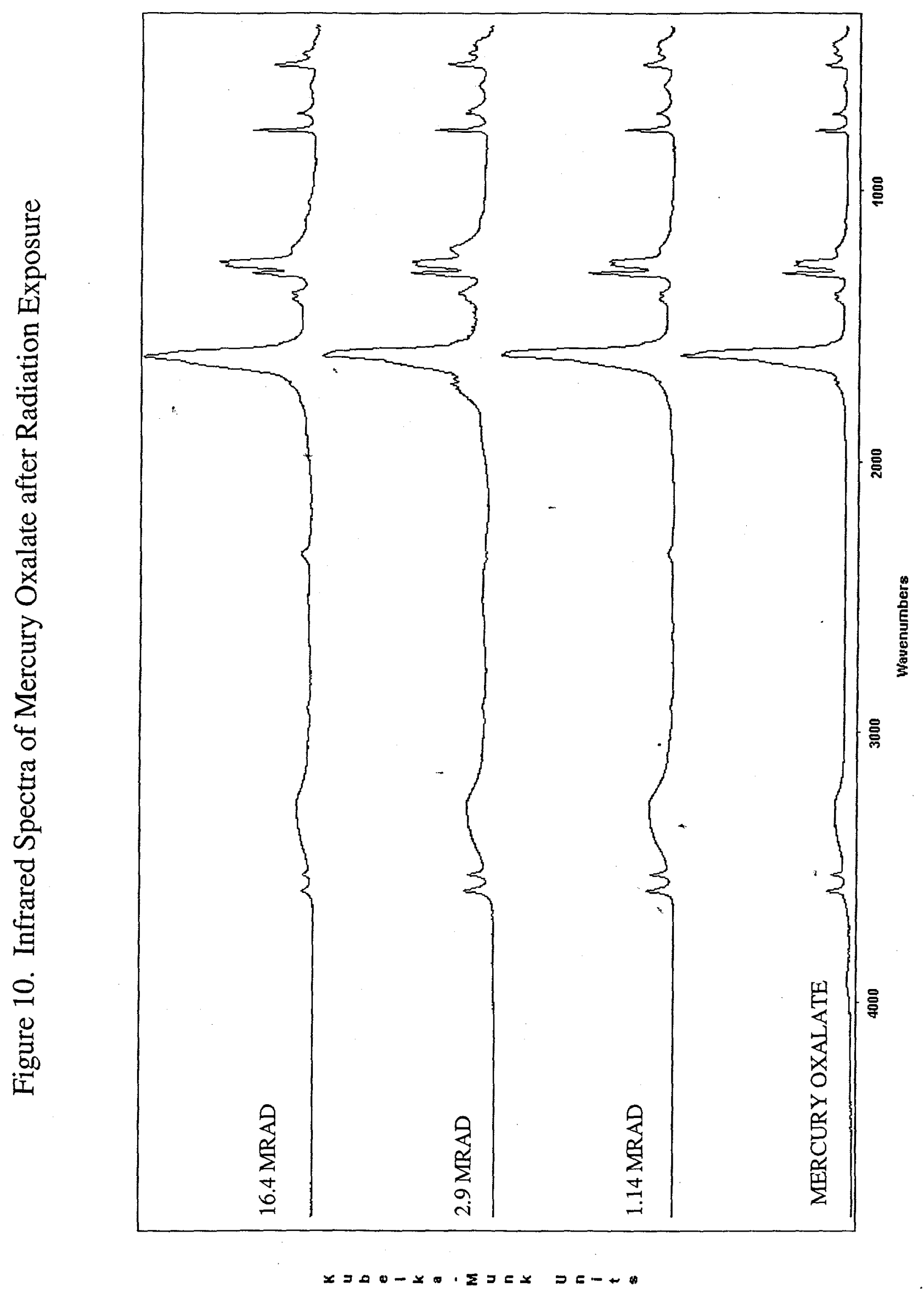


Figure 11. Infrared Difference Spectra of Mercury Oxalate After Radiation Exposure

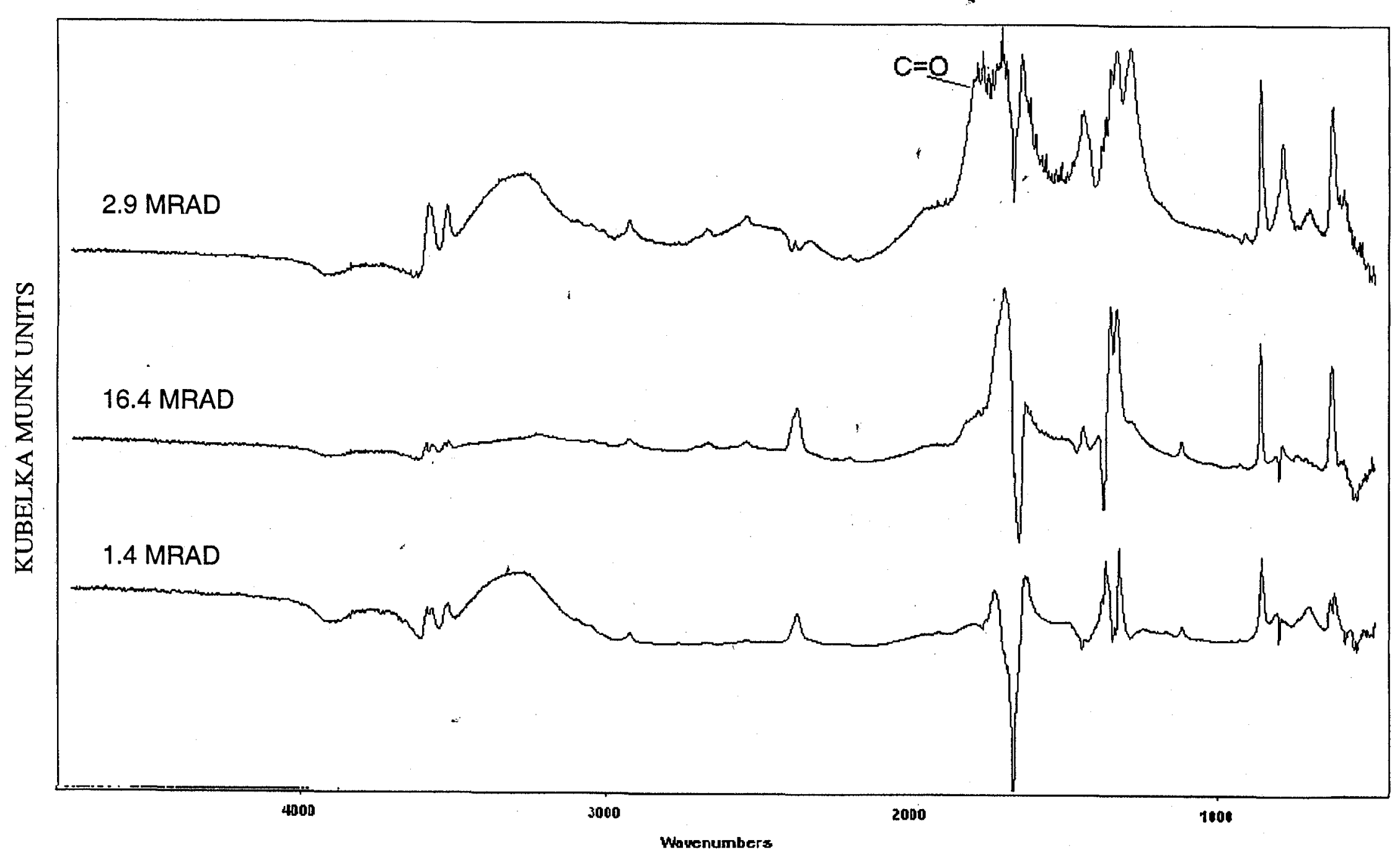




\section{The Effect of Radiation and Wet Alkaline on Energetic Materials}


Figure 12. The Effect of Alkaline Media and Radiation on the Mercury Oxalate

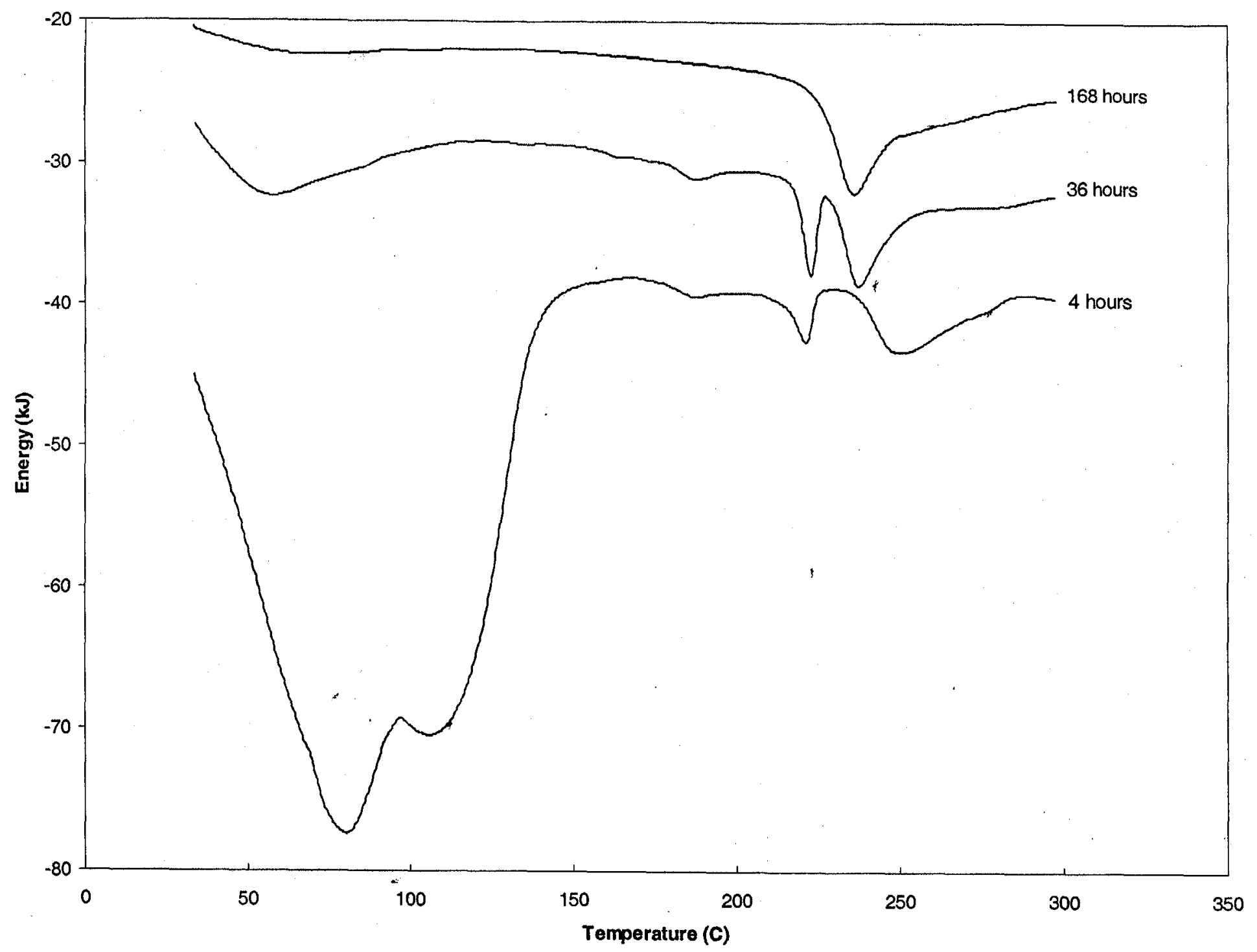




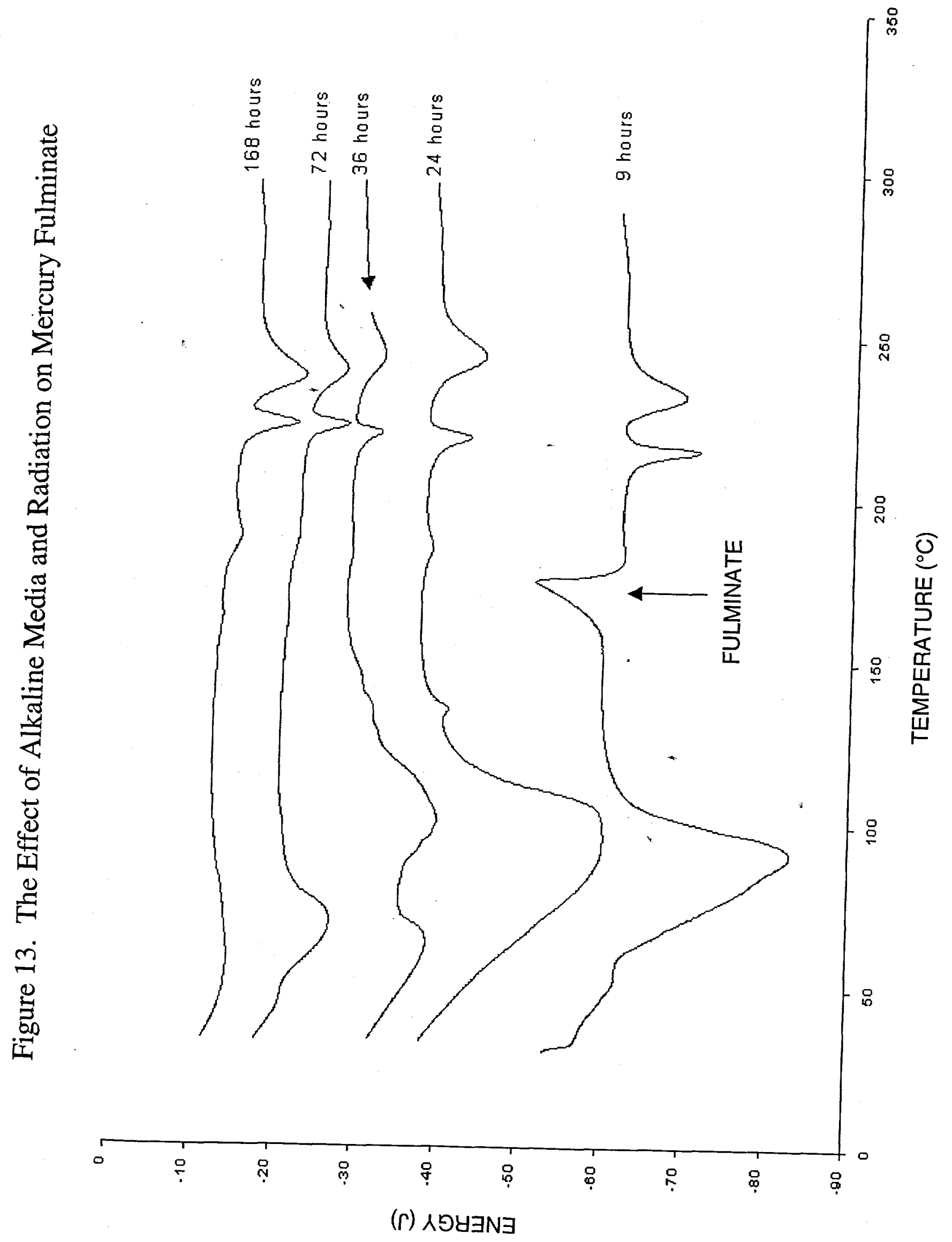




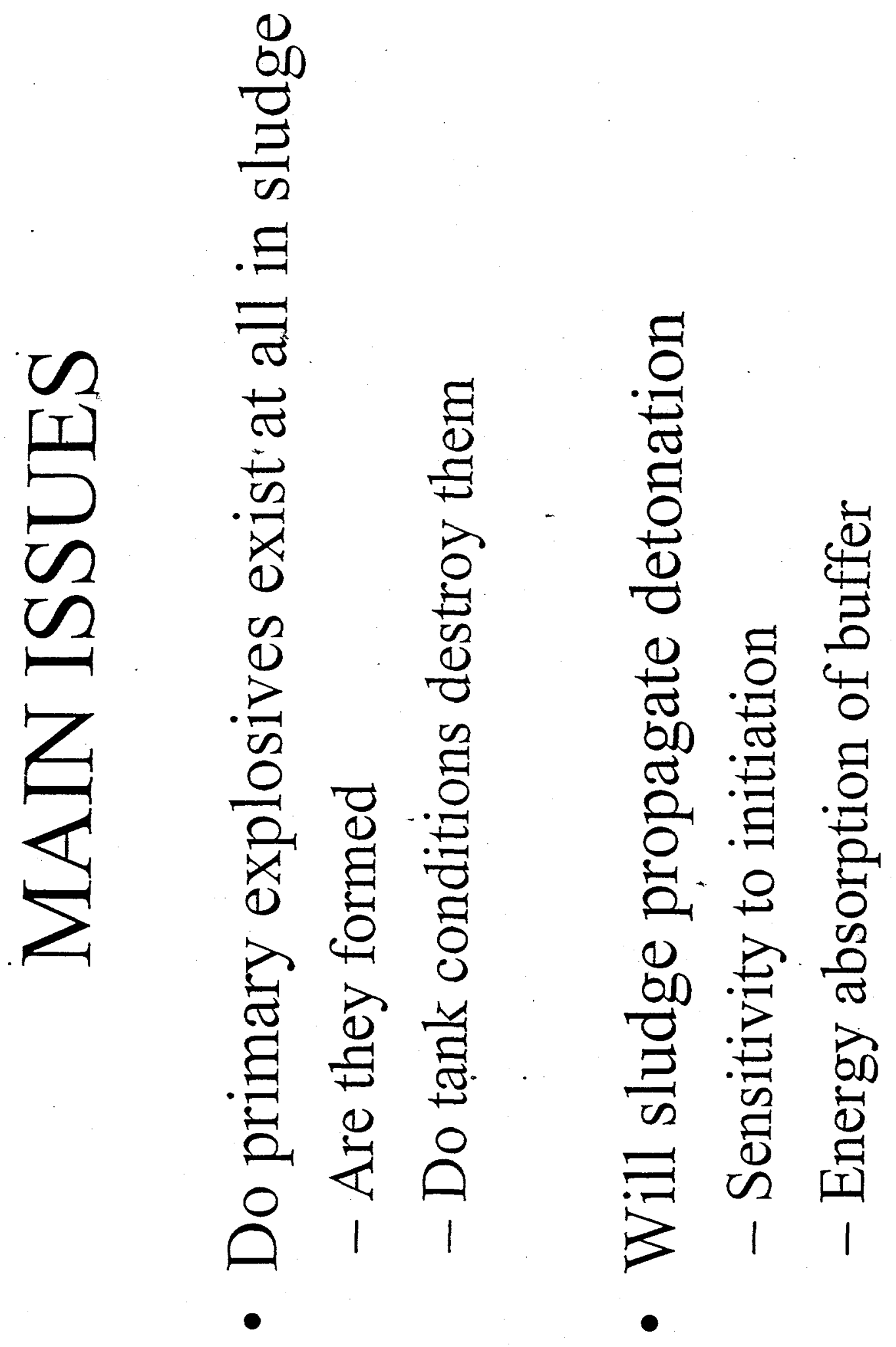




\section{General Impressions}

- Approach

- Two pronged simultaneously wise

- Experimentation

- WSRC work thorough and well executed

- Vendor Validation

- Tendency to cloud the issue 


\section{Program Completeness}

- Additional Tests (Existence)

- Higher levels of irradiation of both oxalate and fulminate

- Irradiation of Chilworth fulminate

- Potential irradiation of Millon's Base (to avoid getting into circular arguments about surrogates) 


\section{Program Completeness}

- Additional Tests (Propagation)

- Drophammer with surrogate (white) sludge

- Determine if initiation occurs

- Determine what initiation energy truly is

- Alternative: Increase fulminate \% in sludge until an observable "Go" occurs 


\section{Program Completeness}

- Additional Tests (Propagation) ,

- Larger scale cook-off, thermal run-away

- Gap test

- Ignition test

- To be run in the event that existence of energetic materials is believed to survive irradiation 


\section{Program Completeness}

- Silver Nitride

- Tests of limited value

- Silver in low concentration

- Handling very problematic

- Need cost/benefit analysis

- Immediate impressions are against 


\section{Program Completeness}

- Individuals

- Gerald Laib (NSWC); Primary explosive expert

- Peter Hefferen (CAD); Primary disposal specialist 

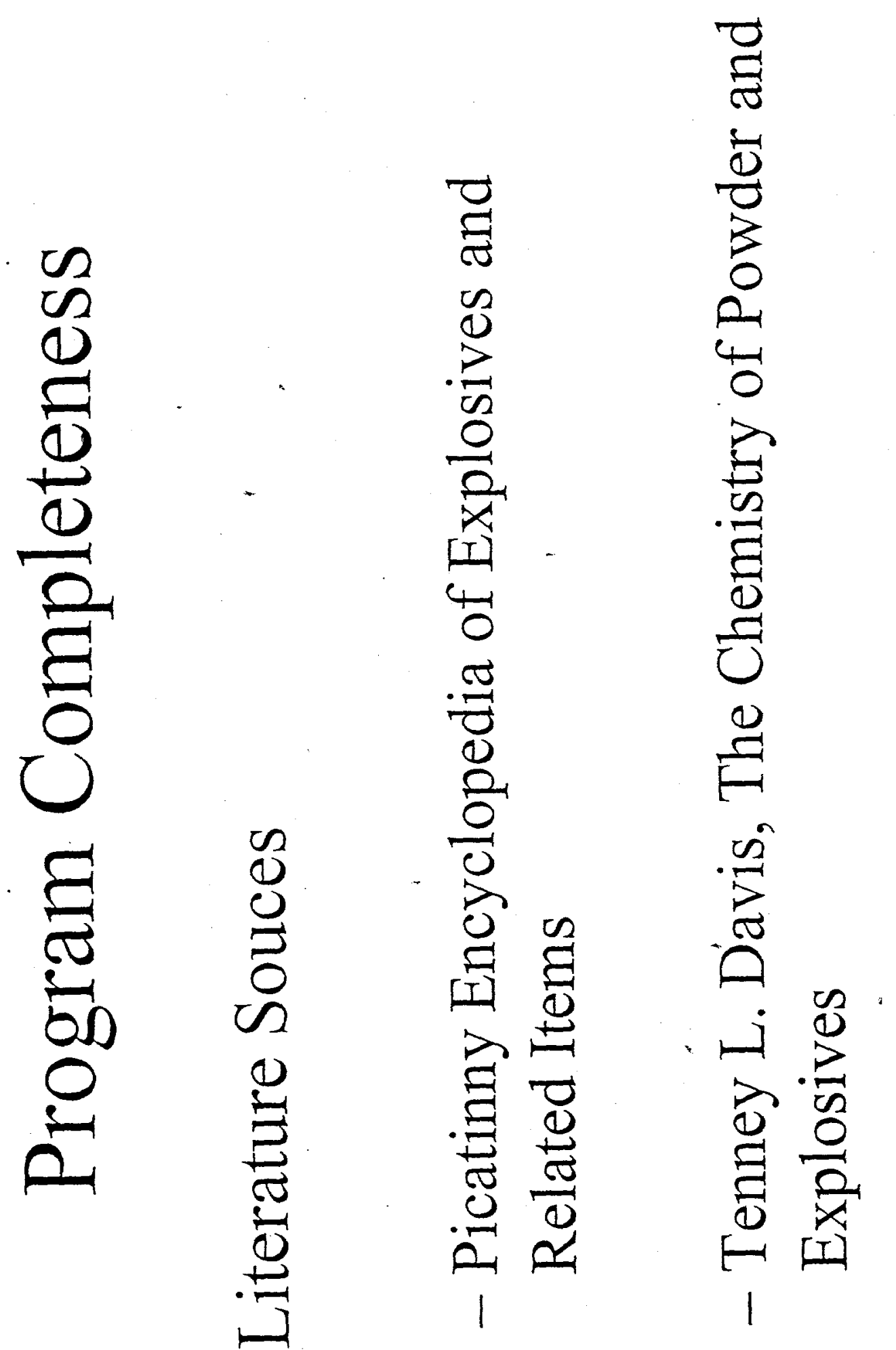


\section{Program Completeness}

- Scale of testing

- Small-scale (DSC, Impact) good for determination of existence .

- Propagation needs to be on intermediate scale 


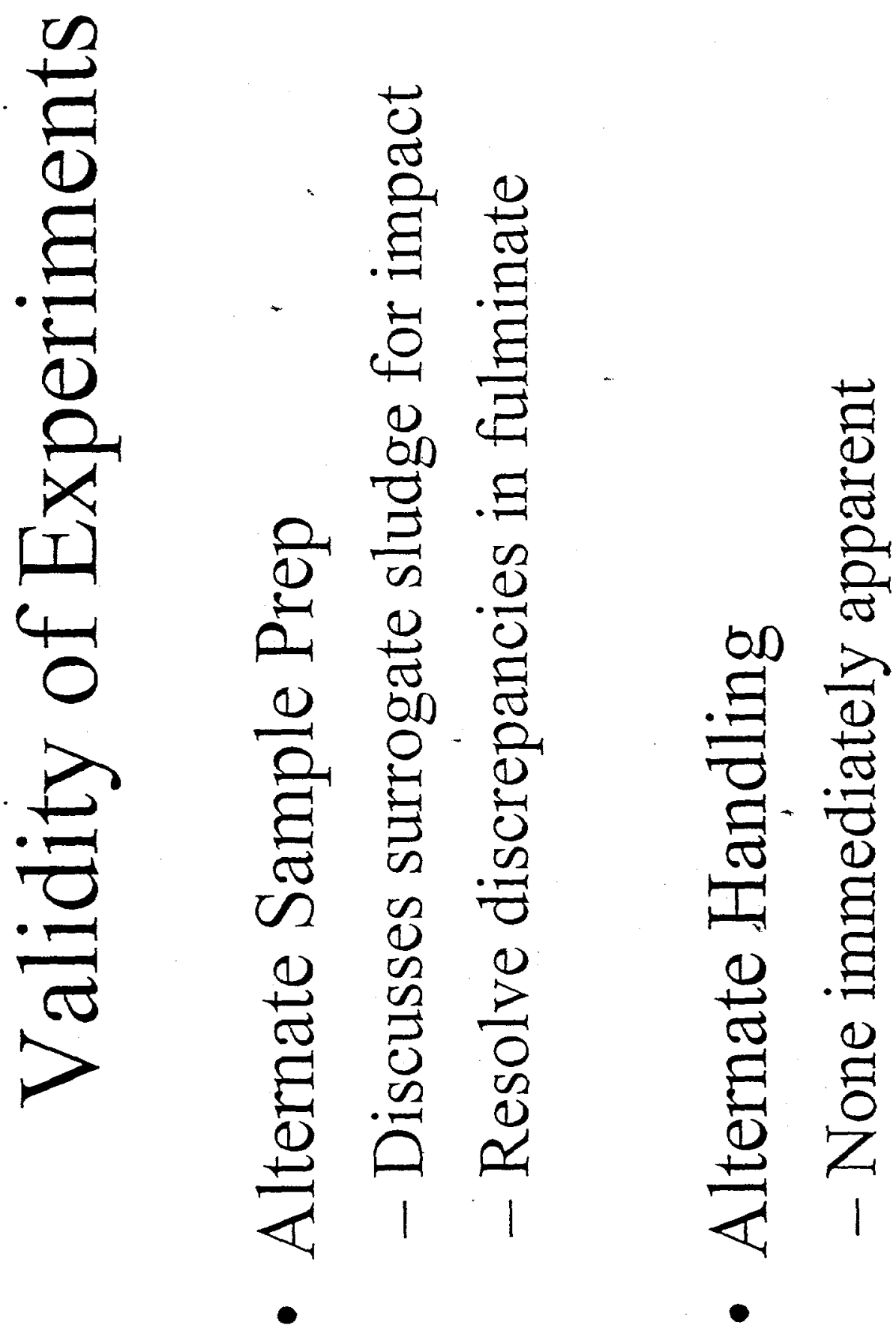




\section{Validity of Experiments}

- Concerns over test results

- Carius tests did not include baseline runs for the sludge samples

- Chilworth vs. WSRC fulminate issues

- Uncertainty in initiation in drophammer

- Results of more representative doses on explosives 


\section{Chemistry of Interest}

- Alternate energetic compounds

- Minimum of literature search on suspected Hg compounds

- Other instances with alkaline solutions

- Needs further research, none currently known 


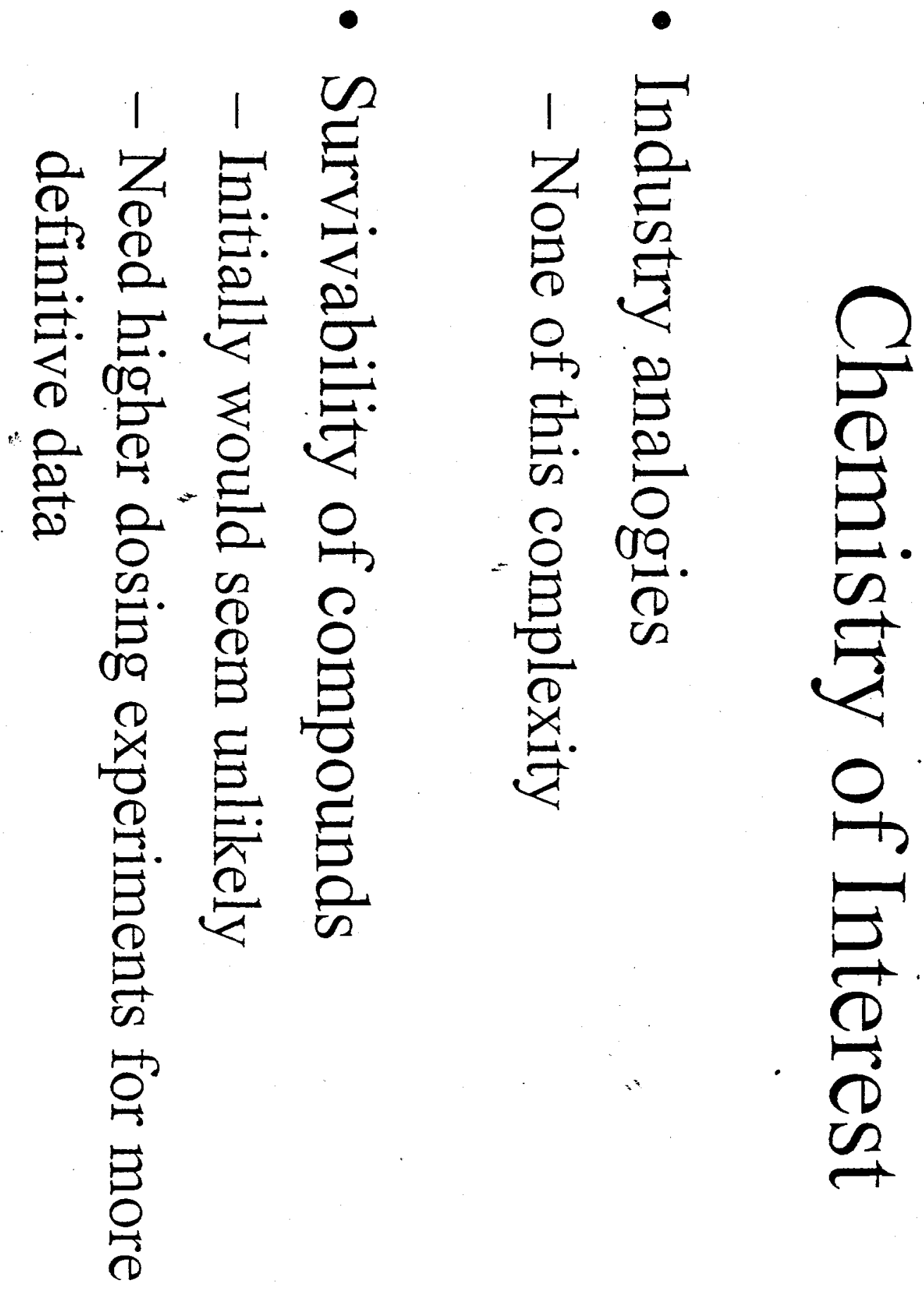




\section{APPENDIX B}

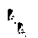 \\ Literature Review of Explosives \\ Based on Mercury \\ Studied by SRS}

